\title{
Chapter 1 \\ Non-affirmative Theory of Education as a Foundation for Curriculum Studies, Didaktik and Educational Leadership
}

\author{
Michael Uljens and Rose M. Ylimaki
}

\begin{abstract}
This chapter presents non-affirmative theory of education as the foundation for a new research program in education, allowing us to bridge educational leadership, curriculum studies and Didaktik. We demonstrate the strengths of this framework by analyzing literature from educational leadership and curriculum theory/didaktik. In contrast to both socialization-oriented explanations locating curriculum and leadership within existing society, and transformation-oriented models viewing education as revolutionary or super-ordinate to society, non-affirmative theory explains the relation between education and politics, economy and culture, respectively, as non-hierarchical. Here critical deliberation and discursive practices mediate between politics, culture, economy and education, driven by individual agency in historically developed cultural and societal institutions. While transformative and socialization models typically result in instrumental notions of leadership and teaching, non-affirmative education theory, previously developed within German and Nordic education, instead views leadership and teaching as relational and hermeneutic, drawing on ontological core concepts of modern education: recognition; summoning to self-activity and Bildsamkeit. Understanding educational leadership, school development and teaching then requires a comparative multi-level approach informed by discursive institutionalism and organization theory, in addition to theorizing leadership and teaching as cultural-historical and critical-hermeneutic activity. Globalisation and contemporary challenges to deliberative democracy also call for rethinking modern nationstate based theorizing of education in a cosmopolitan light. Non-affirmative education theory allows us to understand and promote recognition based democratic citizenship (political, economical and cultural) that respects cultural, ethical
\end{abstract}

\author{
M. Uljens ( $\square)$ \\ Åbo Akademi University, Vasa, Finland \\ e-mail: michael.uljens@abo.fi \\ R.M. Ylimaki \\ University of South Carolina, Columbia, SC, USA \\ e-mail: YLIMAKIR@mailbox.sc.edu
}


and epistemological variations in a globopolitan era. We hope an AmericanEuropean-Asian comparative dialogue is enhanced by theorizing education with a non-affirmative approach.

\section{Challenges for Policy, Educational Leadership Research, Curriculum Theory and Didaktik}

The main argument driving this volume is that educational leadership and policy research, curriculum theory and Didaktik, despite their unquestionable contributions over the years, appear limited in their capacity to conceptually explain institutional education in increasingly complex environments and globalized nation-states. In addition, we will argue, many contributions in curriculum theory, educational leadership research and Didaktik are typically either remarkably functionalistinstrumentalist or prescriptive-normative in ways that make them appear, if not problematic, less fit for democratic education systems around the world.

We think, a mere dialogue between these strands of research does not suffice. What is needed is a conceptual system capable of coherently taking care of and relating these research specializations to each other. Without conceptual coordination, contributions in curriculum theory and Didaktik, as well as in educational leadership research, run the risk of being counterproductive or dysfunctional in terms of representing a too limited perspective on education, not only from the teachers' and principals' perspective but equally for policymakers and governance (Uljens 2015, 2016; Uljens and Ylimaki 2015; Ylimaki et al. 2016). Let us explain.

Nation-states and our schools of today find themselves operating in permanently renewed national and global contexts. We have witnessed new geopolitical repositionings and changes in the economic production. We see new energy systems evolve; we identify a need for sustainable development. Increasing multiculturalism, demographic movements, and aging population challenge us in new ways. Technological developments provide us new public spaces, and a global economy results in increasing interdependencies on all societal sectors. Many of these changes have been positive. Globally, poverty has decreased, more countries call themselves democracies, the number of military conflicts are, for the time being, less than in decades, and the education level is higher than ever. Yet, the developments mentioned all have created profound challenges for nation-states and their schools, for curriculum making, policy work, leadership and teaching. The political agenda in global, post-industrial, knowledge economies and information societies has thus changed the role of the nation- or federal state, the ethos of knowledge, education and research as well as the governance and leadership of the education sector.

Recent neoliberal educational and accountability policies have intensified a focus on school leadership, learning results, and national curriculum standards. The increased focus on leadership occurs as parts of new policies of curriculum making, leadership as enacted practice, and evaluation as a steering vehicle, all of which are occurring amidst increasing global interdependencies among all societal sectors as 
well as increasing multiculturalism and rapid developments in communication technology re-defining spaces for learning and teaching.

We can observe a redefinition of how power and influence is distributed anew between levels, e.g. transnational agencies, central administration and local schools, between state level administration and private (family) interests, but also within each level. These changes are far from only being functional or organizational but ideological. This is particularly well demonstrated by the move from a socialdemocratic welfare state (old public governance) to a neoliberal competition-based model (new public management/governance). This shift has had profound consequences for professional activity, identity and development. In a neoliberal, accountability paradigm, the customer is at the center, with various institutions organized around customer choice in the free market. In other words, neoliberal policies and trends have, in effect, shifted the focus of administration from the state as a provider of services to a buyer of services. This movement and related discourses are truly international, but they take different forms and stages in various countries (Paraskeva and Steinberg 2016; Gunter et al. 2016; Pinar 2004). We can observe, for example, an increase and changes in policy borrowing patterns, the ways in which curricula are harmonized, and new procedures of how we work with evaluation (SteinerKhamsi 2013).

Second, while a kind of cultural homogenization has been ongoing for decades transnationally and has become dramatically intensified through modern technology, the situation within states is the opposite. Here we see, simultaneous to global homogenization, an increasing cultural, ethnic, linguistic, professional, political pluralisation in most countries, as well as an economic differentiation and specialization (in the labourmarket). Recent neo-conservative movements both in Europe and in the USA have been interpreted as reactions to this pluralization and globalisation, which by definition, challenge established ways of sustaining unity and national identity or sense of belonging within states.

Third, we have been witnessing various types deregulation and decentralization since the 1980s as well as reregulation and recentralization of political power within nation-states (Gunter et al. 2016). However, an increasing number of counterproductive consequences emanating from deregulation of laws, decentralization of administration, a focus on cost-benefit and efficiency including idea of increased individual choice and reduced focus on egalitarianism to minimize disparities, initiated stepwise since 1980s, especially after 1989, have resulted in increasing mistrust, especially in Europe, as to whether a neoliberal model may provide sustainable solutions. Diane Ravitch (2010) and many others (e.g. Sennett 1998; Frontini 2009; Lingard and Rizvi 2009; Lindgard et al. 2015) have persuasively argued that neoliberal approaches have had unexpected results in application in various societal factors (e.g. healthcare, housing, education). For example, it seems obvious that large portions of citizens in the US and in Europe feel that recent developments regarding welfare, health-care, education and work have developed in a very unfavorable direction. It may be that the roots for expanding political populism in the USA and Europe partly are to be found here. These counterproductive consequences make it more important to see connections between economic neo-liberal globalization, 
national and transnational governance policies, educational ideals as well as curriculum and leadership practices.

Neoliberalism has many meanings and phases, with many references beginning in the 1980s with the Reagan and Thatcher administrations, the fall of the Berlin Wall, and the collapse of the Soviet Union. For some, neoliberalism equals globalization. Smith (2001) identifies three forms of globalization relevant for curriculum and leadership studies. Globalization One arises from the 1980s collapse of binary logics regarding cold war national borders and consonant revival of liberalism toward a borderless world vision of open markets guided not only by nations and states but also by newer transnational institutions with a global reach. Neoliberalism, then, redefined the rules of obligation between nation-state governments and people to privilege the free operation of a global market system over the state as the primary means for solving social problems, shifting the focus of administration from a provider of services to a buyer of services (Friedman, von Hayek).

In the education sector, the presence of the cosmopolitan dimension (Beck 2006; Kemp 2010) is practically visible both in terms of increasing global harmonization regarding core curricula but also through evaluation procedures (e.g. PISA) (Sahlberg 2015). Many countries have moved from an input oriented government policy driven by curricula towards an output centered governance policy driven by evaluations. An increasing number of transnational organizations influence, and are influenced by, national education systems. The globalization process inevitably leads to a restructuring of the role of the nation state and its governance practices in relation to the global scene. The nation state and its education must be thought anew in the light of new forms of, and previously unseen, versions of transnational and even global practices.

In a broad sense, then, the challenge for changing nation states involves organizational relations among education, politics, economy, and culture in order to continuously establish a sense of collective belonging and coherence to a unified whole with spaces that allow for recognition of individual difference and freedom (autonomy). Further, such societal and ideological changes, including the tension between the European social-democratic welfare state model (old public administration) and a neoliberal competition-based model (new public management and new public governance) and tensions between unity and plurality have consequences for professional activity, identity and development. This movement, and related discourses, are truly international, but they take different forms and stages in various countries (Roth and Burbules 2007; Paraskeva and Steinberg 2016).

These challenges have turned our attention towards understanding educational leadership as a much broader and complex undertaking than typical perceived of. It is a project with power redefined and redistributed anew between levels, interest and professional groups, e.g. central administration and local schools, between state level administration and private (family) interests, companies, between transnational organizations (e.g. European Union, OECD) and nation states, but also within each level. These developments make it crucial to understand the interplay among policies, societal trends/aims, methods, governance, social interactions of leadership-teaching-studying-learning within and between levels. We think that 
both curriculum research and educational leadership research would benefit from seeing how each connect sociocultural aims to curriculum contents and methods.

Our point of departure is that any successful accomplishment of educational practice, be it teaching, educational leadership or policy work on different levels, is partly guided by prevailing conceptual frameworks and theories, dominating policies, cultural and historical traditions. However, if the undertakings are informed by theoretical positions that conceptually highlight only disparate if important activities and processes of the educational system, and even in conflicting ways, their guiding power may be limited. While we recognize the value of debates within and between fields and disciplines, we argue that a more general and theoretically solid educational framework will inform new research studies and fields, as well as create a coherent language for policymakers, preparation programs, school development programs and practitioners. As we argue that curriculum theorists, Didaktik, leadership scholars, political scientists and policy scholars have yet to make these connections explicit this volume bring representatives from all these fields together for deliberation.

Deliberation has to be deliberation about something for some reason. The reasons were pointed at previously. Regarding the contents of this deliberation the leading question throughout this volume is: how should we understand the character and task of educational theory and research in order to handle the contemporary challenges? What should those conceptual answers concerning citizenship (e.g. cultural, economical and political) be and look like in order to understand and guide leadership and governance of our educational institutions in an era where all nations worldwide internally develop towards increasing plurality while being simultaneously framed by challenges that call for a cosmopolitan view? Where should we look for answers with the aim being a more profound and foundational approach to curriculum, educational leadership and teaching? How could a position look like and be constructed for these purposes? In the following, first, we outline the research strategy and how it was applied to meet the challenges described above. After this we describe how the volume as a whole is structured.

\section{Approach and Guiding Questions}

Given the existing multitude of theories on educational leadership, curriculum and Didaktik, are there any reasonable possibilities of developing a position that would allow us to approach these fields of research, i.e. curriculum, Didaktik and educational leadership, coherently? Because, if these theories are being developed with a limited awareness of an interest in each other they run the obvious risk of providing possibly distinct, yet only limited and disparate, answers. The strong twentieth century expansion of research has been welcome, but it has brought with it differentiation and specialization that is increasingly counterproductive in an ever more complex world. 
As a result, a fruitful strategy may be to move the starting point of theorizing educational leadership, curriculum and Didaktik to a level beyond each and all of them. Where and how can we find such a level? Our assumption is that such a metalevel does not need to be invented. It is provided to us by a long tradition of theory making in education, also called general education in Europe (Benner 1991; Uljens 2002). In this volume the German-Nordic tradition of general education will be made use of for these purposes, i.e. used as a meta-language and meta-perspective. Often general education theory starts off by asking foundational questions about the nature of education as such, as well as questions related to what role institutional education plays in and for societal development, politics economy and culture. Moving to a level beyond the specific theories and model of teaching, leadership and curriculum becomes our choice.

This chapter builds upon the non-affirmative theory of education as this position has been developed by the german education scholar, professor Dietrich Benner in Berlin. The non-affirmative theory of education is very much a German phenomenon. The approach was introduced in the Nordic countries in the mid 1990s at a education theory symposium on European identity in change in Finland (Uljens 1997b). More extensively the approach was discussed by Uljens (1998), Kivelä (1998), and Siljander (2000) in Finland and Sweden as well as by Oettingen (2001) in Denmark. This dialogue has stepwise expanded in all Nordic countries the past two decades (e.g. Bengtsson 2003; Kivelä 2004; Benner 2015; Damgaard Knudsen and Andersson 2008; Oettingen 2006, 2016; Saeverot and Werler 2017). The position has partly been made accessible to english speaking readers, primarily within philosophy and theory of education (e.g. Uljens 2002; Benner and English 2004; Friesen and Sævi 2010; Siljander et al. 2012; English 2013; Schaffar and Uljens 2015; Saeverot 2016; Uljens and Ylimaki 2015, 2016; Ylimaki and Uljens 2017). Benners works have been translated into Chinese, Japanese and some European langauges, but not yet into English. The specific contribution of the present volume and other publications by the co-authors the past 3 years relate to the application of this non-affirmative approach to bridging educational leadership, Didaktik and curriculum theory in a transnational perspective. Following this tradition we assume that following questions are central to answer in any theory of education, curriculum or educational leadership:

(a) How is education related to politics, economy and culture?

(b) How do we explain educational interaction?

(c) How do we deal with cosmopolitanism and the nation-state in a globalized world?

Next, the first two questions above are elaborated on and a preliminary answer on them is provided. We do not consider these questions as hierarchically ordered, but rather share the view that in conceptualizing education we need to understand how individual interaction and human agency is related with socioeconomic and political structures as well a historical developments and cultural patterns (Engeström et al. 1999). 
In order to understand institutional education, we must first (a) explain how a theory specifies the relation between education and other societal practices including e.g. culture, economy, politics and religion. To exemplify: how do we explain how political interests transforms into pedagogical action? Obviously national curricula, educational leadership and evaluation practices, teacher education and many other things mediate in complex networks between politics and schools' practices. In this respect, educational leadership is a mediating activity between different epistemic practices and value-spheres. But the question must also be put the other way around: How should education be organized, led and practiced to support and contribute to political democracy, if that is a system considered central? Naturally both questions are crucial from a curriculum and leadership perspective as practical tasks. For curriculum theory and educational leadership research, the problem is present as a theoretical dilemma and requires a position to be taken.

To indicate the idea of a non-affirmative position it can be contrasted with two normative-prescriptive positions frequent in contemporary curriculum theory: a reproduction-oriented model and a transformation oriented model.

From education history we know the conservative, socialization and reproduction oriented model in many versions since John Locke's book On Education from 1693 (see e.g. Durkheim 1893/1997; Parsons 1963; Bourdieau 1977). The radical, transformation oriented model is familiar since Rousseau's study Discourse on the Origin and Basis of Inequality Among Men from 1755. The first, reproduction oriented model subordinates education to politics by locating education within the existing society or culture. Here the task of education equals socialization into an existing society and culture wherein societal practices and norms function as the guiding principles. For example, according to Dewey, education in schools should be organized according to democratic principles as schools are expected to prepare for democracy. In contrast, transformation oriented models are guided by ideals for future. In its most radical form, revolutionary or transformation-oriented education allows itself to be positioned as super-ordinate with respect to societal interests (Freire 1970/2000; Giroux 1983; McLaren 1998). Educational efforts are made legitimate by their intentions - that education may liberate citizens from oppressive social values and practices aiming at a more socially just society. The ideals to be worked towards are not yet real, but can be made real.

According to non-affirmative theory of education both socialization/reproduction models as well as transformative curriculum models, are educationally problematic, regardless if they are ideologically conservative, radical, or counter-hegemonic. One of the fundamental issues is that these positions may be counterproductive with respect to political democracy. Strongly normativeprescriptive models run the risk of manipulation, indoctrination and of turning education, curriculum work, teaching and leadership, into a technological-instrumental profession.

In the mainstream literature these models are typically considered as critical of and opposite to technical-instrumental models, such as the Tyler rationale (1949). However, the normative-prescriptive character of both socialisation and transformative curriculum and leadership models make them congruent with technological 
instrumentalism: to the extent values and norms are prescribed, as they are in most models above, the task for education is to fulfill these pre-determined ideals as efficiently as possible. Yet, a non-affirmative position is not value neutral as it is assumed as a theory in and for a political democracy. Transformative theories are more explicitly suggesting what interests teaching and leadership should promote within democracies. Explicitly normative models often enter a dialogue with curricula as existing policy documents. Critical discussions of such documents belong to a public debate in democracies, but the question is if a curriculum or leadership theory is to be seen as a policy document among others?

The line to be drawn between critical-transformative and a non-affirmative position is fine. Both belong to a western family of critical theories. Yet we think this difference is worth pointing out. A non-affirmative theory is critical in that it reminds of that the task of education in and for a democracy is to recognize the existing individual, cultural and societal interests, yet not affirming them, but keeping these interests open as topics for reflection. As a theoretical construct non-affirmativity asks to what extent a given practice or policy allows for teachers and learners to cocreate spaces for critical reflection, not only to substitute one ideology with another. Although education is always political, the task of education is also to prepare for political participation the forms and aims of which are not determined in advance.

Coherent with the non-affirmative theory the position developed in this chapter, education stands in a non-hierarchical relation to politics, culture and economy (Benner 2015). Education is not solely placed either "outside" or "inside" society and is thus neither super- nor subordinated with respect to politics, economy and culture, but intends to mediate between these. In this non-hierarchical conceptualization, educational institutions are given relative independence with respect to societal and other interests. It is this space that both allows for and requires reflective, professional educational leaders on each level of the education system. Discursive institutionalism then offers a language for explicating these discursively identified spaces.

It should be observed that a non-hierarchical understanding accepts that hegemonic political interests frame and influence education, but this position recognizes that if the curricular policies and practices would be reduced in the service of some political ideology, it would be in conflict with principles for democratic education. Thus, political democracy requires a specific form of critical curriculum and educational leadership, including a relative independence for educational practitioners guaranteed by the political system itself. The same holds true regarding the relation between, for example, law and politics. In the modern, post-Kantian tradition laws are established by humans themselves. In a political democracy laws are established by an elected parliament. Simultaneously, however, laws regulate political activity. In the same sense, education is partly subordinate to political influences but simultaneously superordinate with respect to politics. Education, then, prepares the subject for active citizenship and political democracy as well as for a working life to be developed by the individual. Importantly, in this tradition, the individual is prepared to transform the very same society or culture into which that person is educated, but 
how this is or should be done cannot be decided upon in advance thus avoiding the normativity problems associated with the two dominant perspectives.

A problem with the closed models is that they do not leave room for developing the principal's, teacher's or learner's ability to decide upon what is to be considered valuable and meaningful. Pushed to an extreme, these approaches do not prepare the individual for self-reflective decision making about the future in a democratic society. Given that the future is thought of as open and undetermined and the question of morality something that cannot ultimately be decided upon in advance, the individual's cultural competence to critical reflection - autonomy, self-awareness and self-determination - is seen as something which must be developed.

The second question above (b) includes an expectation that any theory of educational relevance must explain human educational interaction. Although the individual can learn in and from all kinds of situations, all possible human interaction cannot reasonably be considered as educational or pedagogical in nature. Where, then, does educational interaction start and where does it end? Is there something we have to presuppose in order for education to be possible? For what reasons or ends would education be necessary? While the first question above (a) point at aims and contents of education, this second question (b) asks about the methods of education. How do we explain how teachers and learners' activities are related? How do we understand pedagogical leadership in contrast to other forms of leadership? How does educational leadership relate to teaching? Although educational leadership and teaching refer to different professions, what would the differences and similarities, given that both work with and relate to aims, contents and methods of education? Can educational leadership at a district or national level be seen as educational interaction of some kind?

In this chapter a non-affirmative position regarding pedagogical work is defended, regardless if we talk about teaching, educational leadership or curriculum work at the national level. The two previously described normative-prescriptive conceptions regarding the relation between education and societal development correspond to affirmative education. Affirmative education theory means that a theoretical position for curriculum, education or leadership is ideologically explicit regarding what interests and aims practitioners should affirm, regarding the present situation, or then regarding aims considered important for future needs of society. A dilemma with such an ideologically loaded position is that it runs the risk of ending up in manipulative education. Affirming a given reality, given values or future ideals can mean to uncritically relate one's professional practice to these. Affirmative teaching would be concerned with that learners really reach certain aims as given. An affirmative attitude ends up having a fundamental dilemma: to the extent that aims are given and accepted, educational leadership and teaching is expected to fulfill these resulting in a technical rationale for teaching and leadership.

In contrast, this chapter argues for the non-affirmative position. This means, for example, that existing knowledge, values or ideals are recognized but not affirmed. Non-affirmative education then means, in the pedagogical situation, to focus on the questions to which existing practices, experiences, norms or knowledge are seen as 
answers. By learning to understand how contemporary practices are seen as answers to given problems the learner is expected to develop a reflective relation not only to the answers provided (positive knowledge) in order to evaluate their relevance or accuracy, but also to develop an awareness regarding the questions behind the answers. This awareness includes reflection on in whose interest certain questions are. Of equal importance is the ability to learn to formulate new answers to old questions as well as to produce totally new questions to be answered. This means that irrespective of what values or norms education confess to, education cannot be about socializing the learners into these norms and values. The norms themselves must be brought into question for educational reasons. They are to be recognized, but not affirmed in order to create a pedagogical space for the learner to step back and see how one-self relate to these. In this respect non-affirmative education theory is clearly a critical theory. Some critical theories again are of course critical to existing hegemony. A counter-hegemonical discourse is crucial for any democracy. The question we raise is how valid such a position is as a foundation for education?

Our support of non-affirmative education theory is also grounded in that this approach lies, as will be demonstrated, at the heart of the western, modern tradition of education theory developed by "the classics". In our argumentation we rely on Dietrich Benners and others' reconstruction of this modern tradition, that for the most part has become forgotten. In order not to fall behind a theoretical level that is already attained such a historical awareness is necessary. We clearly understand that this such a position has developed within a given cultural, political and economic tradition. As will be shown this position was a response when leaving the dominating religious cosmology as societal or cultural "root metaphor".

The reason to why non-affirmative pedagogy reminds of pragmatism (Dewey), neo-pragmatism and deliberative democracy (Habermas) consist of their common roots. Both positions argue that there is an interdependent relation between education and politics. Also deliberative democracy requires individuals capable of participation in such a democracy. However, from a non-affirmative education theory perspective, a theory of how a deliberative democracy works is something else than a theory of educational preparation for participation in such a democracy. If this distinction is not identified there is a risk of ending up in normative-socialization oriented pedagogy again, now with deliberative democracy as the directing norm. Education "theory" would then reduced, once more, to drawing implications and developing prescriptive recommendations from e.g. sociology, psychology, cultural studies, ethics or the like, for how teaching should be organized to best prepare the learner.

We think that non-affirmative education theory is reflected in Bill Pinar's understanding of curriculum as complicated conversation. Pinar et al. (1995) observes that "Curriculum, then, is a provocation to reflect on and to think critically about ourselves, our families, our society" (p. 267). As we will see this kind of theory about educational activity, i.e. provocation to think critically, falls back on a long tradition of being aware of the difference between theory of Bildung and theory of education and how they are related. 


\section{The Modern Roots of Education: Cultural-Historical Grounding of Theory}

There is another reason to why we think it is not only valuable but also fruitful to turn to the German-Nordic tradition of general education to find a platform for coherently approaching educational leadership, curriculum and Didaktik. The reason is simply that the present day education dilemmas pointed out in the beginning of this chapter are not entirely new. The dilemmas we face today have a history, but not any history but a very specific one. It is the history of dealing with the question not only of how to educate in and for a pluralist society, but also to deal with the question of how education can, in principle, prepare the growing generation for a future that is not known by us? This move towards education for a future that is not known is one of the core dilemmas of modern education and schooling. How to support the development of the individual's cultural, economic and political citizenship, and educate for a society featured by mutual recognition and respect for differences, simultaneously creating societal cohesion without violating individual rights? The modern education theory was, in the end, a response to how to organize education in and for a pluralist society that left both religious frame of reference and a society built on given social classes.

These are questions we need answers to also today. Luckily these questions and answers to them are known to us as historical insights in the discipline of education. As principled dilemmas they point at those questions and answers that were identified in moving from a pre-modern to a modern societal order, i.e. moving from a pre-determined (teleological) cosmology to a view of the future as radically open where man no longer was only seen as law-abiding but also as law-making and where education became structured by a stepwise evolving nation state and new political order. The American revolution (1765-1783) and the European revolution (1789) came to be not only symbolic but historical turning points in this respect. The long history leading up to these occurrences included rethinking education. Is it too far-reaching to look back 200 years in order to find solutions for today's dilemmas? Our answer is a no. We argue that the modern classics of education theory like Rousseau, Fichte, Herbart, Schleiermacher, and also Dewey later on, formulated educational theory positions offering answers for the new postrevolutionary era. We think these philosophers of modernity and modern education developed conceptual categories and structures by which we still live, but have sometimes forgotten (Mollenhauer 2014). It is fascinating that these contributions were introduced as philosophical theories 100 years before any democratic societies were established, but they were not abandoned but rather built upon during the whole twentieth century until this day. These early contributions were not limited to teaching, curriculum or leadership alone but presented broader approaches to how education was to be understood. We argue for that a reconstructive visit to the core ideas in this tradition may revitalize and guide us in defining and specifying questions and answers to be provided. 
The first two questions (a) and (b) above constitute the core challenges in any education theory as we know of since ancient times. These questions were answered differently by the modern or classic education theory, as developed since Rousseau onwards including Kant, Fichte, Hegel, Herbart and Schleiermacher, i.e. as developed between 1760s and 1830s (Benner 2015; Uljens 2002; Schaffar and Uljens 2015). Our intention is to ask and answer to what extent this modern mode of theorizing education, as developed by these classics, is still relevant? And why should we bother about in asking if these classics make sense for us? There are mainly two reasons for this.

The first is connected to the fact that the modern, or today classic, education theory was developed parallel to the establishment of the modern concept of the pluralist, independent and liberal nation-state and a corresponding concept of the subject, not determined by origin, heritage or anything else This modern view of man, in contrast to a pre-modern conception thus recognized the subject as free or indetermined. The establishment of freedom of speech, religion and thought, as well as abandoning the religious idea of a predetermined cosmological development required a dramatic reform of educational thinking and theory. Previous religious cosmopolitanism as a regulating idea for explaining what it meant to be a human being and develop as such, was stepwise, by and large, replaced by the concept of the autonomous citizen in the independent nation-state. Consequently, the modern society could no longer manage with a pre-modern theory of education. The task of a pre-modern theory of education was about socialization the subject into a given order and future. Despite the original sin the individual was seen as free to make up her mind regarding the predetermined options available.

When religion stepwise was replaced by humanism and later with language as the constitutive dimension for nation-state, new building blocks were established framing education. Now education was supporting the birth of a man expected to make herself. Modern education was to prepare for a society that was in a stage of continuous development. Norms and values could be renegotiated. Westerners learned to live with the question of good life as an open one. Language was upheaved not only to a functional role but was made a constitutive question of personal and collective identity by e.g. Herder. An education for a pluralist society was created. We see that the challenges regarding unity and plurality have remained but that they have received new shapes. Today societies are more plural than ever, as societies have become increasingly multicultural, while at the same time increasingly interdependent both locally and globally. Modern education thus corresponded to a moving from an agricultural to an industrial society. In the agricultural society education as reproductive socialization was good enough, in the modern industrial society the individual's role and position was no longer given. In essence modern theory of education originally was an answer to the same principled dilemmas we experience today. Yet, educational theory as well as the discipline of education has in many instances lost the connections to its own roots as a discipline. This is why historical engagement with seminal ideas may be fruitful (Uljens 2002). 
Modern, or classic, European theory of education was developed along with the establishment of the ideas for the modern nation-state, abandoning previous forms of teleological views of societal development (Benner 2015). Through versions of enlightenment, human reason and rationality were elevated as to replace faith (Autio 2009). Education turned out as a crucial project for the nation-state from the beginning of the nineteenth century. How education was envisioned as a solution was evident in Fichte's Addresses to the German Nation (1808). This project was built upon the idea of establishing a connection between language, culture and state formation. In this concept religion was no longer considered crucial as the moral laws were to be established by man himself. While religious cosmology point beyond the particularity of the nation-state - towards spatial universality and temporal eternity, the modern project connects the concept of people as 'demos' (political citizenship) and 'ethnos' (cultural citizenship). In the beginning of this nation-state era, citizenship as cultural identity and religion was promoted over citizenship as political participation. Today the idea of education is, therefore, connected to a political-democratic citizenship idea, both in terms of that education was to be equally offered to each and everyone, but also that education was to prepare individuals for political participation, economic life and culture. The recent policy, education for the globalized competition state, is redefining concept of citizenship emphasizing the subject, not as a cultural or political citizen but as an economic one.

The seminal ideas developed in modern education theory were a response to an evolving new political, economical and cultural order. But these ideas were also partly utopian in that they presented ideas of how something could be, rather than they described as reality that was present. In a sense, the ideas regarding the task of education presented by of the classics were visionary as they went beyond their own contemporary societal practices and cultural contexts. In other words, these ideas were developed before any political democracies were established more broadly. Yet contemporary educational theory, curriculum and leadership research has to a large extent lost their connections to the seminal ideas of modern, western education theory. The loss of these roots make true progression difficult.

The point made here is that the demonstrated need to conceptually and practically rethink nation-state education reminds of what process the modern nation states lived through when the prevailing educational systems and philosophies were established (Oelkers 2000). There is a question of continuity and discontinuity. To what extent are we able to keep to seminal concepts of education developed as a response to the modern nation state? And to what extent are we forced to rethink citizenship as well as educational research, philosophy, policy and practice in the light of globalization? In order to accomplish this task, we will contribute to a reconstruction of fundamental tensions, issues and features of modern educational thought with a focus on post-Kantian educational thought as developed by Fichte, Schleiermacher and Herbart.

We do not make this argument in order to defend any classic philosopher or position in education. Further, this argument does not indicate a naïve relation to modernity. On the contrary, we emphasize a 'self-reflective consciousness of modernity 
itself' (Heller 1999). We see 'modernity' as one among many ways to organize and understand the individual, society and the world. But in order to move beyond contemporary positions and develop traditions, an insight in fundamental assumptions is necessary (Paraskeva 2016).

Another reason why we claim it is important to engage in the seminal ideas of modern education theory is that we today experience increasingly new forms of transnational organizational, national, corporeal, etc. aggregations of various kinds, new interdependencies and common challenges which require us to redefine what an "autonomous subject in an independent nation-state" is.

\section{The Return of Cosmopolitanism and Nationalism}

The third of the questions (c) pointed out above to be answered by a contemporary theory of education is that of cosmopolitanism. As a topic, cosmopolitanism has re-occurred many times in European history but always in new constellations and with new motives (e.g. Papasthephanou 2016). For example, both Kant and Herbart proposed cosmopolitanism as an ideal. "Das Weltbeste" (Kant 1915), meaning the best for the world, rather than private or national interests, was to be the aim of education (Perander 1883). What is needed today is a renewed and extended discussion on cosmopolitanism and the modern, nation-state centered heritage (e.g. Brincat 2009; Moland 2011). With the most recent 'globalization' movement, cosmopolitanism is back on the agenda after about 200 years of establishing independent, legal states (Rechtsstaat) based on some concept of collective nationhood, often invented around language, formal equity of citizens and history (Fichte 2009; Lewellen 2002). And while we recognize there have been perennial dominance and oppression issues with regards to language and distinctions among dialects, race/ethnicity, and class, the contemporary situation of globopolitanism is also radically different in many regards.

Whereas already Immanuel Kant replaced cosmopolitanism based on religion with universal principles of ethics, we today experience new, previously unseen practical cosmopolitanism or, rather, as we choose to call it, globopolitanism. In addition, with globalization, i.e. an ever increasing political, economical and technological process and policy of increasing interconnectedness, we witness a need for a better understanding of not how such processes are related to those processes within nation states. Many different transnational agreements and organizations today frame intentions and initiatives on the nation state level. Understanding educational leadership and curriculum today also must include the understanding of how nation states operate in relation to each other and in transnational aggregations. Educational leadership and curriculum theory, therefore, cannot be limited to the above two classical, questions but must be reconsidered in light of the global dimension. We argue this is a direction where curriculum theory, educational leadership and policy research should be moving, and, with this volume, we begin this direction. 
Globalization involve crucial developments with implications for curriculum work and policy as well as educational leadership and teaching. Globalization has many faces and is not least connected to technological developments as well as increased economic interdependencies. At other times globalization presents itself as cosmopolitanism. In an educational context cosmopolitanism can, and is to be seen as a question of educational ideals, contents and methods. But globalization as cosmopolitanism is also visible in the form of new interstate, international and transnational governance practices, policies, and procedures, including curriculum work and educational evaluation. Cosmopolitanism as a discourse on educational ideals reflected in curricula, and cosmopolitanism as interrelated governing and governance practices, are interrelated in complex ways. While the dilemma of cosmopolitanism as an educational ideal connect strongly to curriculum as a policy document, conceptually analyzed by Didaktik and curriculum theory, we see new transnational governance practices appearing as new empirical and conceptual challenges for educational leadership. We argue that these two forms regarding how education has developed with respect to global dimensions (cosmopolitanism as ideals and cosmopolitanism as policy practices) are to be treated in connection to, and not disparate, from each other. We perceive of educational governance and leadership as discursive practices at school, regional, nation-state and transnational levels, as well as in interactions between these (Uljens 2016; Uljens and Ylimaki 2015). These practices involve the making and practicing of politically agreed curriculum. The question is, then, how should a theory be constituted as to frame and deconstruct these dimensions?

It was previously concluded that the global or transnational level has complicated educational leadership, curriculum and evaluation. In our approach, we identify several levels of educational leadership as it relates to curriculum work with the intention to answer how the dynamics between, within and across these levels may be approached. It is not like this development has been hidden, on the contrary, empirically it is in front of everybody's eyes. Consequently, we have seen many languages and approaches developing around how the multi-level, multi-centered, and multi-professional processes should be approached. We see functionalist translation theory, systems theory and Luhmann inspired theory of policy borrowing (Steiner-Khamsi), network theories, Marxist inspired world systems theory (Wallerstein) and various versions of institutionalism (Frontini 2009). Few of these approaches have been developed with the core dilemmas of education as the ones to be solved. Most often the approaches advocated would be equally valid for understanding social work or health care. There is nothing wrong with that, except that education as a phenomenon (with curriculum, teaching and leadership as key dimensions) is treated as something what it may not be and as remaining blind for the complexity involved. In contrast, we navigate and position ourselves in this landscape by the help of education theory, not as our roadmap but rather as our guiding question aimed at reconstructing dominant positions. 


\section{A Comparative Perspective}

From a nation-state perspective these shifts in governance, commodification of education and pluralizing of identities reconstitutes the role of education for building social cohesion and national identity (Robertson 2006; Uljens et al. 2013). Especially in Europe with a tradition of "thick" states compared to a model of "thin" state in the USA, the policy shift is foundational. The Nordic welfare state has been built on the assumption of mutual positive effects between economic growth, welfare, educational equality as well as cultural and political citizenship. Movements towards entrepreneuralization of the subject have been received differently in the USA with a tradition of education more as a private rather than public good. More recent developments towards strengthening of nationalism all over the world, not the least in Europe, USA and Russia may be a reaction to economic liberalisation. In light of the complexity of the contemporary situation described above, we propose the need for a new approach to comparative methodology as well.

\section{Aim of This Chapter}

This chapter and the contributions included in this volume are, in different ways, part of a larger project and movement initiated and led by the co-editors with the expressed aim to develop a coherent non-affirmative theoretical framing (Benner 1991, 2005, 2015) for educational leadership and curriculum theorizing and Didaktik (Uljens 2015, 2016; Uljens and Ylimaki 2015; Ylimaki et al. 2016; Ylimaki and Uljens 2017; Uljens and Ylimaki 2017). Over the past 4-5 years (2013-2017) the co-editors have contributed to and engaged a wide range of prominent European and American scholars from the traditionally disparate fields of educational leadership and curriculum theory/Didaktik in a series of sessions, symposia and presentations at in Europe and USA (Uljens and Ylimaki 2017).

This initiative connects to and expands beyond the transatlantic dialogue on Didaktik and curriculum theory started in the beginning of 1990s (Hopmann and Riquarts 1995). Both projects share the idea to "investigate Didaktik and curriculum theory as historically evolved forms of reflection within the social system" (Hopmann 1992, 2015). The present project expands the focus in two ways.

Methodologically a meta-theoretical level is made use of with three guiding core questions: (a) how to specify the task of education in a democratic society; (b) how do we explain the nature of educational interaction; and (c) how can or should the above questions be treated at different levels within a nation-state (national, district, and school level) and beyond a nation state level. On the first question (a) a nonhierarchical understanding regarding the relations between education, politics, culture and economy is defended. Such a position is fundamental for democratic education as it avoids the pitfalls of functionalist and strong normative approaches to leadership and curriculum. The second question (b) argues for a non-affirmative 
interpretation of teaching, educational leadership and curriculum work. This question is opened up is handled by three classic education concepts - recognition, summoning to self-activity and Bildsamkeit as these are constitutive for a non-affirmative view for democratic education. The third question relates to cosmopolitanism and its necessary counterpart, i.e. individual and national identity, and citizenship. Moving from being an abstract, theoretical idea, cosmopolitanism has developed into an empirical reality; however, educational theory, leadership and curriculum research has only recently and still to a very limited extent developed a reflected position on cosmopolitanism and globalization. The nation-state perspective has dominated. We conclude that this theoretical framework allows us to more coherently conceptualize and study curriculum as policy and practice, educational leadership and teaching. In addition, a non-hierarchical position offers a foundation for discursive institutionalism valuable for understanding school work from a policy perspective.

Consonant with this purpose, this chapter is organized into four main sections. First, we analyze curriculum theory/Didaktik and educational leadership studies, including a discussion of strengths and limitations. Second, we present our general framework that considers core concepts and literature on non-hierarchical and nonaffirmative relations from general education theory, organizational theory, and discursive institutionalism that address the shortcomings from curriculum theory/ Didaktik and leadership studies, as well as cosmopolitanism as an educational ideal, and cosmopolitanism as empirical transnational relations. Fourth, our conclusions open the following chapters in the volume.

The first two sections analyses literature from two distinct fields, educational leadership and curriculum theory/Didaktik. Specifically, we examine strengths and weaknesses and then identify a shortcoming common to literature in both fields, a blind spot that, in our view, points toward the need for a new general framework that merges and extends educational leadership and curriculum theory/Didaktik. As it is not possible or meaningful within this frame to describe all varieties, we aim to identify core issues and distinctions.

\section{Theorizing in Didaktik and Curriculum Studies}

As the aim is to contribute a theoretical framework not only bridging European Didaktik and the Anglo-American curriculum studies but also to find out how these may be related to educational leadership studies in a broad understanding of the concept, we are engaged in a complex comparative dialogue. It is a dialogue moving across disciplines and fields of research, between epistemological schools and research methodologies, and between traditions in different countries and continents. Needless to say, such an attempt is a challenging undertaking. Within both fields of research considerable variation may be found. In addition, between European countries there is a variation in how education and curriculum is theorized. The same holds true for the US, although writing the US tradition equals 
writing the history of one European country. Despite a long and still ongoing dialogue on Didaktik and curriculum between US and Europe (Hopmann and Riquarts 1995; Hamilton 2000; Hamilton and Gudmundsdottir 1994) insight in each others traditions is weak. Some approach may attain significant interest in a country or two, but are hardly known in neighbouring countries. Also contemporary developments in one of the continents can pass relatively unnoticed in the other. For example, the remarkable Dewey interest in the 1990s remained for a long time mainly a movement within anglo-saxon discourse, including Scandinavian research, but hardly noticed in continental Europe (Oelkers 2000). As English has become the dominating 'lingua franqua' of Western academic discourse, parallelled by globalisation this has put non-english speaking countries in a very different position regarding their voices on education. Furthermore, in Didaktik we are talking about a historically seen very long tradition of different ways of structuring teaching, curriculum and education in general.

Although partly representing different approaches, curriculum studies and Didaktik have over time been mutually influential between US and Europe (Gundem 1995; Kansanen 1995, 2009; Kliebard 2004; Hamilton 2000). Joseph Dolch (1965) reminds us that the word 'curriculum' has occurred both in English and German but that while the notion survived in English, it was first replaced in the german tradition by 'Lehrplan' (instructional/teaching plan) by the end of eighteenth century. The curriculum term made its way back to Europe in the end of 1960s by Saul Robinsohn who, in turn, was influenced by Dewey's pragmatism (Robinsohn 1972). However, Dolch (1965, p. 359) observed that the distinction between a subjectcentered and a child-centered curriculum in U.S. corresponds to a movement from a 'Lehrplan' to a 'Bildungsplan' in Germany at the end of the nineteenth century, both acknowledging, on the one hand, structuring the contents and subject matter and, on the other, organization of teaching according to the learner's varying needs. In the U.S., the child centered, learning psychological approach to curriculum, originally based on Thorndike's idea of content neutral, psychological principles, grew strong early on.

Sometimes the differences are larger within Europe than between Europe and the US. Hudson and Meyer (2011) has argued that the increasing differentiation of Didaktik in Europe has resulted in a need to seek for common grounds within Didaktik. It is not clear how Didaktik should be understood as the research on teaching and learning has become very differentiated with various influences (Terhart 2009). In addition, European Didaktik has gained renewed interest in China (Bu et al. 2016; ChiKin Lee and Kennedy 2017), although European and German Didaktik was introduced in China via Japan already in the early 1900s (Deng 2016; Kennedy and Chi-Kin Lee 2016) when Herbartianism spreading also to the USA and Finland.

Most approaches to Didaktik, like theories of (general) education (Allgemeine Pädagogik), are directed by the ambition to cover both theory of Bildung (aims and contents) and theory of teaching (educational influence) in a systematic manner. Theory of Bildung traditionally then includes reflection on the aims of education and how selected cultural contents may support reaching these aims, while theory of education explicates those educative interactions involved in treating the contents for reaching given aims. Making use of these distinctions a first step must be a delin- 
eation structuring of the fields of Didaktik and curriculum studies with respect to the two questions posed as necessary for any theory of education to answer, i.e. (a) how educational interaction is explained, and (b) how the relation between education and other societal practices like politics, education and culture is defined. From a Didaktik perspective, however, questions of aims, contents and methods, or the why, what, and how of teaching are valid for both questions.

\section{Historical Developments: From Pre-modern to Modern Didaktik}

Historical studies have played an important role in Didaktik. Primarily this research has focused on the curriculum as a policy document and how it has developed (e.g. Sivesind 2008) or the history of ideas have dominated (Schaller 1995; Benner 1993, 1995; Gundem 2010). In order to understand the field both perspectives are required.

Although the contemporary western theory of education and teaching often relate to both ancient greeks and to rennaisance (fourteenth to seventeenth century) thinking the literature on Didaktik does not always point out features of these traditions compared with our contemporary, modern thinking. For this reason it is useful to discern between premodern and modern education theory (Benner 1991; Schaffar and Uljens 2015). The difference between these are related to the paradox of learning and teaching. We are familiar with the pre-modern paradox of learning as present in Plato's writings about the young Menon's learning of mathematics. Plato asks us how we should explain learning given that we cannot search for knowledge if we don't know what to look for. And, on the other hand, if we had knowledge it would obviously no longer be necessary to look for it. Plato's answer to this dilemma was the nativist one: paradoxically he claims that the condition for reaching knowledge is to already possess that knowledge, which obviously is paradoxical. How does he construct his case? According to his form of nativism a soul is connected to the individual by birth. This soul contains all eternal knowledge but the individual is unaware of that. Given this, the individual's knowledge cannot come from outside, e.g. from a teacher. Instead, the learner, according to Plato, had to learn to strive at reaching "in-sight", search for something that she already possessed. In other words, in this paradox the learner has to reach something she already has. The teacher's role is to direct the learner's attention by questions so that the learner may reach what she already is in possession of.

The Christian theological version of the paradox is also pre-modern. According to this version the paradox emanated from the view of man being created in God's image (1 Moses 26-27) and yet standing before the task of fulfilling this "likeness". The concept of Bildung (Ge. Bild meaning picture, image) has these roots. According to the Judeo-Christian doctrine, human beings are in need of maturing and becoming worthy of His image, while at the same time it is forbidden to make any image of Him (cf. the Ten Commandments). This dynamics, to strive for something that one cannot picture in advance, and of which one already is an image of is paradoxical (Meister Eckhart), and has since been a crucial dilemma of Bildung (Schaffar and Uljens 2015). For the major seventeenth century developers of 
Didaktik (e.g. Comenius) Christian cosmology was self-evident, a given. All education had the preparation for eternal life as its ultimate aim.

The paradox of learning changes in leaving the above described predetermined, pre-modern cosmology. By moving from a premodern to a modern ateleological view of individual and cosmological change, i.e. to viewing the future as indeterminate and not moving towards a given end, and the individual as no longer as predetermined, also the paradox of learning changes. Freedom and autonomy becomes key-concepts around which the modern paradox evolves.

Modern educational thought, from Rousseau and onwards, reformulated the premodern pedagogical paradox or paradox of learning. One of the cornerstones of modern pedagogy is the notion that autonomy (Mündigkeit) as the highest objective of education - discerning thought and action regarding issues of both knowledge and values. According to Herbart, moral freedom means following the reflected will, not acting conventionally from impulse or emotion. Consequently, education consists in the summoning of the Other to reflect over, for instance, the reasonableness of one's own will in relation to others and to the interests of others. Educating the will is then about the cultivation of discernment with the help of reason.

In modern theories of Didaktik knowledge is not considered to exist within the individual before experience nor that knowledge is transferred to the individual. Rather, education is often viewed as provocation to self-reflection. However, in order for the individual to transcend her present state, to reach autonomy, become self-directed, culturally free and reach competence to reflect, she must, according to this line of reasoning, already be conceived of as being autonomous, free and selfreflecting. This modern paradox of education is that education thus seem to presuppose the very existence of that which coming to existence education is considered necessary for. Expressed differently, in order for education to be possible there must be a somebody who's reflection is provoked, but simultaneously it is thought that the individual becomes a somebody, i.e. through the process starting with a provocation. Still differently stated, the pedagogical paradox concerns the following dilemma: in order for education to be possible the individual must be free and selfactive, and simultaneously, in order for the individual to become free and self-active education is necessary. Again we face the problem of how the individual can become something that she already is. The modern version of paradox is to consider the learner as already being able to do what she may become able to (Benner 1991, p. 71; Uljens 2002). Using this argument for understanding teaching it is assumed that the learner can reach cultural, productive freedom (ability to act), only by being recognized and treated as if she already is free (or reflective, capable, trustworthy). Teaching is therefore understood as an invitation, intervention or provocation, a violation, disturbance or expectation concerning the Others relation to herself, world and others. Teaching is to recognize somebody as if she already is capable of doing what she is supposed to become capable of - and act accordingly (Benner 1991). When discussing Didaktik, first, in terms of a relation between school and society and, second, as teaching-studying-learning process (Uljens 1997b) the above mentioned distinctions are interwoven in the following two paragraphs. 


\section{Didaktik as Theory About Educational Interaction}

It is quite obvious that Didaktik is widely considered a field of research and theorizing focusing on primarily educational interaction, especially from the perspective of initial teacher preparation (Jank and Meyer 2002). This is evident also in the etymology. 'Didaktik' originates from the Greek 'didáskō', which meant to demonstrate, show or teach. 'Didaskalos' ( $\delta 1 \delta \alpha ́ \alpha \kappa \alpha \lambda$ os) referred to the teacher. This term was also used in the Old and New Testament for a teacher of religion (Gundem 2010).

Historically, much research in both curriculum and Didaktik has focused either on epistemological, ethical, ontological, political, cultural, organisational, institutional and psychological foundations of substantial dimensions (aims, contents, methods, media) of teaching, or on the process aspect of curriculum as a plan for teaching, i.e. how curricula are constructed (initiated), communicated (implemented) and practiced (institutionalized) (Hopmann 2003). Following Hamilton's (2000) conclusions, modern didactics and curriculum arose "from a crucial distinction: the separation between the activity of 'teaching' from the activity of defining 'that which is taught' (p. 62). Before, this distinction between methods and contents was not made.

According to a widely accepted understanding, the German-Nordic Didaktiktradition of today would connect the mastery of subject matter as a necessary prerequisite for teaching activity, while the Anglo-American tradition (Tyler 1949) to a larger degree have treated principles of teaching as separate from any specific content. Instead reflection of methods would be grounded in psychological learning theory. Yet, these different positions have merged the past two decades. 'Didactics' may be contrasted with 'Mathetics' "for which the focus was the learner and the process of learning, as attested by the Socratic method of eliciting knowledge from the mind of a person through interrogation and logical reasoning (Maieutics)" (Sousa 2015, p. 282). This antique tradition of dialectic or dialogue centered reflection on education was focused on engaging the learner or the student in an reflective process. Dialectics rather than rhetorics made up the core of the teaching-studyinglearning process (Myhre 1976; Uljens 1997a). Later, for Descartes 'mathesis universalis' referred to general theory of quantities and proportions (Mittelstrass 1979).

Pierre de la Ramée (1515-1572) is often recognized as one of the first to use the word curriculum to signify goals and content for teaching while St. Victor in Paris in his Didascalicon from 1120 emphasized dialectics instead of rhetorics. Nordkvelle (2003) demonstrates how this dialectic tradition, where teaching was strongly connected to stepwise verbal commentary of the contents of a book in order to reveal its idea and structure for the student (lectio, meditatio), transformed into Didaktik. In essence, it was the rising number of universities and students attending classes that led to more structured presentations and monologic dictating of the contents (Nordkvelle 2003). However, with fifteenth century Italian humanism dialectics, classical rhetorics and dialogue were rediscovered from Antiquity, e.g. Quintilianus' (35-96) Institutio Oratoria consisting of 12 volumes describing the development 
from childhood to the adult speaker able to participate in public life. Hamilton $(1995,2000)$ argues that the mass schooling towards the end of the sixteenth century went through an "instructional turn" regarding how an existing body of knowledge, later a syllabus, could be organised to more effectively enhance learning (Hamilton 1995, 2000).

In this context the dynamic and vivid developments of Didaktik starting from the dialectic and rhetorical traditions of Antiquity, as well as transformations during the Middle Ages, Renaissance and Humanism can, however, not be explored. For extensive studies in history of Didaktik and curriculum research we refer to e.g. Diederich (1988), Schaller (1995), Nordkvelle (2003), Gundem (2010), and Hamilton (2000).

The intention of one of the classics in Didaktik, Johan Amos Comenius' (15921670) Didactica Magna (Comenius 1907/1633), aimed at presenting general principles valid for teaching of any contents. Comenius' idea was that the teacher reflects the contents (what), methods (how), when and in what order as well as with what kind of aids (Kroksmark 1989; Sadler 2007). Teaching principles transcending the contents have been starting from the familiar and moving to the unfamiliar, moving from the simple to complex, starting from sensory experiences in order to reach understanding through reason and pointing out the relation between principles and examples. Thus, despite continuous tensions, subject matter Didaktik (Ge. Fachdidaktik) and general Didaktik describe the same process but from different angles (Hultman et al. 2012). General Didaktik focuses on general principles.

In teaching, the teacher's task was to extrapolate the educative qualities (Bildungsgehalt) of the selected contents (Bildungsinhalt). To this end Didaktik aims at being a vehicle or a tool for thinking about or for reflecting education. Didaktik turns the teacher's attention towards the idea and character of the educational activity itself as it is related to aims and contents, as well as to the teacher's knowledge of the learners. For Klafki (1963) this type of pedagogical analysis (Ge. Didaktische Analyse), occurs before the actual planning of instructional and study activities.

For Wolfgang Klafki (1963), then, the idea with selecting content to be worked on had to represent or exemplify something general. It had to be exemplary and at the same time be experienced as meaningful by the student's given their present life-world or life-situation but also relevant in a future perspective. This Bildungtheoretical (Eruditioncentered) Didaktik continued the tradition of considering the task of teaching to develop the learner as a whole person, not just the individual's competencies.

We can now identify a difference between the Didaktik tradition in general and for example Shulman's pedagogical content analysis (Gudmundsdottir and Shulman 1987; Gudmundsdottir 1988). Bromme (1995) and Menck (1995) argues that Shulman's motive to focus pedagogical content knowledge stems from empirical studies on teacher effectiveness that identified a relationship among teachers' knowledge, treatment of contents, and successful student learning. However, because the Didaktik tradition as a whole puts the main focus on the teacher-student interaction as a reflective practice around selected cultural contents in essence as 
something non-predictable, this tradition stands in a radical opposition to contemporary output-centered approaches to learning, instruction and curriculum.

For the most part Didaktik has been developed as a doctrine, i.e. as principles for teaching directing planning of instruction. Didaktik is considered a field of knowledge central to the teaching profession and has a central position in teacher education programs (Jank and Meyer 2002). Given the practice oriented, methods centered and doctrinal status of the literature in Didaktik it has been a core element in teacher education over the centuries. Since its birth Didaktik has focused the structuring, sequencing, simplifying, organizing and communication of and around the teaching contents in order to facilitate learning, or rather pupils' studying hopefully resulting in learning what was intended (Uljens 1997b).

As a result, Didaktik, since Johann Amos Comenius' (i.e. Jan Koménsky) 'Didactica Magna' (originally the Czech Didaktik) has functioned both as "theory" or principles for teaching and a tool for lesson preparation, thereby receiving a similar role in teacher education as curriculum work did in the US (Hopmann and Riquarts 1995; Jank and Meyer 2002; Sousa 2015). Contributions to Didaktik with teacher education in mind (e.g. Wolfgang Klafki) typically emphasizes instructional planning with regards to aims, contents and especially the methods of teaching with the learner as well as the cultural context in mind, while contributions do Didaktik as curriculum theory (theory of the syllabus) looks at aims, contents and methods from a macro perspective focusing on what interests influence the making of a national curriculum so as to support transformation and reproduction of culture. However, teachers' professional development regarding their teaching competence is often not dealt within Didaktik and curriculum theory literature (e.g. Dreyfus and Dreyfus 1986; Berliner 1989; Dall'Alba and Sandberg 2006; Wermke 2013).

Despite the strong emphasis on Bildung in European Didaktik it should also be observed that much European empirical research on teaching and learning is not explicitly framed by a Didaktik theory. Rather, learning theory developed from the 1960s to a major frame of reference for research on teaching, especially various version of cognitivism.

However, in Scandinavian curriculum research and Didaktik in the 1970 and 1980s, the contents of teaching started to receive a more central position in research on teaching and learning. Curriculum research increasingly emphasized the differences between curriculum as intended, practiced and perceived. Instead of explaining differences in learning outcomes by the help of cognitive strategies applied by the learners studying the same contents, it was no longer taken for granted that learners perceived the content of teaching similarly or in the way the textbooks or teachers did. As a result, some scholars developed different approaches to studying how the contents was perceived and understood by the learners (Marton 1981) and teachers (Doyle and Carter 1984; Shulman 1986).

The turn towards individuals' experiences naturally required new research methods to be developed. Qualitative methods in educational research building on principles from hermeneutics and phenomenology (Bengtsson 2003), represented a significant shift in empirical research on Didaktik. European-Nordic research on Didaktik combined successfully empirical phenomenological research and the 
growing focus on teaching contents. Rather than focusing the learner's learning strategies, learners' ways of understanding the contents described. The phenomenographic approach developed by Marton and numerous colleagues (Marton 2014) has been influential since. Phenomenology and hermeneutics have most often been applied as epistemic positions (Claesson et al. 2011) but also as ontologically oriented theory of human experience and Bildung (Gustavsson 1996; Bengtsson 2003; Kristensson-Uggla 1999, 2010). This phenomenological-hermeneutic turn in Scandinavian Didaktik significantly contributed to expand the previously dominating interest in curriculum as primarily a governance issue. In Germany MeyerDrawe (1984) is a good exponent of this turn. However, these approaches were critiqued for disregarding sociocultural and institutional dimensions of education thereby remaining limited for understanding regarding the relation between politics and education pointed out as one of the two core questions to be answered by a theory of education.

Also cognitivist learning psychology as a foundation for research on teaching and Didaktik was criticized for disregarding the cultural and institutional context of learning. Which led to a support for a variety of sociocultural, situated and distributed approaches to learning inspired mainly by Vygotsky (e.g. Engeström 1987; Cole and Engeström 1993; Hutchins and Klausen 1990; Rogoff 1990; Lave 1988; Brown et al. 1989; Säljö 1994; Matusov 2011). These studies were mostly carried out in non-institutional learning, thus paying little attention to how organized teaching intervened in the learning (Bildung) process. Engeström (1987) developed an approach that was more relevant for Didaktik and institutional education by establishing the Scandinavian school of Vygotskian cultural-historical learning and activity theory (Engeström 2000). Further, this approach combined a contentcentered view of learning and teaching by locating this process in a larger social, cultural, historical and institutional activity system.

\section{Didaktik as Theory About the Relation Between Education and Society}

Didaktik grew into a more systematized field of reflection as a response to the sixteenth to seventeenth century developments in Europe with the embryonal construction of the modern state although teaching of reading was taken care of by the church. Naturally the printing press was a crucial technological invention allowing for a movement from an oral to a written culture (Ong 2002) that prepared for mass schooling and especially distribution of printed versions of the holy book. As the cultural institutions like the church and school were so crucial for the needs of the state it is easy to see why Didaktik covers both curriculum as the national or state based policy document (Lehrplan, syllabus, curriculum) and the practice of pedagogical or curriculum work within schools. With schools questions of teaching as 
separate from upbringing evolved. Also, as Hamilton (2000) reminds, the 'world of knowledge' began to be mapped pointing out the contents of teaching raising questions of how this contents should be organised to support learning (the course of schooling, curriculum). The questions has often been answered by describing how different levels decide on, act around and evaluate the selection of aims, content and method, i.e. curriculum work on a societal, institutional, interactional and personal level (Lundgren 2015; Gundem 2010; Reid 1994; Uljens 1997b).

In European practice of curriculum policy making the decisive selection, formulations and decisions regarding aims and contents of teaching is typically made on the nation-state level, far above each single school. Methods, in turn, have regarded primarily a topic to be decided by the teacher on the school or classroom level (methods freedom of teachers). A longstanding topic occurring in both curriculum studies and Didaktik is how the macro and micro levels connect (Goodlad 1966, Klafki 1995). While Didaktik as a field of research traditionally tries to keep together questions of aims, contents and methods of teaching as they occur different levels, in anglo-american research curriculum theory more often is discerned from instructional theory and its base in psychology or teaching contents.

While the curriculum as a public policy document, syllabus, and Lehrplan (since the seventeenth century in Europe) are seen as vehicles for governing the school as a state-driven public institution (Dolch 1965; Tenorth 1988) and for providing schools with the general aims of education and subject matter, such an understanding of a state or federal core curriculum is very recent in the US. In England and Wales national curricula were introduced 1988. In U.S., with a tradition of more state independent schools, the 'curriculum' has instead more often been considered a tool for local school leadership and organization of teaching (Robinsohn 1972; Hopmann and Riquarts 1995; McKernan 2008; Ylimaki 2011). While most European countries have lived through various stages of decentralisation of curriculum work the past three decades, the opposite movement have been visible in the anglophone world, thus reflecting a harmonisation across traditions.

For the Didaktik tradition, curriculum making involves an authoritative selection of contents from culture or tradition that must become embedded in the forms of teacher thinking (Hopmann 1997; Hopmann et al. 2000). This selection of contents is naturally done on a policy level as well as on a school or a teacher level. It is not surprising, then, that for one prominent twentieth century german researcher in Didaktik, Erich Weniger, Didaktik did not primarily refer to teaching methods or planning of teaching but mainly to the study of selection of contents for a curriculum as Lehrplan or syllabus (policy document) on a societal level (Weniger 1965). Today some might perceive this as the task of education policy research. As a consequence, for Weniger, Didaktik in narrower sense referred to the study of curriculum as a policy document while Didaktik in a wider sense also captures methods of teaching. Very often the opposite interpretation is found in the literature.

Throughout history, in Didaktik teaching in cognitive contents (qualification) has, in principle, been considered subordinated to and as a vehicle aiming at cultivation of more general capacities (reflected will, moral and rational reasoning, identity or character). That is, the selection and treatment of contents should serve 
educative purposes beyond learning the subject matter itself (e.g. Herbart's 'educative teaching', C. H. Judd's view of transfer; Somr and Hrušková 2014; Benner 1993). When saying that Didaktik also reflects contents in relation to the aims of teaching means that the core of education or Didaktik as an academic discipline is, in the end, about reflecting upon the ethical responsibility of teaching (Menck 1995). For what ends is education organized? What should the learner become?

The modern tradition, developed by Rousseau and Kant still today is a point of reference for the educational field as a whole, typically assuming that teaching and education is about dealing with how to live out our responsibility to support the student's stepwise development toward an independent cultural being and citizen able to participate in common tasks of the society, culture, politics and economy (labor market). This means that a theory of Didaktik is expected to answer how the question of pedagogical responsibility (Blankertz 1982). The ideal of the autonomous individual in the autonomous state was the regulative ideal that was transformed into a guiding point of reference for teaching.

Didaktik - A Theory for Educative Teaching In the German-Nordic tradition the discipline of education (Erziehungswissenschaft, Pädagogik), including Didaktik, identifies a difference between activity of teaching (Ge. Unterricht, Fi. opetus, Swe. undervisning) and activity of education (Ge. Erziehung, Fi. kasvatus, Swe. fostran). Some equate 'education' with primary socialisation typically occurring in the homes, while 'teaching' is seen as secondary socialisation that primarily would occur in schools. Others see education (Ge. Erziehung) and teaching (Ge. Unterricht) as two dimensions of one and the same process. Irrespective of position both notions refer to intentional activity to pedagogically influence the learner or student. 'Education' is focused on formation (Bildung) of the personality, i.e. supporting the individual's development towards autonomy and ability to self-directed responsible or ethically reflected action. 'Teaching', in turn, is not limited to the mere distribution of information or about training in a limited sense, but aiming at the development of learners' conceptual or theoretical understanding of a phenomenon, which also may guide future activity (Jank and Meyer 2002).

It is useful to be aware of the two different ways in which education and teaching may be considered as connected. Empirically seen schools always "educate" in the above sense of the word, intentionally or not (hidden curriculum): just by participating in social interaction and the practices of educational institutions values are always transferred and identities are being formed. Theoretically seen we may identify a more or less prescriptive relation between the two (teaching and education), i.e. that teaching always should educate (Jank and Meyer 2002). Through his concept of 'educative teaching' (Erziehender Unterricht) J. F. Herbart (1776-1841) pointed out that the primary idea or meaning of education was to support Bildung, i.e. the learner's development towards becoming autonomous (self-directed and responsible) and independent subject (Herbart 1908). Teaching that did not serve this educative purpose did not deserve to be called teaching but was rather about indoctrination or manipulation, according to Herbart. 
As we can see Didaktik primarily focus on the why-, what- and how-questions. Especially in broader conceptions of Didaktik like the one by Wolfgang Klafki the school's responsibility is clearly to be aware and reflect upon forces framing the school. Klafki's famous 'five questions' from the 1950s express the ambition to see Didaktik as a unifying theory regarding intellectual, social, historical and psychological justification inclusion of educational contents in the curriculum: (1). What wider sense of reality is prefigured in course content?, (2). What significance does course content already have in the learner's mind?, (3). What significance does course content have for the learner's future?, (4). How does course content relate to the other elements of a school programme?, (5). How does course content stimulate the learner's own inquiries?

Since 1960s, Didaktik has often been structured according to the research paradigm specific approaches represented. A paradigmatic division was made between an empirical-analytical approach, critical theory and hermeneutics reflecting a theory of science perspective, focusing on general ontological and epistemological positions. Both erudition centered Didaktik and progressivism during the twentieth century continued in many ways the longstanding tension between so called 'formal' theories and 'material' theories of Bildung. While the 'material' theories were emphasizing the importance of learning the contents in order to be socialized into the culture, 'formal' approaches focused on education as being about the development of general capacities to reflect, to solve problems and to deliberate. One of Wolfgang Klafki's contributions to german Didaktik was to connect the two by the concept of 'categorial Bildung' (Klafki 1995). The idea was that while the content in terms of categories for understanding opens up the culture for the learner, learning to e.g. reflect, argue and communicate 'opens up' the learner for the culture.

In Scandinavian Didaktik Swedish curriculum theory research by Dahllöf (1967) and Lundgren (1972) continued the approach initiated by Erich Weniger, viewing curriculum from a nation-state perspective. Curriculum theory was here not understood as theory or principles of teaching practice but rather as a framework for understanding how the school system was governed and "how knowledge transmitted in an educational context is selected, valued and organised and how such processes can be understood" (Linné 2015). This research developed later into studying curriculum codes inspired by Basil Bernstein.

Critical theory from the 1970s pointed out that traditional Erudition- or Bildung centered Didaktik was ideologically conservative contributing to preservation of the class society. The empirical turn in educational research in the 1960s in considered Bildung centered Didaktik as too philosophical and distanced from empirical practice of schools. As a result of this critique Wolfgang Klafki $(1994,1995)$ developed his 'critical-constructive' approach. As in critical curriculum and pedagogy in North American literature (e.g. Freire 2000; Apple 2005), this critical dimension is value laden in the sense that his critical-constructive Didaktik accepts self-determination, co-determination and solidarity as aims for education. Klafki's (1995) criticalconstructivist approach to education considers objective, institutional dimensions of schooling as well as the possibility of critical consciousness for eliminating barriers and changing society. The 'constructive' task of Didaktik then would initiate and 
develop new concepts, program, models for future educational practice moving beyond what is. Critical-constructive Didaktik thus is very close to a political program for democratisation of education (Jank and Meyer 2002).

\section{Sociocultural Reproduction and Transformation Perspectives in Curriculum and Didaktik}

More broadly, curriculum/Didaktik theorists also tend to fall between one of two dominant perspectives on relations between society and education but with more explicit ways of understanding education as subordinated to or located within existing society or superordinate to or located above existing society, socializing students into the values and norms of the organization and its goals to prepare students for an existing society or preparing them to change or transform society itself.

Curriculum theorizing and Didaktik scholars whose work is grounded in a sociocultural reproduction perspective explain curriculum in terms of a control function or paradigm, meaning that curriculum functions to prepare all students with existing important societal knowledge, values, and norms (Molnar and Zahorik 1977). Here, often drawing on Tyler (1949) and his followers, curriculum is a technical, rational system for planning and management. Dewey's (1916/2008) philosophy regarding relations among individuals, education, and society were not as widely utilized for curriculum development and planning in the US; however, his influence continues for many other contemporary curriculum theorists, including Henderson and Gornik (2007), Kesson and Henderson (2010), and Castner et al. (this volume).

Dewey (1916/2008) emphasized the idea of educational and social connections throughout his theories. As he described,

\footnotetext{
In directing the activities of the young, society determines its own future in determining that of the young. Since the young at a given time will at some later date compose the society of that period, the latter's nature will largely turn upon the direction children's activities were given at an earlier period. The cumulative movement of action toward a later result is what is meant by growth. (pp. 29-30)
}

In other words, education has no greater end than to create the capacity for further education in students; a democratic way of life is not a means to some larger end or outcome. It is in itself the realization of political, social, and educational ends supportive of growth (Ylimaki 2012). According to Dewey (1916/2008), such a democratic society must have a type of education that gives individuals a personal interest in social relationships and control, and the habits of mind that secure social change without introducing disorder. From this more or less sociocultural reproduction perspective along with a Darwin influence, Dewey (1916/2008) writes about curriculum subjects, arguing that the subject matter of education consists primarily of the meanings that supply content to existing social life. Here the continuity of social life means that many of these meanings are contributed to present activity by past collective experience. Dewey's rich pragmatic philosophy had a major impact 
on education in the early part of the twentieth century with many schools including his own Chicago lab school applying his ideas (results of which were reported in the Eight Year Study with Ralph Tyler as the primary evaluator).

Decades later, following in a neo-pragmatist and reconceptualist tradition of curriculum theorizing, Englund (1997, 2006), considered curriculum work as deliberative practice and communication. This deliberational and sociopolitical take on curricular dialogues in schools acknowledged how meaning was negotiated and constructed around subject matter in institutional settings, preparing the learner for a self-determined participatory and deliberative democratic citizenship. In the U.S., between Dewey and later reconceptualist theories (Pinar, Macdonald), Schwab (1969a, b) similarly drew on pragmatism to conceptualize curriculum making as deliberation in the "arts of the practical". Schwab considered the "practical' as a mode of inquiry or a way of dealing with the kinds of problems philosophers called uncertain (Gauthier 1963). To deliberate, according to Schwab (1969a, b), is to examine within a specific context, the complex interplay of means and ends in order to choose actions wisely and responsibly. While there are similarities with regard to a focus on environment or context and authority, these curriculum theorists did not explicitly consider organizational ontology, epistemology, or the role of leadership in these contexts.

Dewey's and later neo-pragmatist work (e.g. Englund, Schwab) notwithstanding, according to Westbury (2000), authority and management were central to anglo curriculum theory in the US with its decentralized system; authoritative agencies for public school systems, including district and school leaders were necessary to direct and institutionalize curriculum work and teaching in documents specifying objectives, experiences, and evaluation processes, such as in the system popularized by Tyler (1949). And while the role of district and school leaders is not explicitly considered here, classical anglo american curriculum theory was heavily influenced by behavioral psychology as well as the same rational perspectives and instrumentalism grounded in an underlying sociocultural reproduction perspectives that informed classic educational leadership approaches reviewed earlier. In one illustrative curriculum example, Bobbit's (1918) The Curriculum and its rational approach to curriculum development and planning were later popularized with Ralph Tyler's (1949) Rationale, identifying four broad open but fundamental questions concerning curriculum and instruction: (1) What educational purposes should the school seek to attain? (2) What educational experiences can be provided that are likely to attain these purposes? (3) How can these educational experiences be effectively organized? (4) How can we determine whether these purposes are being met? Tyler (1949) clearly disconnects ends and means; the question of objectives or aims must be identified first because they are considered "criteria by which materials are selected, instructional procedures are developed and evaluations are prepared" (p. 3). Values and morals are not an explicit part of curriculum planning as articulated in the Tyler Rationale (1949) and subsequent more instrumental models (e.g. Taba and Taba 1962).

In this control paradigm, the notion of human interactions around academic subjects (or the role of the student/subject) requires a rational approach to self-regulation, 
one that conflates morals and values with methods. From a classical curriculum theory standpoint, then, the success of rationalistic regulation of individual selves is dependent upon the behaviorist and cognitive measures tools of scientific psychology (i.e. curriculum). Subsequent scholarship regarding Tyler's Rationale tended to apply this system to very instrumental curriculum approaches grounded in behavioral psychology and learning theory, approaches that by design emptied the subject from consciousness. Pinar's critique of this grounding and underlying intent to empty the subject is explicit throughout his curriculum theorizing and that of his followers in the Reconceptualist Movement.

While U.S. educational leadership students and faculty members may not have read Ralph Tyler's (1949) Principles of Curriculum and Instruction, John Dewey's (1916/2008) pragmatic philosophy providing some counter arguments regarding the curriculum, the child, and democracy, or Pinar's (2004) contemporary curriculum theorizing as part of their leadership preparation courses, the above principles are very familiar in practical, mechanistic terms as the scientific procedures of Tyler's Rationale have become synonymous with U.S. curriculum work for decades. We can find a number of new practical models for curriculum planning and developed popularized in the wake of externalized evaluation policies connected to state and now more centralized (national Common Core) curriculum standards with Understanding by Design (Wiggins and McTighe 2005) probably among the most widely utilized example. Understanding by Design (UBD) is a curriculum planning approach to 'backwards mapping', looking at the outcome in order to design curriculum units with objectives (big ideas), performance assessments, and classroom instruction. Such curriculum planning also follows guidelines often promoted in practical workshops using divisional categories, such as the written curriculum, overt curriculum, recommended curriculum, and learned curriculum among others (Porter 2002). While Wiggins and McTighe clearly consider 'understanding' as a primary goal for curriculum work, we cannot consider this model as curriculum theorizing in the same way as Pinar's (2004) notion of curriculum as understanding and complicated conversation. In our view, these approaches to curriculum development and planning are control oriented in that the subject (both content and student) require a rational approach to regulation of learning from understanding self to the world. In other words, curriculum development models from Tyler (1949) and Taba and Taba (1962) through Wiggins and McTighe (2005) are also grounded in various learning theories. We do not go into all of that here but only to recognize that there is an underlying realist ontology and related epistemology at work, in for example, behaviorist theories that suggest knowledge is finite; learning is said to be overt, observable, and measurable, all of which aim for changes in behavior through some form of regulation and (implicitly) aim toward reproduction of existing society. We acknowledge that UBD and similar curriculum planning models now popular in the US context are not curriculum theories or theorizing as accepted in the curriculum field. During the same time, in the US and elsewhere, we also see a number of critical education scholars writing about the ideological conditions (e.g. neoliberalism) of social reproduction that influence schooling, including all kinds of curriculum work (e.g. Anyon 2006; Luke 2010; Purpel 1989). Across this work, we also find 
more attention to a critique of ideology and sociocultural reproduction than curriculum theorizing toward sociocultural transformation aims.

In contrast to sociocultural reproduction theories, sociocultural transformation oriented theories seek to critique the status quo and explain how radical change occurs in society. Much of the more recent curriculum theorizing in the North American context answers the question of relations among individuals, education and society in terms of societal change. In the US and elsewhere, this strand of curriculum literature takes its point of departure from either a subjective, radical humanist or psychoanalytic position radical structuralist position. Disputes between the more subjective, existential, even psychoanalytic perspective (exemplified by William F. Pinar), and a more objective structural perspective (exemplified by Michael Apple), have in many ways defined recent curriculum theorizing in North America and elsewhere. Regardless of epistemological and ontological differences, when applied to education, sociocultural transformation theorists argue that education is superordinate, to society (Uljens 2008; Uljens and Ylimaki 2015; Ylimaki et al. 2016). Curriculum functions in a superordinate position to society with planning, methods and content functioning to liberate citizens from existing, oppressive social norms and values. The aim of this scholarship is around liberation; however, according to Pinar and his followers, liberation begins with subjectivity Bildung and then moves outward for Apple, liberation is structural and overt from the beginning. Pinar et al. (1995) observe, "Curriculum is a provocation to reflect on and to think critically about ourselves, our families, our society" (p. 267). Specifically, Pinar et al. (1995) introduced eleven curricular subtexts: historical, political, racial, gender, phenomenological, poststructural, autobiographical/biographical, aesthetic, theological, institutional, and international. Here Pinar and colleagues draw on critical social theory as well as post-structural approaches to draw attention to a dual conception of the subject, content in texts as well as the individual subject and his/ her development through a journey of self-understanding (currere) and a complicated conversation with a range of texts. Reality is a social construction, meaning that becoming a person is a social act and that social meanings which sustain and organize a collectivity are created by the continuing pattern of interactions of increasingly diverse individuals in society.

Closely related, Freire (1970/2000) and his followers describe and critique what he calls 'banking' education as a term to describe the traditional education system. Similar models have followed, including funds of knowledge, defined as the historically accumulated and culturally developed bodies of knowledge and skills essential for households or individual functioning and well-being (Moll et al. 1992).

Other social change oriented curriculum scholars draw more explicit attention to connections among hegemony, ideology, power relations, official knowledge, and economic inequity (e.g. Whitty 1974; Apple 2004). Apple (2004) argues that curriculum must see as its task today the identification of moral, political, and ethical conflicts connected to social inequalities, including class structures, gender, race/ ethnicity, and intersections thereof. In Apple's (2004) view, the subjective, psychoanalytical principle of the social construction of reality does not explain why certain social and cultural meanings and not others are distributed through schools, 
nor does it explain how the control of knowledge preserving and producing institutions may be linked to power, particularly with regards to the ideological dominance of powerful groups in a social collectivity. Rather, Apple (2004) draws attention to the subtle connections among hegemony, ideological stability as raised by social reproductionist critics (e.g. Bowles and Gintis 1975; Bernstein 1975; Bourdieu 1977), curricular knowledge, and economic inequality. Across this critical education literature, curriculum decisions are political acts that contribute to social inequities, including class structures, gender, race/ethnicity and intersections thereof. Epistemological differences notwithstanding, pedagogical influences are not, however, explicitly discussed in much of this literature; however, others have applied the tenets of these critical education theories to various versions of critical pedagogy.

In the German Didaktik, Wolfgang Klafki $(1994,1995)$ would be the most wellknown European researcher representing a 'critical-constructive' approach. As in critical curriculum and pedagogy in North American literature (e.g. Freire 2000; Apple 2005), this critical dimension is value laden in the sense that his criticalconstructive Didaktik accepts self-determination, co-determination and solidarity as aims for education. Klafki's (1995) critical-constructivist approach to education considers objective, institutional dimensions of schooling as well as the possibility of critical consciousness for eliminating barriers and changing society.

\section{Post-Structuralism and Merging of Traditions: Postmodern Epistemology}

During 1990s post-structural developments in curriculum theory (e.g. Doll 1993b; Säfström and Östman 1999) were influenced by late modern philosophy (Lyotard, Foucault, Rorty, Cherryholmes) according to which social reality and its power relations are partly constituted by discourses, which were to be de- and reconstructed. The reception of this movement was received differently in arts, architecture, social and human sciences. In curriculum theory Doll's (1993a) interpretation is seen as a significative. In his reconstruction of historical developments in curriculum research he contrasted post-modern curriculum thinking as a departure from the modernist tradition. For Doll (1993a) modernism refers to Cartesianism which equals to realist ontology and representational epistemology as occurred in natural sciences. In this view learning is about aiming at reaching predetermined and true knowledge in a linear fashion assuming the "learner to be a receiver, not a creator, of knowledge, a spectator... who can only discover that which already is" (p. 283). The Credo of this modernist tradition is considered to be the Tyler rationale which "has led us to emphasize precisely defined, well-articulated, preset goals and a delivery system that matches the clarity of the goal statements" (ibid. p 284). This approach is, according to Doll (1993a), fundamentally challenged by postmodern paradoxical pedagogy viewing the future as unpredictable and where the "Self is understood only in relation to the other." (p. 285). This kind of curriculum thinking "shifts the 
focus of curriculum from receiving or developing to dialoguing, negotiating, interacting. These are not words found in either the Tyler rationale or in modernist curriculum thought." (p. 286). For Doll reaching back to issues Dewey dealt with, "a pedagogy based on Cartesian-modernist separation (of self and world) is either a copy-model pedagogy or, at its best, a discovery pedagogy". In developing his own answer inspired by post-structuralism, instead of replacing a causal view of teaching with a simple learner directed constructivism, Doll finds a role for the teacher: "The teacher's role is now to present the curriculum in just enough of challenging, controversial, "chaotic" manner so that self-organization will be encouraged" (p. 284). However, as will later be pointed out, in our reading of the history of education theory what Doll (1993a, b) describes as features of postmodern curriculum rather represents the very core ideas in modern education theory as developed from Rousseau and onwards, especially by Herbart and Schleiermacher. In Doll's reconstruction we cannot find any references to the classic core concepts of modern education theory as developed during romanticism, i.e. a period when education theory changed from representing a "closed" system and move towards an open one. Given that this tradition is invisible it can result in the conclusion that only post-modern education theory brought about something that was initiated almost two centuries before. We return later to what occurred between Doll's leap from Cartesianism to Bobbitt and Tyler.

In Autio's (2006) reconstruction, we find a comprehensive historical framing, both in terms of the reconstruction of the history of ideas as well as descriptions of the shifts in the political situation and the role of schooling in the nation state over time. Drawing on theological, sociological and philosophical sources, Autio (2006) identifies the roots of instrumentalist thinking and rationality operating in AngloAmerican curriculum theory and Didaktik today and then argues for a reconsideration of these traditions in the midst of contemporary globalization.

Autio (2013) argues that while this classical curriculum theorizing has been linked to the nation-state, the contemporary situation has also shifted with globalization. In his view, the traditional educational systems and models that have guided individuals towards the socialization process of becoming citizens of the nation state no longer apply. That is, an individual is no longer only a citizen of a nation but also has other concerns and responsibilities toward global citizenship. "Globalization is undermining the project of modernity by dis-embedding the political project of the state from the cultural project of nationhood" (Autio 2013, p. 31). For Autio, new conceptualizations of a nation-state force us to re-evaluate the curriculum as a project to build national identity through national ethos, and question the possibility of the curriculum or educational thinking to reflect and reinforce national belonging. Autio (2013) concludes by arguing that the post-national approaches to curriculum theorizing are needed in order to encompass the contemporary situation (p. 31). While Autio's reconstruction of ideas is comprehensive and considers intellectual shifts beyond Cartesianism, there are few references to the core concepts of modern education theory as developed during the later enlightenment and romantics, i.e. the seminal position in modern European theory. We will 
later consider the relevance of these core concepts to the contemporary situation. First, we must explicitly articulate what we mean by curriculum, its objects, processes, and underlying perspectives.

\section{Didaktik, Curriculum and Educational Leadership}

Classical North American curriculum theorizing and theories, when compared to Didaktik, featured a control managerial perspective, one that was formalized in the Tyler Rationale (Tyler 1949) and its psychology-based instrumental applications (Westbury 2000). In both classical American and European curriculum theory, answers to curriculum revolved around technical rationality connected to the idea of building systems of public schools with an authoritative agency directing teachers' curriculum work (i.e. implementation) with a written curriculum document (i.e. the syllabus) containing statements of aims, prescribed content (e.g. textbooks) and expected methods (Westbury 2000). Such control perspectives were not without early criticism, however, including most notably Dewey's (1938) charge that control theories masked value positions, giving the appearance of being value free when they clearly were not.

The managerial or control approach to curriculum (e.g. Tyler 1949) focused on practice, providing conceptual frameworks which were intended to increase the efficiency and effectiveness of the educational process, an intention that dominated much of curriculum theorizing until the 1970s. The reconceptualist Movement and parallel critical education movement in the New Sociology of Education. Since the 1970s, curriculum theorizing in North America has been focused around subjectivity Bildung and Currere in the Reconceptualist Movement (e.g. Pinar 1978, 2011, 2012; Macdonald 1971) and critical education studies in a parallel movement on the New Sociology of Education (Apple and Weis 1986; Bowles and Gintis 1976; Giroux 1980; Arnot and Whitty 1982), and, most recently in a post-reconceptualist era, cultural studies (e.g. Dimitriatis 2009; Helfenbein 2010; Mason and Helfenbein 2012). Across these strands, curriculum theorists have challenged the control or managerial perspectives of classical curriculum theory, such as the Tyler Rationale (1949).

Across these reconceptualist movements, the object of curriculum theorizing has been, on the one hand, critical studies of the marginalizing impact of policies or policy discourses and, on the other hand, a relation between identity construction (e.g. race, class, gender) and schooling. In the former, curriculum theorizing features the development of official knowledge emerging from societal structures, power, ideology, and schooling as exemplified in the work of Michael Apple (2004, 2014) and similarly articulated by others (e.g. Bowles and Gintis 1976; Giroux 1980). According to Apple (2014) schools preserve and distribute what is perceived to be "legitimate knowledge", meaning they confer cultural legitimacy on the knowledge of specific groups. Here the ability of a group to make its knowledge legitimate related to that group's power in the larger political and economic area. In a related strand, more recent cultural studies scholars remind us that such hegemonic 
processes create what Bourdieu termed symbolic violence, eradicating particular cultural identities from official curriculum documents and materials, all of which have a critical impact on identity construction. In other words, for critical education and cultural studies scholars, theorizing is cultural critique, engaging a counter hegemonic dialogue about the underlying ideological bases of curriculum as well as what happens with people's identities as a result of dominant curriculum/policy discourses and knowledge legitimation. Such critical education theorizing also dates back to Bernstein's theories of codes (1975) that heavily influenced the curriculum studies field in the Nordic countries/Europe, including Forsberg et al. (this volume) and is likely to increase with rise of neo-nationalism and authoritarian populism as well as increasing pluralism due to internal cosmopolitanism, population migrations, and refugees.

Pinar's complicated conversation or Bildung centered 'understanding curriculum' approach to curriculum theorizing took steps towards the German-Nordic tradition of understanding curriculum not only as a field of research among many, but as a discipline in its own right, comparable to psychology or sociology, aiming at theorizing curriculum (Uljens and Ylimaki 2017). Pinar gave little attention to institutionalized schooling in his curriculum theorizing, and in fact rejects the need to focus on it early on (Pinar 1978) while Apple has frequently critiqued the inequitable societal structures that schools as sociocultural institutions reproduce. During the same timeframe, Macdonald (1995) took steps toward a more hermeneutic approach to curriculum theorizing but did not explicitly consider organizations/ institutions or leadership therein. Grounded in hermeneutics, Macdonald's (1995) curriculum theorizing pushed beyond development frameworks to propose the importance of ongoing attempts to interpret curricular reality.

Across Pinar's $(1978,2004,2011)$ curriculum theorizing, critical education studies (Apple 1992, 2004, 2008) and various cultural studies literature (e.g. Dimitriatis 2009; Helfenbein 2010), we see important work dealing with contemporary political struggles, and we do not mean to question the importance of such identity issues as race, class, gender, sexual orientation and other -isms. Rather, we point out that theorizing identity in relation to sociopolitical struggles is not the same as theorizing education or curriculum/Didaktik as key aspects of it. At the same time, cultural studies oriented curriculum scholars also connect with those who write about inequitable power structures (e.g. Apple 2004, 2008) as well as related postcolonialism (Rizvi 2009) and critical race theories (Delgato and Stafanci 2000), opening the door for a consideration of internal and global cosmopolitanism as an empirical reality.

Perhaps as a result of these combined curriculum studies movements in the 1970s and 1980s as well as increasing emphasis on postmodern and poststructural approaches of the 1990s, we see fewer references to systems and institutional dimensions of education, and indeed curriculum as policy itself, in these later North American curriculum turns. Curriculum and related evaluation policy documents are studied in the US; however, this research is often carried out by political scientists or policy scholars, not curriculum scholars. Critical policy studies of US policy has been increasingly relevant with trends including policy appropriation (Sutton and 
Levinson 2001), policy enactment (Braun et al. 2010) and policy networks or assemblage (Koyama 2010).

Moreover, unlike recent educational leadership studies and the many empirically developed leadership approaches or 'theories' (e.g. instructional leadership; transformative leadership) in which curriculum is often an object of leadership influence on organizational or social interactions in schools, curriculum scholars, including those who emphasize cultural studies or critical education studies, are less interested in developing frameworks or approaches emerging from empirical realities of work in various educational systems. Moreover, in curriculum theorizing as cultural critique, we do not see explicit connections with educational ontologies and epistemologies.

In some connection to leadership early on, a few educational leadership scholars explained leadership as innate or internal to leaders and, thus, distinct from organizations. Here leadership is a function of a particular set of personal traits or characteristics, such as dependability, assertiveness, and adaptability (e.g. Stogdill 1948). Trait theories have made a resurgence in the wake of the need for so-called heroic leaders who have internal capability to turn failing schools around; however, such approaches do not theorize the leader as a subject in formation and/or one that invites or provocates others in ways that influence others pedagogically in the midst of their own self-formation. More recently, some scholars (Crow et al. 2016) have examined leadership identity, considering how leaders construct their identities as leaders in relation to how they see and are seen by others. While trait theories and more recent leadership identity scholarship could relate to the ontological dimensions of subjectivity in curriculum theorizing and Bildung, these literature bases never crossed, perhaps due to the differences in approaches to theory and theorizing describe here.

Earlier dialogues with regards to curriculum theory tradition (CT) and the European Didaktik tradition (e.g. Karseth et al. 1997; Gundem and Hopmann 1998; Hopmann et al. 2000) illustrated an implicit consideration of curriculum work as leadership, particularly in relation to issues of planning and forms of authority for content selection. In both classic American and European curriculum theory, answers to curriculum-work were connected to the idea of building systems of public schools with an authoritative agency directing teachers' curriculum work (i.e. implementation) with a written curriculum document (i.e. the syllabus) containing statements of aims, prescribed content (e.g. textbooks) and expected methods (Westbury 2000). The central construct is the school system as an agency for the institutionalized and intentional teaching of a 'content', seen in terms of selection from a subject matter. In terms of Schwab's (1978) curriculum theory triangle, transmission of knowledge occurs through an interaction of the system, student, and subject matter, all of which are contextualized in terms of culture and society. In Germany this approach was developed by Paul Heimann and was carried on in the Nordic countries as theory of school Didaktik (Uljens 1997b).

Educational leadership as system based governance was, however, more evident in Swedish curriculum theory research by Dahllöf (1967) and Lundgren (1972). Curriculum theory was here not understood as theory or principles of teaching 
practice but rather as a framework for understanding how the school system was governed and "how knowledge transmitted in an educational context is selected, valued and organised and how such processes can be understood" (Linné 2015). This research developed later into studying curriculum codes inspired by Basil Bernstein.

Ultimately, in Westbury's analysis, the American curriculum tradition and Didaktik differ substantially according to their focus in the core of teaching, the role of the teacher, and relationships between the individual (subject) and society. Specifically, for the American curriculum, the core (normative) foci of thinking centered, first on calibrating 'programs' to the 'needs' of different students and contexts, and second, on system effectiveness for achieving an appropriate and common learning. Due to the central position of the contents in Didaktik this naturally requires decisions concerning what contents should be chosen. In this process the question of the aims of education cannot be avoided. Therefore, the aims of education are also internally related to the content and methods. The classic didactic triangle focusing the aims, methods and content, describes this unity (Diedrich 1988; von Oettingen 2016).

Despite variations within and between European Didaktik and research on curriculum neither typically do not raise questions of educational leadership. Although the Didaktik tradition views the teaching-studying-learning process in a systems perspective acknowledging and embracing policy, governance and culture, the principal is an absent character. Curriculum theorists and scholars may consider and/or critique the role of leadership in social reproduction; however, they do not explicitly theorize leadership work with regards to curriculum and instruction or the social interactions around these in schools as societal institutions. As we see it, curriculum scholars propose strong intellectual arguments and analytical tools, but their views typically and still offer a normative view, promoting a particular set of values and ideals (Uljens 1997a, 2013; Ylimaki et al. 2016). Moreover, in large part, these strong intellectual arguments and debates have not reached educational leadership discourses, research traditions, and paradigms. That is, many curriculum debates establish the need and open the door for leadership and institutional/organizational analyses, but leadership has not been an area of focus in this literature. Most often, across this recent curriculum literature, leadership is only implicit in topics, such as "planning for new international subjects and curriculum homogenization" (Gough 2001), "accountability-based authority" (Palamidessi and Feldman 2003), and "requirements to mediate tensions between intellectual curriculum work and instrumental curriculum policies" (Green 2001).

For the purposes of our project, we begin with a classical approach and define curriculum practice as the process of formulating aims and selecting contents and reflecting methods, including pedagogical experiences through which content is enacted. Here we recognize an interplay among policies, societal trends/aims, methods, social interactions of leadership-teaching-studying-learning within and between levels, however, curriculum, Didaktik, leadership scholars, and political scientists/policy scholars have yet to make these connections explicit. A critical element is the dialogue between administration and politics/policy. Yet, identifying an 
object of research is not sufficient if the interest is to develop a conceptual language, a theory, through which these practices can be handled. In our view, we need a language to study how curriculum is constructed through mechanisms through initiation, implementation and institutionalization (Hopmann 2003; Lundgren 1972) and how teaching and leadership as activities may be treated coherently. We therefore argue that these processes are dialogical and discursively constructed in varying local contexts. And we argue that we must start with a non-hierarchical perspective. Our intention is to catch the process of curriculum; in the construction and implementation process, there is educational leadership at multiple levels from classrooms to transnational levels. In this sense, curriculum making is educational leadership (Uljens 2014; Uljens and Ylimaki 2015).

\section{Educational Leadership: Theoretical Roots and Empiricism}

In this section, we begin with a brief contextual discussion of the history of educational leadership research in the USA and Europe. We then analyze roots of educational leadership research in organizational theory, critical theories, and, in a few examples, hermeneutics. Here we distinguish between theory and theorizing (assumptions about ontology, epistemology, axiology and relations between individuals and society) as it has been utilized in educational leadership and the disciplines that inform these theoretical roots. This section is followed by a further examination of empirically developed leadership models or approaches that have dominated the educational leadership field with a focus on schools and districts within nation states since the 1970s. We conclude with a review of a growing number of studies that draw on institutional theories to posit leadership as a multi-level phenomenon, shifting the focus beyond schools and districts toward the national and transnational level.

\section{National Contexts for Educational Leadership Research in the USA and Europe}

Empirical leadership research has been predominantly carried out in a NorthAmerican context with its longer history of a stronger accountability orientation, decentralized governance systems, and the need for management of differentiated curriculum expectations. In European research, educational leadership studies (in the way they have been carried out in the US) have been far less prominent; however, scholarly interest has expanded partly along with the ongoing shift towards neoliberal accountability policies, emphasizing new ways of efficacy, excellence, competition and productivity but also due to new transnational evaluation and 
governance systems (Pedersen 2011; Moos 2013; Nordin and Sundberg 2014; Gunter et al. 2016).

In the North American context, educational leadership as a distinct field of research has a long history, from early studies reflecting organizational systems theories, scientific management perspectives on efficiency and productivity, and transactional leadership approaches from the twentieth century to more recent empirically developed models, such as instructional leadership that emerged from the effective schools research (e.g. Edmonds 1979; Hallinger and Murphy 1985), transformational leadership approaches developed in the wake of devolution policies and related site-based management mandates (Leithwood 1994), and transformative or social justice models developed as a reaction to classical systems theories and scientific management approaches as well as the needs of an increasingly diverse student population (Foster 1986; Shields 2010). Most recently, educational leadership scholars have also applied a multi-level perspective on schools as institutions, new (neoliberal) approaches to efficient and effective governance, critiques thereof, and alternative approaches oriented toward social justice.

All of these evolving approaches within the North American leadership tradition are also situated culturally, historically, and politically. For instance, the Coleman Report (1966) posited that student socioeconomic status made a larger contribution to student success that school practices, inspiring a host of studies on US effective "outlier" schools that were successful in educating all students regardless of socioeconomic backgrounds (e.g. Edmonds 1979). Such effective schools studies were also prevalent in the UK in the later 1980s and 1990s (Harris 1992). Similarly, the publication of A Nation at Risk (1983, p. 15) during Ronald Reagan's term in the U.S., accentuated a national perception that American schools were failing as well as a wave of local, state, and federal school reforms. A Nation at Risk foreshadowed a growing shift toward neoliberalism in the U.S. and a reformulation of the individual as responsible for his/her own life as well as societal progress. In that report, we clearly see the American ideology around education as a vehicle for equality of opportunity, individualism, and a collective effort toward an improved democratic society. The report saw that all "regardless of class or economic status are entitled to a fair chance and to the tools for developing their individual power of mind and spirit to the utmost. This promise means that all children by virtue of their own efforts, competently guided, can hope to attains the mature and informed judgement needed to secure gainful employment and to manage their own lives" (National Commission on Excellence in Education 1983, p. 15). In other words, the responsibility for students learning was moved towards the schools. This policy shift was echoing the responses to the earlier Coleman (1966) report that demonstrated that students sociocultural background was a strong predictor for success. However, in comparison, the same observation regarding everybody's right to access to a fair chance, "a school for all", was guiding the social-democratic initiatives in Europe in the 1960s. As we see it, this policy resulted in abandoning a differentiated system with parallel schools, and in the introduction of a comprehensive school equal for all regardless of region, language, religion social class or the like. In this context the 
conclusion was that the state took the responsibility developing schools with an all encompassing curriculum, accepting negative discrimination, i.e. that amount of support was increased to those in need (Blossing et al. 2014).

Effective schools and leadership research accepting local accountability has thus been strongly promoted by U.S. policy initiatives over the past five decades (Coleman Report, A nation at Risk, No Child Left Behind, Race to the Top). We also see the emergence of discourses around improving professional action on all levels through externalized evaluation and accountability ideology. This policy approach has become global (Sahlberg 2015). National reports in the U.K. (e.g. TIMMS) and policies signaled shifts in educational work toward a neoliberal agenda in other countries as noted in Leadership for Learning with members including England and Australia among others (MacBeath 2012).

In the European tradition, principals were to a larger extent civil servants taking care of the administration and management of schools but related to an idea of the school as a societal institution directed by a nation state curriculum. In Europe, with its tradition originating in the idea of education as a public good rather than a private good, schools have been less independent. Thus, the role of the principal as the single pedagogical leader for the school has been less prominent. Rather, we see a growing trend toward shared or collaborative approaches whereby leadership becomes a capacity for school improvement. Regardless of whether instructional/ pedagogical leadership is a single or collective construct, in much of the leadership research, curriculum is an object of leadership work, one that is under theorized.

Despite the variation between European countries in how leadership and governance is practiced and conceptualized, the recent change of the European policies moving from a social-democratic welfare state model towards a more social-liberal state model changed the nature of school governance and leadership. The movement towards performative accountability and educational managerialization consist partly in hopes expressed concerning the role education and innovation could play in post-industrial knowledge economies operating on increasingly globalized markets (Uljens et al. 2013; Gunter et al. 2016). Also, the past 25 years, after the collapse of Eastern Europe and the Berlin wall in 1989, the neo-liberal agenda emphasizing education has increasingly been received as a private rather than public good. New social technologies have become essential for new forms of public governance. These technologies in combination with neo-liberal policies transform complex and contextualized information to outcome indicators. At the heart of the new public governance is the idea of customer choice will boost quality of educational services in the 'competition state' (Cerny 1997; Genschel and Seelkopf 2015; Saari 2012). And while there is growing concern and resistance to the neoliberal agenda in many countries, the governance trends and leadership are evident on a global scale. With this historical and cultural framing in mind, we further consider approaches to educational leadership theories and theorizing that are important for understandings distinctions among educational leadership, curriculum, and didaktik fields. 


\section{Theory Versus Theorizing: Disconnected Roots of Leadership Studies}

Curriculum theorizing and Didaktik (described in the last section) and leadership theories have influenced each other over time but there are clear conceptual distinctions. More specifically, curriculum/Didaktik scholars frequently take a different approach to theorizing than we see in much of the educational leadership field, and these distinctions in theorizing traditions explain some of the differences between the educational leadership and curriculum fields as well as the difficulties in merging them.

Prior to the 1970s, there was an elaborated discourse about organizational theory that informed empirical educational leadership research; however our impression is that the connection has been weakened over the past three decades. Thus, our intention in the following is to return but expand on the theoretical base in order to retheorize educational leadership (Uljens and Ylimaki 2015; Ylimaki and Uljens 2017).

Social theories, including organizational theories and critical theories so prevalent in framing educational leadership studies, are based upon a philosophy of science and a theory of society, considering ontology, epistemology, and axiology, all of which are related to methodological assumptions as well as assumptions about human nature (relationships between the individual and his/her environment). In other words, social scientists approach their subject (e.g. organizations) via explicit or implicit assumptions about the nature of the social world and the way in which it may be investigated. To begin, assumptions of an ontological nature concern the very essence of the reality in general, such as whether the 'reality' to be explained is external to the individual, imposing itself on individual consciousness, or the product of individual consciousness (Burrell and Morgan 2003). Further, social theories are based upon a second set of assumptions of an epistemological nature, about how one might begin to understand the world and communicate this knowledge to others. As examples, we can distinguish between rational organizational theories as those theories that conceptualize organizations as material realities that can be observed objectively from the outside through a singular view of Truth and those that consider organizations as socially constructed based upon a vision of reality which holds no greater truth than alternate views. Here so-called natural organizational theorists seek to understand different individual realities in order to make generalized statements and provide a link between social experience and reality. In a third category, many organizational theories conceive of organizations as open systems that combine both rational and natural system assumptions about reality. Closely related, an axiological dimension of organizational theories whereby the 'organization' identifies its internal valuing systems and the ways in which values and ethics influence its decisions and actions.

The emphasis on how we view and come to know organizational reality and values is, of course, very relevant for leadership in schools and districts/municipalities as educational organizations/societal institutions. The poststructuralists remind 
us, however, that a dichotomy or even a continuum of what is true and what is false presumes a certain epistemological stance and indeed challenges the very notion of a paradigm. We further argue that organizational ontology, values, and assumptions about how we come to know these cannot be conflated with educational ontology, epistemology and axiology as in modern education theory and related assumptions about the Other, freedom, and the role of education. We will return to this point in more broadly in our presentation of non-affirmative education theory.

Closely related to all of these assumptions about human nature are the relationships between human beings and their environments and between schools/education and society. That is, all social theories are predicated upon a view of how humans individually and, in this case, within organizations like schools, respond to their environment (as an instrument and subordinate to society or as one with agency and superordinate to society). In one key relation within organizations, many theorists make references to 'authority' and 'management' with early descriptions of authority often informed by scientific management (Fayol 1949; Taylor 1947) practices aimed at productivity and formal hierarchical organizations of modern society in bureaucracy (Weber 1978). The word 'authority' is important here as it gave rise to early conceptions of transactional leadership in classical educational administration literature and management theory grounded in functionalist organizational theory and positivistic research approaches (Bass and Avolio 1990; Forsyth and Hoy 1978; Leithwood 1994) that have been applied to principals organization and management of teachers learning and effective classroom practices. Here authority can be given and taken away; managers and followers can make transactions or deals to accomplish organizational goals, and manager-worker relationships are connected to transactions. Here an organizational theory-based directs leadership focus to system elements (e.g. staff learning in relation to other system elements) rather than education as defined by education theory (Benner 1991). Further, we do not see the use of the term transforming leadership (Burns 1978) or transformational leadership; rather Leithwood (1994) and others (Avolio et al. 1999) developed these models from a combination of organizational theories and empirical generalizations or models. We will further describe these empirical generalizations as we explore the empirical turn in the educational leadership field in the next section. Although not always explicitly articulated in educational leadership studies, assumptions about knowledge, reality, and values have important consequences for the ways in which researchers attempt to study and obtain knowledge about the social world, including leaders and education (with curriculum/Didaktik as key aspects of it) in schools.

We also recognize that functionalist organizational theory, related systems theory, positivism, and their inherent assumptions are also grounded in a long history of functionalist sociology, and we do not go into full detail on the roots here. Briefly, elements of functionalist sociology can be traced to the Greeks and in many analyses to Comte, Spencer, Durkheim, Pareto, Simmel, Weber, and Mead. Because most references to organizational theory informing educational studies of schools/districts, and leadership therein date back to various systems theories (Mead 1967; Merton 1968; Follett 1918; Simon 1976; Weick 1976), we use examples from these latter theories frequently cited in leadership literature to illustrate our arguments. 
According to Merton (1968), organizational theory approximates interrelationships between the external environment and the organization; it is firmly rooted in the sociology of regulation and approaches ontology in terms of assumptions about reality of the system and its relations to organizations (educational and otherwise). Ontologically, then, from Merton's (1968) perspective, the organization exists as an observable reality with concrete boundaries within the larger societal/cultural/political environment, which corresponds to a version of representational epistemology. The environment influences organizational outcomes by imposing constraints and demanding adaptation at the price of survival, all of which affect the organizational behaviors, values and ethics, and the assumptions under which social scientists understand and communicate organizational behaviors.

In a related strand of organizational theory, drawing on Simmel and Mead, Follett (1918) theorized organizations in relation to understanding how social groups organize as interpreted by the social actors who are actually engaged in the experience; that is in terms of interpretation as the mode by which we live and interact with others in social organizations. Importantly, she acknowledges different individual uses of power operating within social interactions, gesturing closer toward an ontological dimensions of individual human relations. Follett's (1918) theorizing is important as she opens the door for the human relations approach and later scholarship. Here we also see some influence of movements such as phenomenology and hermeneutics; however, in the wake of Follett's (1918) theorizing, there is largely a white spot with regards to these perspectives in educational leadership studies. Further, we also argue that Follett does not consider ontology in terms of individuals' assumptions about the Other's freedom and intersubjective relations as educational problems. In the 1940s, other leadership scholars explained leadership work beyond organizational and societal functions; leadership is innate or internal to leaders. Here leadership is a function of a particular set of personal traits or characteristics, such as dependability, assertiveness, adaptability (e.g. Stogdill 1948), an approach that has regained popularity in recent studies of heroic leadership in turnaround schools (Drysdale et al. 2014).

Merton and Simmel among others also make distinctions among macro, disciplinary theory of societies (and organizations within them) and models of organizations developed from empiricism, even when these empirical models are framed by macro, disciplinary theory. Empirically developed forms or models are later subject to further empirical testing, but such testing does not make an empirical model a theory nor, according to Weick (1976), does such testing equate with the process of developing theory (i.e. theorizing). Here Weick (1976) echoes Merton and Simmel in arguing that theorizing is, of course, important but the ultimate goal in organizational theory is to produce a theory.

Critical social theorists, whose work heavily influenced contemporary educational leadership studies of social justice and culturally responsive leadership practices, have similar goals for theorizing (to produce a theory) but here the aim is to change society. Critical intellectual traditions and perspectives traced back to the tenets of German idealism and complex ontological views of the world as a product of individual consciousness or radical humanism as well as an objectification of the 
social world or radical structuralism (two views representing epistemological breaks of Marx).

More specifically, critical theorists' epistemological beliefs are largely based upon critique; the best way to know something is through criticizing it. Critical social theorists, thus, share a sociocultural transformation perspective on relations between the individual, systems (e.g. schools) and the environment with differences in ontological and epistemological positions. Critical theories, albeit through different epistemological perspectives, seek to explain social (dis)order and social change, differing largely in terms of whether the world is an objective reality (radical structuralism) or a subjective, constructed reality (radical humanism). Further, the axiology of critical theory stresses the importance of being upfront with values; values should guide research and theorists should strive to change the social construction that is the subject of their critique. From what has been referred to paradigmatically as radical humanism (Burrell and Morgan 2003), objectifications encountered in the social world are humanly created, pointing the way toward an emancipatory philosophy which stresses how individuals, through self-consciousness, could create and thus change the society in which he/she lives. In essence, the work of theorists located within the radical humanist paradigm (as it relates to education including curriculum/Didaktik and leadership), there is an aim toward setting human consciousness free and, thus, facilitating the growth and development of human potentialities.

In later works, beginning with The German Ideology, Marx (1946) moved away from the idealist perspective to one rooted in a more realist interpretation of the nature of the social world in what some paradigmatically refer to as the epistemological break toward radical structuralism (Althusser 1970/2006). Radical structuralism holds that modern social structures (and conflicts between them) exist in an external reality and can be investigated objectively. In other words, clear, observable superstructures legitimize power and domination such that radical social change can only be achieved through conflict (defined as crisis and revolution), placing much more emphasis on deep economic and political structures in their theories. Radical structuralism, then, is a view which focuses upon the essentially conflictual nature of social interactions and the fundamental process of social change this generates. It is a sociology of radical change, but in contrast to radical humanism, radical structuralism tends to place relatively little direct emphasis on 'man' as an individual human being. Importantly for some educational leadership scholars, in the context of radical structuralism, including the so-called radical Weberians (e.g. Rex, Dahrendorf), we see a focus on bureaucracy, power, conflict, and authority as points of concentration for theoretical analysis as a means of understanding important aspects of social life. Much of the most recent leadership literature, however, reflects empirically-developed theories more than theorizing associated with social theories that explain relations between organizations and society or the nature of societal change. 


\section{Social Reproduction and Social Transformation}

In the next two sub-sections, we further consider assumptions about relationships between the individual and his/her environment that have dominated macro social theories over time, including those that have informed organizational theories and critical theories that are often used to frame empirical leadership research: (a) social reproduction - schools should operate within society to transmit uniform knowledge and values to future generations who will inherit a largely unchanged society or (b) social transformation - schools should operate in a distinct role apart from society to prepare individuals to transform existing society and social values.

Social reproduction hinges on a certain set of shared fundamental ideals that are determined 'from above' in the form of ultimate values and also 'from below' in the form of more or less institutionalized objectives that individuals internalize as goals for their lives (Parsons 1963). Social reproduction perspectives often embrace a classic notion of subjectivity that is normatively tied to the idea of individual self-determination.

Bourdieu (2011) explains how reproduction occurs when individuals internalize the social world through habitus or a pattern of perceptions formed through mental structures, such as institutionalized values and objectives (Bourdieu 2011). More specifically, habitus is a type of socialization or "social conditioning" that predicates our class-based tastes, classifications, values, and choices. As such, "the habitus implies normative integration and a 'sense of one's place' but also a 'sense of the other's place, providing a "world of common sense, a social world which seems self-evident" (p. 132). Bourdieu (2011) further argues that education itself is an agent of cultural reproduction, which occurs primarily through the hidden curriculum or socialization; students acquire appropriate attitudes and values needed to further succeed within the confines of education. Thus education provides functional prerequisites whereby education provides individuals with necessary values and attitudes for future work. Regardless of the trade an individual participates, they will all need a similar set of social skills for their everyday interactions. In other words, education is an ideological state apparatus (Bowles and Gintis 1976), sorting individuals and assigning them the skills necessary to fulfill their destined occupation. Those students with high levels of accumulated social and cultural capital from parents or other sources are more easily able to excel within the system of education.

Social transformation perspectives date back to Rousseau (1762), who argued that education should not replicate problematic aspects of a less than ideal society; rather, education should promote a new ideal that does not yet exist. In other words, education would work toward an idealized more socially just future by educating a new generation of citizens entering society with social justice values. Social transformation theories critique the status quo and seek to explain, either through "subjective" (e.g., Lukacs; Frankfurt School) or "objective" (e.g., Althusser) ontologies, how radical change occurs in society. 
The above distinction (social reproduction versus social transformation) also resonates with the classical Aristotelian division between two modes of human action, techné and praxis in our time developed in Habermas' early works. The many versions of functional-instrumental approaches in educational leadership studies typically ask for efficiency - how should the work be rationally organized to reach intended aims? Overemphasizing rationality leads to a hiding of normative issues. Leadership is assumed to be adaptive to existing needs and ideals while ethics and politics dissolves. Today's educational governance initiatives operating over and across different levels operate along a logics of rational choice of means that work, both from the systems, organizational, and actor perspective. Yet few (empirical) leadership studies refer directly to these roots of theory and underlying assumptions (reproduction or transformation). regarding relations between individuals and societies.

\section{The Empirical Turn}

In the 1970s, the educational leadership field took an empirical turn in the North American context, resulting in a preponderance of empirically-developed models or approaches (e.g. instructional leadership, transformative leadership). Much of the empirical work was conducted at the nation state level; however, a growing number of international or transnational projects are evident. Across this literature, we argue that empirical leadership research is a bit free floating from theoretical roots. In our project, we seek to (re)theorize the educational leadership field with research closer to the roots.

In the 1970s, empirical approaches were primarily conducted from technologicalinstrumental or reformational perspective. Often a rationalist, functionalist and systems oriented thinking guided this research. Also the degree to which this research is empirically descriptive or guided by more or less explicit theoretical assumptions varies. Functionalist-empiricist research is often quantitative in nature, but equally often qualitative and interpretative. More recent empirical studies take a critical, transformation or social justice oriented position framed by various critical theories and earlier seminal research studies. Critical, transformation oriented research is often qualitative in nature.

\section{Systems-Theoretical and Functionalist Research into Educational Leadership}

Classical leadership literature has been firmly grounded in structural functionalism as it has informed classical organizational systems theories: (1) the rational systems theories and related scientific management principles of efficiency and effectiveness 
(e.g. Fayol 1949; Taylor 1911); (2) the human relations or natural systems theories (McGregor 1960) and (3) the open systems theories (e.g. Perrow 1970; Callahan 1962) merging both.

Such functionalist and reproduction oriented approaches may also include a larger perspective, looking at relations between organizations and broader social systems as is done in organizational theory (e.g. Fayol 1949; Simon 1976) interactions between levels of governance as well as interactions between different stakeholders as is done in institutionalist research. In using the term 'structural functionalism', we draw on Parsons and others who explain structural functionalism with regards to organizations in that organizational activities, including curriculum management and instructional supervision, are defined by social regulation and order at the micro level. In other words, behaviors within organizations (rational, natural, or open systems) are linked to the controlled functioning of social behavior and interactions within organizations. To promote labor efficiency and control behavior, rational systems utilize hierarchical structures that create clear divisions of labor and clear managerial spans of control (Taylor 1911); labor is expected to have specialized expertise in performing a function within the organization where all functions are broken down into their most basic components for effective and efficient completion (Gulick 1937). By contrast, the natural systems model views organizations as organisms emphasizing the perspectives of individuals as members of social groups with valuable input to the organization; relationships are valued above all other aspects of the organization (Metcalf 1942; Follett et al. 1942; Hoy and Miskel 2005). Systems perspectives have evolved over time in relation to historical, cultural and policy trends of particular times.

We spend a bit more time in a discussion of systems theories, including particularly open systems theory that represents a merger of scientific management/rational systems theory, bureaucratic theory, and natural systems theory. Taylor's scientific management theory proved successful in industrialized companies at the turn of the century but has not been utilized successfully in many modern companies as its philosophy of production over people has left a legacy of declining quality and work satisfaction as well as a loss of organizational pride. Weber (1947) expanded on Taylor's theories with a emphasis on the need to diverse ambiguity with clear lines of authority and a hierarchical structure of power in bureaucracies. Closely related, rational administrative theory (Fayol 1949) emphasized a universal set of management principles for all organizations. Such classical theories were rigid and mechanistic, shortcomings that quickly became apparent and gave rise to natural systems theory with its emphasis on relationships and human needs/motivations (Follett 1949). Natural systems theories were supported by several experiments of the time, including the now famous Hawthorne Studies in the Western Electric Plant (Mayo 1933) whereby the act of paying attention to employees in a nonthreatening way was more effective for productivity than manipulating the work environment. Simon (1991) made an important contribution to the study of organizations when he proposed a model of "limited rationality" to explain the Hawthorne experiments, arguing that workers could respond unpredictably to managerial attention and that external influences have a major effect on internal organizational 
behavior. Simon's insight was important to later articulations of open systems theory insisting on the importance of the environment and its impact on the organization (e.g. Perrow, Weick). Early open systems theories were subject to critique, including the lack of explicit attention to social interactions; however, these gaps were addressed by Rogers (2010) with a network analysis approach, Habermas (1984) with a communicative approach, and by Weick (1995) with a sensemaking approach that reminds of hermeneutics and phenomenology. We find Habermas (1984) and Weick (1995) particularly relevant as they argued that consensual meaning is created through iterative and adaptive communication (e.g. rational discourse, double interacts), referring to social norms and values. Across these open systems theories, Hoy and Miskel (2005) identified inputs, outputs, feedback and transformations of organizations in relation to schools as open social systems, giving more explicit attention to the importance of internal culture to social interactions, but their application gave little attention to educational activity.

For our purposes here, regardless of the particular approach (e.g. rational, natural, open), organizational theorists consider curriculum as an object of management; administrators must manage curriculum work in state, district and school systems, bringing disparate efforts toward a clear goal or outcome (Fayol 1949; Callahan 1962). While not explicit, organizational theorists (e.g. Callahan, Merton, Senge, Simon) understand education as located within existing society, socializing students into the values and norms of existing society, and thus, helping to maintain social regulation. For our purposes in making an argument for education theory, it is also important to note that organizational theorists (e.g. Fayol, Merton, Simon, Weick) and those drawing on organizational theory to study educational leadership (e.g. Bass and Avolio 1990; Hallinger and Murphy 1985; Leithwood 1994) have written in varying ways about the distinctions between "theory" and "theorizing". In the early North American educational leadership field as it developed in the 1940s-1960s, organizational theorists dominated this debate. According to Merton (1968), organizational theory approximates an explanation about interrelationships of a societal condition (i.e. organizations). He goes on to make a distinction between macro, disciplinary theory of societies and organizations and empirically developed forms or approaches to organizations, often distinguished by a particular aim or style. Empirically developed forms or approaches are later subject to further empirical testing, but even numerous empirical testing does not make for theorizing nor, according to Weick (1976), is the process of developing theory. And while rational (closed) organizational theory perspectives on educational leadership studies have been enhanced with open systems theory and, more recently, with institutional theory (Dimaggio and Powell 1991; Meyer and Rowan 1977, 2006) and critiqued with various critical/normative social theories (e.g. Apple 1992), the theoretical logics applied in empirical studies of educational leadership remain largely the same.

At the same time, we argue that much of the educational leadership theory development since the 1970s has been empirically-based, framed in seminal leadership studies that were explicitly grounded in structural functionalist perspectives and organizational theories. In two classical examples, Bass (1985) and then Leithwood 
(1994) drew on organizational theory, psychology, and as well as Burns' (1978) empirically developed theory of 'transforming' leaders to frame their empirical studies of school leaders' behaviors. Bass (1985) extended Burns' (1978) transforming leadership but used the term transformational, explaining the psychological mechanisms that underlie transformational leadership work in school organizations as open systems (Forsyth and Hoy 1978). Bass's (1985) aim was to measure transformational leadership in terms of influence on followers (we will come back to how influence is defined here in the next section). Bass' findings indicated that the followers of such a leader feel trust, admiration, loyalty and respect for the leader and because of the qualities, are willing to work harder than originally expected with leadership practices organized in four elements: individualized consideration, intellectual stimulation, inspirational motivation, and idealized influence. Later in the article, Bass (1985) clearly noted that the function of leaders and teachers revolved around school improvement in order to meet existing societal needs. Many others have followed Bass' example, drawing on functionalist organizational theory as well as Bass' empirical methods and tools to verify the use of transformational leadership with its four elements (e.g. Leithwood 1994).

In probably the most frequently cited example, Leithwood (1994) further studied Bass' (1985) transformational leadership elements with his own research of principals in effective schools. He later conducted a meta-analysis (with Riehl 2003) of additional effective leadership studies and a North American research project (with Seashore 2011), indicating that four leadership practices were necessary but not sufficient for effectiveness in any context: setting directions, developing people, redesigning the organization, and managing the instructional program. Leithwood and Seashore (2011) concluded, based upon a mixed methods study with a large North American sample, the effects of leadership influence on student outcomes is indirect. Teaching or instruction and related classroom practices have a direct causal effect. Further, while these and similar research studies have been widely cited, we argue that these transformational leadership approaches have become free floating from the original roots (organizational theory, political science, and psychology).

We can make similar examples from other empirically based leadership approaches or forms. A wide body of research examined principals' practices in socalled "effective" schools makes this point as these studies gave rise to instructional' leadership approaches. Effective schools were those that were successful with teaching all children regardless of SES, an important topic in the wake of the Coleman Report that concluded school-based poverty concentrations had far more impact on student achievement than school-based efforts (e.g. teaching, curriculum, culture). These effective schools studies most often considered schools as open systems with similar correlates of effectiveness, including safe and orderly environments, management of the curriculum, instructional leadership, and frequent monitoring of student progress (e.g. Edmonds 1979; Lezotte 1986; Purkey and Smith 1983). In conceptualizing effective schools as "open systems", Lezotte and others argued that the school organization always maintains effectiveness and efficiency through its formal structures, functions, and objects of these while concurrently acknowledging and serving the various aspects of the external circumstances 
(Hoy and Miskel 2005). Effective schools research led to the formulation of so-called instructional leadership approaches (e.g. Berman and McLaughlin 1976; Edmonds 1979; Hallinger and Murphy 1985; Lezotte 1979).

While recognizing the role of input from the external environment, according to Edmonds (1979) and other effective schools researchers, effective leaders influence followers' performance of various organizational tasks, including curriculum management and instructional supervision, all of which indirectly affect 'outputs'. Such leadership studies emphasize instructional leadership as the role of the principal in educational organizations (schools), including practices like supervision that affect classroom improvements, and indirectly affect student outcomes (e.g. Caldwell 1998; Edmonds 1979; Berman and McLaughlin 1976; Hallinger and Murphy 1985; Harris 1992). Across this literature, instructional leadership is an individual and often directive construct (Hallinger 2004).

In another frequently cited example specific to instructional practice, Hallinger and Murphy (1985) constructed an 'instructional' leadership model from earlier effective schools research (Edmonds 1979) and then tested that model with mixed methods on so-called outlier schools that exceeded expectations in neighborhoods with few resources. In this literature of the 1980s, it is important to note that relatively little reference was made to teachers, department heads or assistant principals as instructional leaders; there was little emphasis on instructional leadership as a distributed construct or a function to be shared. Instructional leaders were described as strong, directive leaders who had been successful in "turning their schools around" (Edmonds 1979; Hallinger and Murphy 1985); relatively few case examples of instructional leaders were conducted in schools with average or high performance. Drawing on results across this literature as well as their own empirical findings using survey methods, Hallinger and Murphy (1985) identified three dimensions of instructional leadership: (1) defining the school's mission, (2) managing the instructional program, and (3) promoting a positive school learning climate delineated into ten instructional leadership functions, including framing the school goals, supervising and evaluating instruction, coordinating curriculum, monitoring student progress, protecting instructional time, providing professional development, maintaining high visibility, providing incentives for teachers, and providing incentives for learning. While Hallinger and Murphy (1985) instructional leadership model has been widely tested and utilized worldwide since the 1980s, we argue that this model is grounded in empiricism and a language of the organization, and administrative functions therein, with little language of pedagogy, education or an educational ontology.

Another more collaborative leadership approach considers principals' instructional leadership in relation to other informal leaders and their social interactions within schools (e.g. Marks and Printy 2003; Jackson 2000; Hallinger 2004), defining instructional leadership as a shared capacity for school effectiveness improvement. Here the principal models appropriate leadership behaviors and invites teachers and others to join their efforts toward school improvement (e.g. Shephard 1996; Jackson 2000; Marks and Printy 2003; Hallinger 2004). Like earlier effective leadership studies that focused on individual principals, these scholars emphasized 
leadership roles in school changes/improvements but defined leadership more broadly (teachers as well as head teacher). Across these studies, we find quantitative methods, with regressions from findings from Hallinger's (2004) survey, mixed methods as in Marks and Printy's (2003) study of leadership in communities of practice or qualitative approaches with case studies of instructional leaders' collaborative approaches (e.g. Jackson 2000). With the growing pressures of external evaluation systems (e.g. PISA), North American and European scholars have renewed or focused more attention on instructional leadership approaches, leadership in professional learning communities, and teacher leadership (York-Barr and Duke 2004).

There is also a growing empirical literature in many countries on leadership in professional learning communities, learning organizations, or communities of practice (e.g. DuFour and Eaker 1998; Hord 2004; Silins and Mulford 2002). Although there is some variation, such approaches seek to understand how administrators, teachers, and others build capacity in schools to impact student achievement. While not explicitly connecting to natural systems approaches (Follett; MacGregor) much less Dewey's $(1916,1938)$ perspectives on growth and democracy in schools, DuFour and Eaker (1998) define a professional learning community as educators creating an environment that fosters mutual cooperation, emotional support, and personal growth as they work together to achieve what they cannot accomplish alone. Senge (1990) approach to learning organizations follows a similar conceptualization but adds an emphasis on organizational theory and adult learning in various disciplines. Across the above studies we see an empirical emphasis on knowledge constructed in professional learning communities. Lick and Murphy (2004) draw on Vygotsky and add an emphasis on staff development in collaborative teams and their use of study group plans focused on curriculum, instruction, and classroom assessment. Across this literature, argue that studies of professional learning organizations is useful as it connects leadership with curriculum and pedagogy; however, we also see much of this literature as free floating from Bildung and a theory of education.

More recently, still considering organizational elements of instructional leadership interactions but adding social capital theory, other scholars (e.g. Kelley and Halverson 2012; Klar 2012) have considered instructional leadership as a distributed construct, drawing on Spillane's (2002) research to consider how social networks affect such objects as curriculum and instruction. A distributive view of leadership recognizes that leading schools can involve multiple individuals in addition to the school principal_-"the leader-plus aspect"-and that leading a school is fundamentally concerned with social interactions around curriculum/instruction and other important objects of group leadership influence rather than about the actions of individual leaders- "the practice aspect" (Spillane and Healey 2010). According to Harris (2007), this view of distributed leadership also rests on an idea of leadership as cognition as well as an idea of leadership as mediating social networks and the capital needed to develop these. Thus, the democratic features are specifically taken into consideration, and they have also been the focus of several studies on educational leadership within the Nordic context (Moos et al. 2004; Moller 2009a). While perhaps not intentional, many of the recommendations from 
an organizational perspective (transformational, instructional, collaborative or distributed) on schools result in a technical or even instrumental approach, recommending leaders utilize a particular set of practices in order for educational organizations to develop effectively.

Essentially, research studies grounded in these organizational systems theories and more or less structural functionalist perspectives primarily focus on concrete relationships (rational, natural or open) among administrative functions, behaviors, social relationships or interactions, objects of these functions or behaviors and organizational effectiveness (e.g. Barnard 1968; Roethlisberger et al. 1943; Simon 1976). Such areas of focus are not surprising given the historical timeframe and the background of the seminal scholars (i.e. sociological perspectives on systems and later management practices associated with systems productivity).

\section{Critical, Transformative Oriented Approaches}

Educational administration scholars who conduct critical, transformative oriented empirical research draw support from Marx, Althusser, Freire, Gramsci, and Habermas as well as extant research studies devoted to explaining relationships between inequitable societal structures and education and/or the effects of various 'isms on leaders' work and the leaders themselves (e.g. feminist theories in women's leadership studies from Brunner 1998; Grogan 1996; Lumby 2008), racism from Gooden 2012; Tillman 2004). Drawing on radical humanist and radical structuralist versions of critical theory (e.g. Freire, Gramsci, Marx, Rex), Foster (1986) challenged classical educational leadership/management studies grounded in functionalist organizational theory. In Foster's (1986) argument, for instance, leadership must be critically 'educative', meaning leadership cannot only look at the conditions in which we live but it must also decide how to change them. Foster (1986) challenged the organizational ontology and values inherent in classical educational leadership literature, arguing that leaders needed to more explicitly understand the impact of macro policies and societal conditions on schools. Many leadership scholars have extended Foster's approach in various empirical studies with a transformation aim (e.g. McKenzie et al. 2008; Shields 2010; Theoharis 2009).

Although not always explicit, across this literature, leaders focus on education as a vehicle to improve the lives of all children, including the use of critical pedagogy to support development of a critical consciousness and social justice values (e.g. Brooks 2012; McKenzie et al. 2008; Shields 2014; Theoharis 2007). Scholars who focus on implementation of more revolutionary teaching methods aimed at radical social change through the creation of inclusive practices (e.g. Scheurich 1998; Shields 2014; Theoharis 2007) and critical pedagogy in schools (e.g. Boske 2014). Indeed, as Uljens and Ylimaki (2015) as well as Ylimaki and Henderson (2016) note, the educational leadership field has been recently dominated by various models and approaches to social justice leadership with a clear set of critical values and aims, such as the development of students who critique hegemonic ideologies, 
recognize market forces, work to eliminate injustices marked by various - isms (feminism, racism, classism among others). Yet as we argued earlier, teaching methods (revolutionary or otherwise) and student learning about critical perspectives are only parts of education. Closely related, some scholars devote more specific attention to the relevance of traditionally marginalized students' identities and home cultures for teaching, learning, and leadership (e.g. Capper 1993; Cooper 2009; Dillard 2000; Johnson 2006; Moller 2009a, b). We return to a discussion of culturally responsive leadership later in this chapter.

Taking a radical structuralist perspective on recent policy and related societal trends, other leadership scholars have examined the ways in which neoliberal discourses (e.g. modernizing the economy with educational competition in an open education market) and neoconservative discourses have the social life and interactions in schools (e.g. Anderson 2009; Apple 2008; Pedroni 2007; Ylimaki 2012). For example, Anderson (2009) takes a critical education perspective on schools as "sites of struggle over material and cultural resources and ideological commitments" (p. 38). Anderson (2009), thus, proposes advocacy leadership as a way for leaders to mediate between neoliberal and neoconservative ideologies and the pressures of these on what we teach and how we lead in an era of educational externalized accountability. Similarly, Ylimaki $(2011,2012)$ proposed critical curriculum leadership as a mediational approach between hegemonic social formations and progressive curriculum aims and values in schools.

Also transformative leadership forms stand in contrast to more functionalist views of transformational leadership, and transactional leadership approaches. Similarly, other scholars (e.g., Ryan 2003; Shields 2010) have indicated the importance of inclusive, transformative practices to effective educational leadership in diverse school contexts. Drawing on Freire (2000) and qualitative case study findings, Shields (2010), for instance, argued that transformative leadership begins with questions of justice and democracy, critiques inequitable practices, and offers the promise not only of greater individual achievement but of a better life lived in common with others. Distinguishing transformative leadership from transformational leadership, she argued that "transformative leadership holds the most promise and potential to meet both the academic and the social justice needs of complex, diverse, and beleaguered education systems" (p. 562). Shields also clearly acknowledged the challenges of transformative leadership work in diverse school contexts, including deficit thinking. Taking a similar approach $\mathrm{n}$ a specific 4-year examination of school leaders' perceptions of racism in diverse schools, Ryan (2003) explored the extent to which principals believed that racism existed in their schools and the ways in which they understood it. Specifically, Ryan (2003) found that many principals were reluctant to acknowledge that racism occurred in their schools. Those administrators who acknowledged the presence of racism in their schools identified situations of harassment, graffiti, and other similar forms of representation. In essence, then, the principals saw racism primarily in terms of individual actions or isolated incidents.

In such transformative or leadership for social justice models or theories, now dominant in the educational administration field, then, leaders are identified as an 
important counter hegemonic force in developing students through education, or critical pedagogy to critique and transform existing social structures and values, generally either through awakening an internal critical consciousness or recognizing the importance of conflict to radical social change. A number of scholars (e.g., Johnson 2007; McKenzie et al. 2008; Theoharis 2007) have examined leaders with a social justice orientation, identifying ideals for leaders, such as the importance of a critical perspective, self-awareness, ideological clarity, and inclusive pedagogical practices. Across this literature, scholars most often promote a future more equitable and ideal through school-based inclusive practices, attention to academic achievement, support for traditionally marginalized groups, and community activism with solutions grounded in previous empirical studies as well as various critical theories. In our analysis, we also note that transformative approaches to educational leadership or leadership for social justice so prevalent in the last three decades are increasingly grounded in previous empirically developed models and theoretical or conceptual frameworks more than the roots of critical theory.

Consider, for example, Capper et al.' (2000) study of principals' practices that influenced more inclusive democratic schooling for traditionally marginalized students. Capper drew on Foster's (1986) approach to educative leadership as well as Aronowitz and Giroux's (1985) notion of a transformative intellectual building on Gramsci's (1996) organic intellectuals. Drawing on her own empirical findings, Capper proposed an inclusive, transformative intellectual approach to leadership where leaders mediate between children's needs and structural inequities that affect schooling. Theoharis (2007) drew on Capper as well as Giroux and McLaren to frame his examination of principals' struggles and resistance practices to influence teachers, students, and parents to adopt an equity oriented agenda. Here influence is defined in critical terms as practices that develop teachers' and students' critical consciousness and agency aimed at social transformation. Other scholars (e.g. Bogotch 2002; Brooks et al. 2008) have similarly framed social justice leadership studies with a combination of previous transformative leadership models and their own empirical findings. Critical perspectives on educative influence notwithstanding, these social justice leadership approaches include principals' pedagogical influence on teachers' use of inclusive classroom practices or critical pedagogy as well as resistance strategies.

Most recently, a number of educational leadership scholars have studied leadership preparation programs with an explicit social justice mission to prepare leaders who can organize schools around inclusive principles and who can, if necessary, work through resistance to critically oriented changes, including critical pedagogy. Here scholars examine teaching methods in universities that have affected aspiring and seated principals to enact social justice ideals in their schools. In one example study with a clear expressed purpose for preparing social justice oriented leaders, Boske (2014) promoted the use of Freire's problem-posing cases and other related experiences to help leadership students develop a critical consciousness regarding various social injustices. Boske (2014) defined her course aim as social justice, identified relevant content from the literature on social justice leadership, and described educational experiences used to help students develop a critical 
consciousness about social injustice of all kinds. In other words, social justice is the educational purpose that the leadership program seeks to attain and educational experiences feature problem-posing cases and dialogue around social inequities. She used qualitative methods to assess the extent to which students' developed a critical consciousness and indicated intentions to seek social change. Here we can see Boske gesturing toward curriculum understandings that recognize the subject (leadership) formation process occurring through content and experiences. That is, Boske draws on Freire's work on critical consciousness development that students must read literature like Freire that help them become social justice leaders. She does not, however, specify an educational ontology in the importance of leaders' formation, being and becoming, which Dewey (2008) refers to as the heart of democratic living or that which Pinar (2004) maintains as essential to curriculum theorizing. Others have documented similar leadership preparation processes aimed at developing social justice oriented leaders who seek equity and excellence in schools (e.g. Brunner et al. 2006; Miller and Martin 2015). Recent syntheses of social justice leadership literature (e.g. Bogotch 2002; McKenzie et al. 2008; Ryan 2006), teaching practices focus on future opportunities for student success. It is never enough to merely transmit existing knowledge to students (Bogotch et al. in press). Rather, pedagogical practices must focus on creating new knowledge, new spaces for pedagogical practice, fighting and overcoming resistance and barriers (Ryan 2006; Theoharis 2007). Here social justice is an object to be realized after educators teach students how to attain social transformation by changing the material conditions of students, parents, colleagues, and community members (Bogotch et al. in press).

Regardless of underlying views of reality, epistemologies, and specific social justice applications, when applied to education and leadership thereof, we also argue that critical theory perspectives share a perspective that education is superordinate to society. In other words, education should promote a new generation of student or citizens (or educational leaders) who enter society (educational organizations/institutions) with critical theory informed aims and social justice values. Applied is a deliberate word choice here as our review of this literature indicated use of various critical theories combined with previous empirical studies that used the same theories. Thus, while critical leadership approaches contribute many understandings about how leaders can support radical social change and promote culturally diverse student identities in education/curriculum work, in our view, critically oriented scholars often take a position on a pre-determined vision of an ideal future society, one that is also sometimes a bit free floating from a critical theory base. Further, critical scholarship in educational leadership is often normative, promoting ideals, norms, and values that are decided upon in advance but is not explicitly theorizing in the ways we see in curriculum studies (critical education specifically) or education theory. Here we do not mean to minimize the importance of critical perspectives and an emphasis on identity. Rather we argue that the strong normative position taking on a future ideal solution does not support education in a democratic society. This is why a non-affirmative education theory perspective is so important. We see some scholars gesture toward a 
non-affirmative perspective in interpretive or hermeneutic approaches; however, these scholars do not focus on education theory as framed by Benner (1991) and precursors.

\section{Interpretive or Hermeneutic Approaches}

A third interpretative or hermeneutic approach may also be identified. We are then talking about research that is culturally and historically sensitive and oriented towards understanding the complexities involved in educational leadership practices. While functionalist-empiricist approaches are often guided by an instrumental knowledge interest, i.e. improving practices and collegial cooperation ultimately enhancing student learning, by utilizing research generating testable general explanations, this does not satisfy interpretative leadership research. Here interest is rather on studies accepting a multitude of dimensions operating in parallel.

Yet, interpretive leadership research may be equally strategic and instrumental, for example, by aiming at finding out the most efficient or successful practices. Such interpretative or hermeneutic, and sometimes phenomenological, approaches represent typically either an ideologically critical, a more neutral humanistic, or an ideologically unreflected position. At the same time, we see few leadership studies explicitly grounded in hermeneutics from philosophy. Rather, drawing on epistemological underpinnings of interpretivism from the social sciences, numerous educational leadership studies seek to understand leadership actions and their effects from the perspective of those actively engaged in that endeavor. Here methods are most often qualitative in nature.

In this strand, scholars often consider organizations, norms, and values as socially constructed and accessible through the subjective perceptions and experiences of people (Greenfield 1987). In other words, an interpretivist approach to organizations focuses on social life, interactions, and individually constructed meanings of these interactions as perceived by individuals, rather than on so-called objective reality (Salovaara 2011). While structural functionalist, classical organizational theorists are concerned mainly with how organizations operate, interpretivists are concerned mainly with how people experience them. In this paradigm, interpretivist perspectives (e.g. Fullan 2007) include suggestions that school group members ascribe different (even contradictory) meanings to educational work. School group members also assume particular roles in the development and support of a positive (or toxic) organizational culture, including those who are keepers of rituals and histories (Peterson and Deal 1998).

More specifically, in a number of empirical studies conducted from interpretivism or a social science version of hermeneutics, we see an increased emphasis on teacher interpretations or individual constructions of educational work (e.g. Peterson and Deal 1998; Fullan 2007). From a methodological point of view, such research studies proceed hermeneutically by depicted individual construction as accurately as possible in order to compare and contrast it dialectically with the aim of reaching 
and generating consensus with a saturation point of data. As examples, a number of empirical studies in schools (e.g. Day 2005; Ylimaki and Jacobson 2013) or districts (e.g. Brunner 1998) seek to understand leadership, from the perspective of teachers, students and parents as well as the formal leader. These empirical studies grounded in interpretivism focus more explicitly on study participants' interpretations of the phenomenon (e.g. leadership contributions to effective schools and districts with effectiveness defined in varying ways by individuals). Similarly, in some instances, scholars examine various interpretations of a particular leadership practice, such as curriculum work, with curriculum defined in varying ways by those involved in the process, from the content of instructional work in classrooms to the political and social intentions translated into content in K-12 schools (e.g. Norberg and Johansson 2010; Young et al. 2014; Ylimaki 2012). Here, on an epistemological level, these interpretivist studies reflect a contention that the inquirer takes on a subject-subject position whereas facts are values are inextricably linked. Hence, the knower and the known are inseparable; research is value-bound. Across these studies, the intention is to understand curriculum work, and in some studies, the macro influences on the work, as interpreted by those involved in that endeavor. The intention is not, however, to critique the broader macro influences (e.g. neoliberal policies) on the work. Ontologically speaking, there are multiple realities constructed by actors of leadership practice under study and by the researchers themselves. Thus, Guba and Lincoln (1994) argue that interpretive research is grounded on a relativist ontology which rejects the existence of any possible correct reality. And while we can identify a number of leadership studies categorized in an interpretive paradigm, there is largely a white spot in educational leadership studies with regards to an explicit use of hermeneutics from philosophy as described in this chapter. There are some studies that gesture toward hermeneutics grounded in the humanities to further consider multiple meanings of learning through participation. Taylor (1994) also argues that the more interpretive or hermeneutic version of psychology is best suited to the development of a theory of learning which explains how we make sense of, and act on, our worlds.

Across this educational leadership literature, we argue that functionalist research studies grounded in organizational systems theories, research studies grounded in critical theories and transformative perspectives, and various studies grounded in interpretive approaches give explicit attention to the micro level of schools and districts/municipalities shaped by aims and values of nation states as well as what we term globopolitanism. DiMaggio and Powell (1983) and Meyer (1997) have proposed new institutional theories, inspiring studies of leadership as a multi-level phenomenon with more explicit attention to relations between structure and agency beyond school and district levels. Going further, Schmidt posits an institution as a discourse in discursive institutionalism, providing an analytical framework to consider movements of discourses within and between levels. We will return to these points in our theoretical framing, but first we briefly examine some leadership studies that have moved toward considering leadership as a multi-level or transnational phenomenon. 


\section{Leadership as a Multi-level and Transnational Phenomenon}

Similar to curriculum theory, also leadership research has mostly been carried out within the frames of the nation-state. Today leadership is increasingly studied as distributed across levels and interest groups. Often versions of old, new, and neo institutionalism has informed this research, but also new approaches have developed. As education policies including comparative evaluation programmes today are increasingly driven by transnational organisations as OECD through PISA it is obvious that studies of educational leadership and governance expand beyond the nation-state level. However, these questions are typically rather taken care of by policy researchers. Yet, a growing emphasis on transnational organizations requires a corresponding consideration of organizational theory as well as institutional theories (Meyer 2010). Organisational theory and research relating to a transnational perspective has developed early on in the business sector. With an increasing pace after 1989 educational policy researchers have responded to the growing emphasis on transnational organizations in the educational sector.

More recently, also empiricist-functional or instrumental leadership studies have started to move beyond the individual or school level toward multilevel approaches, including both a nation-state perspective and sometimes transnational influences. There are many reasons to this. Investigations into success factors for school development have pointed out the need for a system wide perspective in understanding leadership for school development. Lateral and hierarchical cooperation and professional responsibility have been regarded as crucial for moving schools forward beyond high-stake testing (Hargreaves 2007).

Nation-State-Perspectives Functionalist and transformational understandings of leadership occur in a different fashion in studies adopting institutional theories. Some of these explain how societal and policy structures create homogenization in related organizations through isomorphism (Meyer and Rowan 1977), for example, Bennett et al. (2014) studied Southwest Arizona schools and district reforms embedded within state and federal policy pressures and changing demographics. Specifically, drawing on institutional theory, Meyer and Rowan (1977, p. 340) argued that organizations are driven to incorporate the practices and procedures defined by the prevailing rationalized concepts of organizational work to the point that they take on "rule-like status". According to these authors, new institutionalism explained how structures (policy and non-policy formulated or driven) replicate between related organizations through the mechanism of isomorphism and through leadership as a power dynamic. Pressures from the organizational field account for the homogeneity of organizations within them as a result of the press for the "legitimacy imperative," even though they may not result in increased technical efficiency (DiMaggio and Powell 1983, 1991). In other words, organizations experience change by adopting structures or routines that have been legitimized externally in organizational field in order to achieve similar status. Mimetic isomorphism explains the process by which organizations consciously or unconsciously borrow or mimic structures or processes that have been "legitimated" by their association with a 
high-status organization also considered to be an archetype (Meyer and Rowan 1977). Organizations seek to mimic archetypes in adopting various "templates for organizing" such as "organizational forms, structural components, and rules," which have emerged through interactions in the organizational field in response to scrutiny regarding technical outcomes (DiMaggio and Powell 1983, 1991a, b, p. 28). While institutional theory (Meyer and Rowan 1977; DiMaggio and Powell 1983; Greenwood and Hinings 1996) inspired a multi-level approach to understanding educational organizations (structures) within broader institutional fields, these scholars do not consider how power and ideas circulate within and between institutional levels. In other words, there is reason to observe that the focus in educational leadership research generally has broadened its scope of interest from an organizational to a wider systems oriented perspective.

In trying to understand educational leadership on a municipal level, which has been more or less disregarded in previous research, Moos et al. (2016), for example, suggest that using a filter of multi-level public governance logics would be beneficial for understanding how superintendents and local politicians are positioned in the system, how they develop their commitments and competencies for efficient work for democratic education. As educational leadership studies today acknowledge a multi-level perspective, these reflect a broadening of how educational leadership is conceptualized and points towards merging of curriculum research, organizational and institutional theory, leadership studies and policy research.

These approaches emphasizing the necessity of higher administrative levels expands traditional educational leadership research towards educational policy and governance research. Educational leadership as practised on a nation-state level by governments, central administration and municipalities is different to that of leadership in classrooms and schools - leadership is to govern within organizations on a system level. Moos (2013) and others examine educational leadership in new forms of governance and policies emerging from neo-liberal states. Moos (2013) argues that neo-liberal states have developed new forms and technologies of governance (Foucault 1991) that rely heavily on the market as the logical basis for policy, devolving management from the state to local institutional levels (e.g. self-managing or private schools), classrooms, and individuals. Here governmentality is a social technology of control or a set of strategic acts to act on others' actions as well as the self (e.g. leaders, teachers, students). Moos et al. (2016, p. 236) rely on Louis and van Velzen (2012) and Devos et al. (2012) who identify six key features aiming at understanding educational leadership a municipal level ((i). openness as stakeholders' access to political processes and structures, (ii). decentralization of power, (iii). egalitarianism as principles of justice, (iv). efficiency as scrutinizing public expenditures, (v). quality as a benchmark for effectiveness, (vi). choice as balancing between individual rights and social responsibilities).

Transnational Perspectives While functional and organizational approaches typically perceive their work on organizational change within a nation-state perspective, another way of approaching the multi-level perspective is to approach educational leadership including evaluation occurring at the nation-state level in a transnational 
perspective. We are thinking about the more or less globally occurring policy shift the global educational reform movement (Sahlberg 2015). The movement from a system of old public administration to new public governance and management has been based on focusing core subjects, competition, standardization, test-based accountability and control in ways where the transnational dimension cannot be overlooked. Although the effects of this shift vary, also within Europe. From a critical sociology perspective on educational leadership and policy Gunter and her colleagues (Gunther et al. 2016) have demonstrated that system-level and transnational modifications influence individual states', schools' and professionals' work. Nordin and Sundberg (2014) argue "that an increasing share of state policy formation is not bound to national boundaries but takes place in complex, dense and multi-directional transnational exchange."

In a European perspective, the development of the European Union (EU) quite obviously has contributed to the convergence of nation states toward a European knowledge discourse, identified as "Europeanization". As the European Union lacks coercive power over member states, Normand and Derouet (2017) note that soft governance in the form of expert knowledge and standardization has turned out as central governing strategy. They claim that benchmarks, targets, and recommendations are provided and can be voluntarily adopted to: "Common representation by standards specifies constraints for actors but also possibilities for action and cooperation". Nation-state policy systems featuring stronger regional autonomy demonstrate similar patterns of "governing at a distance" within the nation-state. Educational leadership as a policy and practice of governance from a distance through the use of standards makes it possible to bring together communicative activities across contexts and locations oriented towards simultaneously learning from each other and promoting a competition oriented mentality. This reflects a soft governance strategy identified as "competition oriented cooperation" (Grek 2008; Normand 2016) utilizing international evaluation data.

In explaining the dynamics of a multi-level regional school turnaround process in Finland, Uljens et al. (2016) demonstrated, applying Schmidt's discursive institutionalism and non-affirmative education theory, how Finland featuring a open coordinative policy discourse mediated transnational policies in a non-affirmative manner. Framed in this way regional school administrators acted in recognizing and inviting manner with respect to the schools rather than in coercive and accountability centered ways. Critical of accountability policies regional authorities were not required, by state authorities, to incorporate given evaluative practices, but were, however, invited to do so, allowing for various initiatives on a regional level without sanctions. This governing practice, recognized as historically developed, generated dynamic vertical relations between levels, horizontal relations between schools and diagonal relations between different institutions, each actor recognizing the other in a sustained developmental process over 6-7 years.

Including the transnational perspective turns attention to differences between states and nations but also connect to a sub-state level of analysis like districts and municipalities. It is not surprising that different countries and cultures have developed and operated with different policy cultures. Nor is it unexpected that regional, 
municipal or district level activities mediate between various epistemologies, values, and national policies in different ways. In curriculum theorizing and Didaktik, such a multi-level perspective including the school as organization, the district and the state-level, has been acknowledged for a very long time (e.g. Uljens 1997b).

Another approach receiving increasing attention in North American and European educational leadership research is actor network theory (Czarniawska and Sevón 1996, 2005; Czarniawska 2014; Latour 2005; Law 1986; Koyama 2011; Nyvaller 2015) inspired by Bruno Latour's sociology and Scandinavian institutionalism. Actor network theory (ANT) is considered fit for studying how socio-technological conglomerates operationalize and technologize educational policies into governable practises asking for new forms of professional leadership competencies. This approach represents a non-essential, or relational, thinking whereby the unit of analysis, actor, is not an isolated individual. Representing what is presented as a nondualist ontology the "volitional actant" can be a group or system that "that can associate or disassociate with other agents". ANT is seen as an initiative to integrate what is human and non-human (artifacts and organisational structures). Leadership operates as structured invitations including translational practices often based on new formats of data. Latour (2005) refers to Deleuze and Guattari's (1988) concept of network as a "rhizomatic" structure - a structure, pointing at various directions with no definite beginnings or ends. The dynamics of the rhizome makes it a structure at work, and in principle unpredictable, rather than a static. The power relations between nodes are reflected by the strength of the relations rather than by distances. An actor is seen as strong when it gets others to act according to intentions expressed. Or more precisely, as Latour (1986) argues, power is not something one can possess but rather something one can exert. Here the power of exerted actions are given by the follower. The paradox of exerting power is that mere having it is, in fact, powerless. In a translation model of power "a successful command results from the actions of a chain of agents each of whom 'translates' it in accordance with his/her own projects." As "the others perform the action" focus should be turned to "how people are associated together" according to Latour (1986). In contrast to traditional approaches to leadership, this theory acknowledges not only verbal activities but also coordinated material artefacts, procedures, technologies etc. Whereas transformational approaches in school leadership research have been focused on school internal dynamics in relation to external influences (e.g Leithwood 1994), a translation theory approach is more focused on identifying patterns for how 'master ideas' travel from one context to another by means of various translational processes. In their review, Wæraas and Agger Nielsen (2016) perceive translation theory as an approach with roots in actor network theory, Scandinavian institutionalism and knowledge management. In leadership as translation, different stages are identified - problematization, interessement, enrollment and mobilization (see Callon 1980). The translational approach in educational leadership is, according to Rövik et al. (2014), an instrumentalization of scandinavian-french organisational theory inspired by Latour (1986) and developed by Czarniawska and Sevon (2005). Following Latour's view of power, success of an educational reform is, thus, dependent of actors' competencies to translate these ideas into practice. The quality of 
these competencies consists in the actants' conceptual awareness, contextual knowledge, and knowledge of rules for translation. In this approach, we see a focus on translation of reform from one context to another as well as the social interaction with regards to reform among "actors" in particular settings. As in organizational theories, such approaches are grounded actions and behaviors in the micro level of educational changes or reforms in educational organizations. Again this is why we also see the relevance of institutional theories.

Based upon our review of strengths and limitations in educational leadership studies, we make several points. First, recent educational leadership theories or models have developed from an empiricist direction and second, while useful in many ways, theories of leadership are rather free floating from theory of education that drives our project. We further note that much of the empirical literature on leadership and in organizational theory, we see a focus on teacher/staff learning and other practices that indirectly affect student learning. By contrast, curriculum theory and didaktik focus explicitly on student learning. That is, in theories that frequently frame educational leadership studies (organizational theory, critical theories), general ontological and epistemological positionings only indirectly indicate what education should aim at, but do not explain in any great detail the nature of educational activity. In functionalist and reproductionist oriented leadership literature, there is an implicit acknowledgement that effective school leadership indirectly influences curriculum, teaching and student learning with schools serving a subordinate role preparing students for needs of an existing society. In transformative oriented educational leadership studies grounded in critical theory, we also see a strong focus on leadership as a counter-hegemonic force to overcome structural inequities. Here schools serve in a super-ordinate role, transforming society toward an ideal. As we shall demonstrate later, this is something that non-affirmative education theory handles differently.

\section{Conclusions Regarding Curriculum, Didaktik and Educational Leadership}

\section{Different Focus and Concepts on Different Levels}

The general picture emerging from the review of previous research is that various types of leadership may be identified at different administrative levels. Most often educational leadership studies are focused on the principal's work on a school level looking at how principals' or head teachers build up capacity, manage, lead and develop. Educational leadership focusing on leadership issues on higher administrative levels are closer to policy research. This research introduces different concepts and research questions compared with school leader research. These questions often have to do with the relation between politics, culture, legitimation on the one hand and educational activity on the other. Policy oriented leadership research no longer 
focus on single leaders' activities but on more general policies and principles featuring the governance or administrative system.

In Didaktik we can find a similar division of focus regarding different levels. As we have shown Didaktik theory focus on aims, contents and methods of teaching. Didaktik in a narrower sense has often been limited to questions of aims and contents of Bildung, while Didaktik in a wider sense also captures methods of teaching. The decisive selection, formulations and decisions regarding aims and contents of teaching in the European tradition of curriculum making is typically made on the nation-state level far above each single school. Methods in turn are regarded primarily a topic to be decided by the teacher on the school or classroom level. While Didaktik as a field of research traditionally tries to keep together questions of both aims, contents and methods of teaching as they occur different levels, in angloamerican research curriculum theory more often is discerned from instructional theory. Contemporary curriculum theory in the US is dealt as separate from theories of instruction and teaching as well as separate from educational leadership and policy.

The neoliberal shift toward new forms of governance within and across countries has demonstrated how strongly administrative initiatives, led by a new accountability ideology, influence professional educational activities on all levels. Moving from seeing the state as a provider of services to a buyer of services continues seeing the role of the state as collector of taxes but includes a privatization of public services previously organized by the state. In this respect USA with its privatized education governance sector and schools differ from Europe. Thus, we argue that curriculum theory/Didaktik and educational leadership studies would benefit from a closer dialogue as curriculum theory/Didaktik extends educational leadership studies' focus on local perspectives with an explicit consideration of how societal interests transform into educational content.

\section{Reproduction and Transformations Oriented Approaches Dominate}

As we have demonstrated a paradigmatic analysis regarding how leadership research and curriculum/Didaktik theory relate to the practice they are about, shows that either a functionalist instrumental-descriptive (sociocultural reproduction) or a critical-normative approach (sociocultural transformation) dominate the field. In addition hermeneutic oriented approaches may be identified within both.

From a sociocultural reproduction perspective, curriculum serves a preparatory function, preparing all students to become good citizens in existing society with its knowledge, values, and norms. Anglo American curriculum studies and European Didaktik focus explicitly on the interplay between the macro and micro levels. In particular, many scholars consider questions of how policy makers and educators decide on, enact, and evaluate the selection of aims, content, and method (Gundem 
2010; Reid 1994). Here, state curriculum is seen as a means for governing the general aims of education and academic subject content as well as the organization of teaching (Hopmann and Riquarts 1995; McKernan 2008; Uljens 1997b; Ylimaki and Brunner 2011).

Educational leadership studies, scholars tend to write about curriculum and pedagogy as objects of indirect leadership influence and productive social interactions that affect learning and student outcomes (e.g., Edmonds 1979; Hallinger 2003; Leithwood 1994). And while leadership scholars vary according to how they characterize leadership influence from an individual effort to a shared capacity, they frequently approach leadership through various forms and approaches with dispositions and practices that indirectly contribute to student learning. These educational leadership scholars do not explicitly conceptualize the school as subordinate to society. Indeed, there is little direct attention to societal aims and the role of schooling in this strand of literature; rather, scholars focus on social interactions among formal leaders, teachers, and sometimes students and parents that contribute to effective learning for all children.

Drawing on a tested transformational leadership model (Leithwood 1994; Leithwood and Riehl 2003), other scholars focused specifically on how individual administrators build organizational learning capacity in schools (e.g., Jackson 2000; Marks and Printy 2003). Findings from this later research indicated that by modeling appropriate instructional leadership behaviors, norms, and values, and by then inviting teachers to share leadership responsibilities, principals build instructional leadership capacity for systemic school changes that contribute to improved student outcomes. Instructional leadership research fits within social reproduction perspectives because it focuses on how school organizations and their leaders operate to create school conditions (normative school practices) necessary for schools to be productive and educate citizens in an existing, albeit a less than ideal inequitable society. In these leadership studies are implicitly grounded in normative views regarding the preparatory function of schools for society and its existing values (e.g., order, efficient work practices, high standards, strong academic performance) of the status quo. In these descriptions of instructional leadership and leadership for learning, there is also a clear lack of attention to the interplay between the broader society, culture(s), and school practices, including cultural responsiveness to increasing plurality, a gap that some scholars have attempted to reconcile in social transformation perspectives and social justice leadership.

Instructional and transformational leadership approaches are often contrasted with transformative leadership approaches whereby, as noted earlier, more revolutionary leadership practices are aimed at radical social change or transformation (e.g. Foster 1986; Scheurich 1998; Theoharis 2007). Shields (2014) calls for a distinction between transformative leadership for social justice education aimed at changing "the very nature of the school and its relationship with the wider community" (p. 325). Transformative leadership forms stand in contrast to more functionalist views of transformational leadership, and transactional leadership approaches. 
Here, curriculum functions in a superordinate position to society with plans, content, and methods functioning to liberate citizens from existing, oppressive social norms and values. The role of education, then, is to develop something more socially just, teaching students to work toward an ideal that does not yet exist. Apple (2004), for instance, draws attention to connections among hegemony, ideological stability as raised by social reproductionist critics (e.g., Bernstein 1975; Bourdieu 1977; Bowles and Gintis 1975), curricular knowledge, and economic inequality. In other words, it is in the interplay between curricular knowledge or what we teach, the "legitimate culture," and the social relations of classroom life that the reproductionist theorists describe, that we can begin to see some of the real relations schools have to an unequal economic structure. Apple identified four broad groups- neoliberals, neoconservatives, authoritarian populists, and the new middle class - that have sutured an uneasy compromise in a contemporary hegemonic alliance or the so-called conservative restoration. Thus, Apple (2004) argues that curriculum must see as its task today the identification of moral, political, and ethical conflicts connected to social inequities, including class structures, gender, race/ethnicity, and intersections thereof.

Critical curriculum scholarship has gained popularity in recent decades through various approaches to critical pedagogy (e.g., Giroux 1983; McLaren 1998) and Freire's (1970/2000) teachings aimed at developing critical consciousness about marginalizing conditions in society. Regardless of ontological differences, the role of curriculum is to prepare children in idealized, more socially just norms and values that they will apply as citizens who transform society. Notice, however, that the ideals, norms, and values for a transformed society are decided in advance, thus making social transformation perspectives also normative in nature (Uljens 2002). In our view, sociocultural transformation theories are also normative in that a predetermined set of idealized values guide practice.

Critically oriented curriculum scholars (e.g., Anyon 2008; Apple 2004, 2005) have written more explicitly and critically about formal leaders as agents of the system who direct teachers' work and, perhaps unconsciously, circulate a particular set of (neoliberal and neoconservative) policy discourses that institutionalize official knowledge and create a hidden curriculum.

In leadership for social justice theories, now dominant in the educational administration field, leaders are identified as an important counter-hegemonic force in developing students through education, or critical pedagogy to critique and transform existing social structures and values, generally either through awakening an internal critical consciousness or recognizing the importance of conflict to radical social change. According to McKenzie et al. (2008), a critical consciousness about power, privilege, and social inequities motivates leaders to ensure that schools are safe places for all children and that academic achievement is explicitly linked with activism. 


\section{Leadership and Didaktik/Curriculum: Mutual More and Less Blind Spots}

We observe that educational leadership research, curriculum theory and Didaktik all discuss values, identity, culture, social justice and learning but are often unable or perhaps even disinterested in relating to each other in a systematic way, remaining isolated although teachers' and administrators' work includes all. The practitioner is expected to combine disparate theories and perspectives or rely on "experts"often normative/instrumental recommendations - that research itself is not able to unify or correct.

A blind spot for both curriculum studies and Didaktik is the limited attention paid to leadership forms/structures and interactions (Gundem 2010). Perspectives developed within leadership studies, i.e. how professional groups (teachers, school leaders and superintendents) cooperate in order to work with school development together is an overlooked issue within curriculum studies and Didaktik research. In turn, educational leadership studies are typically less observant for the interplay between, on the one hand educational aims, contents and methods and social interactions within schools (e.g. teaching-studying-learning-leadership).

But, the degree to which Didaktik and curriculum theory has or has not paid attention to leadership really depends on which curriculum theories we discuss and how we define leadership. For example, taking Ulf P. Lundgren's curriculum theory as an example. This approach defines curriculum theory as the study of frame factors such as governance, legislation and national curriculum and their influences on teaching practice. A traditional educational leadership perspective in terms of principals' behavior is certainly not present. However, given that educational leadership research today expands its scope of interest from focusing intra- and interindividual dimensions of principals work in schools, as is done by Moos et al. (2016), then a conclusion would be that leadership in fact increasingly reminds of curriculum research carried out since almost five decades. In fact, Lundgrens systems- and governance-level oriented take on curriculum theory received critique for not paying enough attention even to the process of teaching.

Educational leadership as an organic part of the school system at different levels is a longstanding feature in the European tradition of "thick" states, i.e. a state formation with wide reaching responsibilities. This view of state responsibility include leadership in a broad sense as a question of how schools have been and should be financed, governed, evaluated and developed. This organic or broad approach to leadership, curriculum and teaching is well demonstrated in the first text-book in educational studies in Finland 'School Pedagogics' (Skolpedagogik), published 1884 authored by the hegelian educationalist in Finland Zachris Cleve (Cleve 1884). Here educational leadership (as principal's work) incorporated, first, an idea of the school's task in society, second, an interpretation of the curriculum as a policy document, third, a theory of teaching/didaktik including an elaborate view of the school's internal social climate, and fourth, an awareness of the state's regulations of a school's activities. Cleve's book, based on Hegelian philosophy, was aimed for 
teacher education. In it the task of the school is analyzed in relation to the family, culture and church, i.e. develops a theory of the school as a societal institution. Politics is not mentioned, but the book is written 32 years before all men and women won the right to vote in 1906. Further, Cleve identified different types of school institutions (primary school, comprehensive school, universities). The inner and outer organization, the tasks of the teachers, curriculum and laws and regulations are extensively discussed. The second and largest portion of the book deals with the process of teaching, studying and learning the curricular contents aimed at supporting the development of more general abilities among students. The third part of the Cleve's volume is then devoted to the teacher's profession and staff capacity and the role of the principal in these matters, i.e. how to best run a school given the task, the context, framing, contents and teachers. In essence, this description shows how educational leadership was from the beginning seen as an organic part of institutional education. In this contribution, understanding educational leadership is to see how curriculum and leadership are intertwined and connected to a wider understanding of the school as a societal institution. To connect leadership and curriculum and treat them as a whole is thus not a new phenomenon, although such a connection has got lost over the years, also in the European tradition of Didaktik.

\section{Beyond Prescription and Description?}

A frequent dilemma with reproduction oriented approaches is that they ontologically represent a form of naïve realism assuming that the reality may be described truthfully assuming scientific methods are used correctly. Empiricist-descriptive approaches often accept some version of representational epistemology. A classic dilemma with these approaches is that from an empirical description of how leadership or curriculum work is carried out in some given context, researchers draw conclusions concerning how one should teach or lead in the future. It may be that this research is not always aware of the functional role the results presented have. Despite that it is today widely accepted that empirical descriptions are never completely value neutral this is seldom a topic in this branch of leadership and curriculum research. This descriptive, functionalist research operating from a representative epistemology is a part of sociocultural reproduction. Bourdieu (1977) uses the term "symbolic violence" to explain how particular groups retain dominance in a society (without resorting to physical means). Symbolic violence is "the power to impose instruments of knowledge and expression, of social reality, which are arbitrary but not recognized as such" (Bourdieu 1977, p. 13). When most members of a society accept its norms as "natural," rather than arbitrary, then they also accept the outcomes of these norms as natural, even when the outcomes go against their own interests. To conclude, this reproduction oriented research, does not include any awareness of norms and values as being part of leadership as a societal activity. Yet, the results of this research can unintentionally operate as confirming status-quo. 
Socioculturally transformative approaches in turn accept that the task of counterhegemonic research is to reveal self-evident assumptions thereby revealing otherwise hidden interest. We perceive of this as a welcome approach but at the same time pay attention to that some approaches calling themselves critical instead document another type of naïve attitude. This has to do with the role academic research is assumed to have in democratic societies regarding value driven activities like education. The dilemma with strong normative positions may be that presenting solutions and ideals (aims) for education is maybe primarily a task for a public debate within democratic institutions and not something individual voices within universities should carry out. The dilemma is delicate. Assuming that educational research is never value neutral, one could claim that being silent regarding these values is to act deceptive with regards to users of research knowledge. On the other hand, does then every explication of these guiding values mean a negation of democratic processes? We support the view that neither educational research or educational practice can be value-neutral. Yet, in educational research it may be it necessary to differentiate between fundamental values guiding theory building, like assuming the research being aimed as valid for a democratic society, and more prescriptive-emancipatory aims.

We argue that regardless of whether leadership studies are grounded in structural functional, interpretive, or critical paradigms, the task for an educational leadership theory is to explain how this dilemma of normativity is handled. In line with questioning a too strict division between facts and norms in our view the step between what is (empirical description) and what ought to be (normative prescriptions) always include a discursive process, taking a position in value questions as related to a specific cultural context.

In our view, theories of education address school-society relationships, including the aims and character of teaching-studying-learning process. Regardless of underlying paradigm, conception of curriculum/instruction, or specific form or model, we argue that leadership studies do not really theorize education (with curriculum/ Didaktik as key aspects of it) or articulate an underlying educational theory. We will explain what we mean by an education theory in the next large section.

Although we appreciate that leadership studies, by adopting institutional theory instead of organizational theory, understanding schools as politically directed institutions, we also argue that organizational perspectives are still relevant and that leadership studies do not go far enough to consider education theory, curriculum theorizing, communication and cooperation across institutional levels, or broader questions of societal aims, content, and methods. We argue that educational theories and their core concepts from our framework will not compete with leadership studies but rather enhance empirical descriptions of these. By grounding empirical work in an underlying theory of education, we argue that educational leadership studies will more fully explain the current descriptive influence practices prevalent across much of the research.

To conclude, we see that the challenges in treating educational leadership and curriculum in the Anglo-American tradition is different from treating educational 
leadership and Didaktik in the European tradition. Yet, we have to remember there are common roots emanating from a common western philosophical tradition and many similarities regarding paradigmatic approaches. We argue that a simple merging of curriculum theory educational leadership studies is not possible. In the European tradition such a merging is not possible as governance, administration, curriculum and teaching is seen as a whole. In the American tradition a simple merging is not possible given the wide variety of isolated approaches. To address the interplay between schools and society, particularly in dealing with the normativity problem, leadership as a multi-level project in schools as societal institutions, or the paradoxical relationships inherent in notions of leadership influence requires something else.

\section{Non-affirmative Education Theory: Bridging Traditions and Grounding Comparative Research}

In this section, we aim at presenting a conceptual framework that will bring curriculum theory/Didaktik and leadership studies closer together to improve educational practice in the wake of a growing critique of neoliberalism. Our point of departure is, first, that any successful accomplishment of educational practice, be it or teaching or educational leadership on different levels and of different kinds, is partly guided by prevailing conceptual framework and theories, dominating policies, cultural and historical traditions. However, if the undertakings are informed by theoretical positions that conceptually highlight only disparate if important activities and processes of the educational system, and even in conflicting ways, their guiding power may be limited. Observing that the research traditions and paradigms approaching curriculum, evaluation and leadership, it is obvious that they are not developed in any closer connection to each other, rather quite disparate from each other.

Curriculum theory typically starts from a societal and philosophical perspective, operating nationally and on an interstate level, while leadership research has had a tendency to approach schooling on an individual, interactive, and a practitioner level, concentrating on the school (organizational) issues, effectiveness, and social dynamics between professionals. Didaktik in turn combines these two levels, the societal and the interactional eleve both philosophically and empirically, but lacks a conceptualisation of leadership. And while globalization and internationalization have been recognized in recent curriculum theory/didaktik (Pinar 2000, 2004) and educational leadership studies (e.g. Day 2005; Spillane 2002; Hallinger 2005), curriculum and leadership have not been explicitly connected in theoretical logics.

In the education sector the presence of an inter-state or the cosmopolitan dimension (Beck 2006) is visible both in terms of increasing global harmonization regarding core curricula but also through growth of neo-liberal transnational evaluation 
procedures (e.g. PISA) (Nordin and Sundberg 2014). Both contemporary European and US education policy reflects the neoliberal turn in public education, with an emphasis on accountability, standardization, and the comparative high-stakes testing of learning rather than on curriculum and pedagogy. Transnational institutions of different kinds have definitely challenged the nation-state perspective that has dominated curriculum research (Robertson 2006). The emergence of a 'European policy space' or the European Union as new 'transnational state' (Grek 2009; Lawn and Grek 2012) has naturally challenged the idea of the nation-state as the ultimate location for curriculum work or for any public policy making. Still, especially school leadership is mainly perceived as a 'within-state' dilemma (Clarke and Wildy 2009). Curriculum research and theorizing has partly turned into investigations into how policies travel horizontally between policy systems and how meaning translate between levels (Steiner-Khamsi 2004; Steiner-Khamsi and Waldow 2011). Curriculum and related evaluation policy documents are studied in the US and Europe; however, this research is often carried out by political scientists or policy scholars, not curriculum scholars. In particular, in critical policy studies on US policy, we can identify emerging trends, including policy appropriation (Sutton and Levinson 2001), policy enactment (Braun et al. 2010) and policy networks or assemblage (Koyama 2010). In Europe a transnational perspective on educational leadership is emerging within sociological policy research rather than within educational theory or curriculum theory (Gunter et al. 2016).

Given the above described developments regarding curriculum making and the renewed role of evaluation we can see that understanding how institutional education, including schools and universities, are governed and lead require we do not limit ourselves to those system-internal approaches dominating contemporary educational leadership research. This not to dismiss this research as unnecessary or the like. It is only a reminder that the object of research cannot be limited in this way if our aims is to understand how schools are led. In addition, to understand leadership as distinct or separate from eg. curriculum policies restrict our way of understanding leadership. School leadership and teaching are obviously not private activities but public ones. Leaders and teachers must adhere to curriculum policies regardless if these are aimed at social reproduction and cultural unity or social transformation, i.e. toward transformative (equitable) social justice norms and values that disrupt the status quo toward an idealized, predefined future that goes against existing societal norms and leadership traditions. In both cases leaders' professional identity is formed in the tension between on the one hand, their personal values and identity and, on the other, the institutional position they have accepted to be appointed to. Modern education systems typically operate along contradictory intentions - on the one hand schools are expected to adapt teaching to given needs and evaluate each student according individual progress, on the other hand schools are expected to evaluate each individual in relation to all other students. The principle of qualification stands in contrast to the principle of selection/stratification. Further, curricular policies often expect schools to fulfil both reproductive and transformative aims.

Viewing leadership as an object of study internal to the education system limits the attention to continuous reform irrespective of the aims of the education system 
are reproduction or transformation-oriented. In other words, a system-internal, reform- and betterment-oriented perspective on leadership tends to turn leadership initiatives primarily into questions of effectiveness. If research shares such a view of a system with internal leadership practice, then such research quickly turn into effectiveness research. In contrast, leadership as well as leadership research may also be aware and sensitive of historical, cultural, political, religious and societal dimension of education and break with a system-internal perspective. In this case a counter-hegemonic transformative view of leadership theory and practice is often adopted. When leadership scholars take a position on the role of leaders and schools aiming at creating a future more equitable this is guided by an interest in trying to understand how leadership activities influence and support pedagogical practice in revolutionary or reformatory ways, creating a new more socially just society through education. In leadership for social justice literature (e.g., Bogotch 2002; Ryan 2006), practices focus on future opportunities for student success. It is never enough to merely transmit existing knowledge to students. Exactly the same may be noted regarding to curriculum theorizing. Such a change-oriented interest constructs leadership and leadership research into a culturally critical voice. This may be perceived as problematic if such leadership research is presenting a competing or alternative ideal, compared with a politically agreed curriculum regarding the aims of education.

The dilemma of how educational theory may be related to educational practice goes back to double expectations on education theory. On the one hand educational research is expected to provide trustworthy or convincing descriptions of educational practice. On the other hand, this theory or research is expected to provide guidance for regarding how teaching should be practiced. The question is what role educational leadership theory and research should have and aim at? Should it present alternative views for the education system or should it be focused understanding the function of the system?

A second step in approaching these challenges will be the observation that although globalization/cosmopolitanism forces nation-states to restructure themselves regarding the ways in which political, cultural and economic unity and plurality is established and sustained, the dilemma of dealing with unity and plurality is not new. In fact, the stepwise movement from a premodern to a modern world corresponding to the establishment of modern nationstates (eighteenth to nineteenth century) in similar ways required a new approach to establish and sustain a relation between national and cultural collective unity (sense of belonging) and individual and regional plurality. The modern liberal nation state, framing previously unseen forms of liberalisms (freedom of speech, religion, politics, owning of property), required a corresponding educational philosophy, policy and organization able to meet up and conceptually make sense of the new situation. Although many differences may be identified, the solutions in USA and Europe were close.

In other words, the demonstrated need to conceptually and practically rethink nation-state education in a cosmopolitan light reminds of the process modern nation states lived through when establishing the prevailing educational systems and philosophies. There is a question of continuity and discontinuity. To what extent are we 
able to keep to fundamental concepts of education developed as a response to the modern nation state? And to what extent are we forced to rethink citizenship as well as educational research, philosophy, policy and practice in the light of globalization? In order to accomplish this task will contribute with a reconstruction of fundamental tensions, issues and features of modern educational thought, with a focus on post-Kantian educational thought as developed by e.g. Fichte, Schleiermacher and Herbart.

We ground our framework in a non-affirmative theory of education. This approach explicitly draws on Dietrich Benner's theory of education (Benner 1991, 2005, 2015). We elaborate on and use this non-affirmative approach because we consider this position to more broadly encompass and theoretically ground and thereby also frame a dialogue on curriculum theory, Didaktik and educational leadership. Representing general theory of education (Ge. Allgemeine Pädagogik) nonaffirmative education theory by definition is located on a more general and foundational, partly philosophical, level than various research specialisations. Typically a general education theory answers questions regarding the nature of education, what it means to be, become and grow as, a cultural being and citizen. Also how individual learning is related to societal change is at the fore as are questions around educational support, teaching and influence. Due to its foundational character this approach to education offers a meta-theoretical point of departure for understanding curriculum, Didaktik, and educational leadership amidst globalization processes.

\section{Theory of Bildung and Theory of Education}

A second preliminary observation may be helpful for some readers. In the GermanNordic tradition a distinction is made between Theory of Education and Theory of Bildung (Benner 1991). In German these two fields are often collectively referred to by the concepts of either Erziehungswissenschaft or Pädagogik. However, there is terminological confusion. In the literature, theory of Bildung refers at times to the content and aims of education, and sometimes Bildung refer more to the process of human growth in the broadest sense of the word, trying to explain what it means to become a person and a citizen (Bildung as educative formation). In its processual perspective Bildung is an enduring phenomenon - we learn continuously during our whole life. In this light one may see theories of Bildung as philosophical anthropology. For Herder (1744-1803) philosophical reflection was the core of Bildung. In this way, philosophical reflection and Bildung are both cultural enterprises asking what it is to be human, what it means to have knowledge and what is worthwhile pursuing in life. It is worth observing that the seminal works in modern education theory were clearly under influence of German romanticism indicating a reaction against french enlightenment emphasizing rationalism. A position balancing reason with passion (mind-body) endorsing an organic wholeness from the greek polis developed. According to this line of thought Bildung as the individual's 
self-formation is not limited to an individual vantage point but always completed with an understanding of how one's individuality connects to society in general. Socialisation and personalisation are seen as two sides of the same process.

In turn, Erziehung as an intentional activity on e.g. the teacher's part, is something we may experience at a younger and at an older age, but this is not an enduring process. Educational activity (Ge. Erziehung) has a beginning and an end, or, many beginnings and ends. This educative activity is sometimes perceived as influence, at other times rather as pedagogical interaction. As demonstrated earlier Erziehung sometimes refers to pedagogical interaction related to developing attitudes or values, while Unterricht (Teaching) would be more focused on the cognitive contents or competencies to be learned. Since Herbart we know the ambition of keeping these two together by talking about Erziehung as 'educative teaching' (German: 'Erziehende Unterricht', Swedish: 'fostrande undervisning', Finnish: 'kasvattava opetus'). Theory of Bildung is therefore not the same as theory of Education (Erziehung). Neither can be reduced to, deduced from or explained with the other. However, neither are each very meaningful without the other. The challenge for a theory of "education" (Pädagogik) is to explain how these two phenomena, the process of Bildung and the activity of Erziehung, are related to each other. In English 'theory pedagogical interaction' may cover all of the above. This is what we refer to in talking about 'theory of education'.

\section{Didaktik and Education}

Previously we have seen that a broader concept of Didaktik comprises typically both curriculum theory and instructional theory or theory of teaching. Despite this broad perspective Didaktik start from the school as a societal institution as a given. In turn, general education goes beyond activities within the school and rather sees the school as only one way how the relation between generations can be organized educationally in a society. While didaktik focuses the aims, methods and contents of education, general education often include the relations between politics and education as well as ethics and education to be solved. Both Didaktik and General Education theory typically confess to that the societal task carried out by schools is to bring forth reflective, mature and critically thinking citizens. The autonomy assumed is expressed by the german word 'Mündigkeit'. However, the dividing lines are not clear once for all: some approaches in Didaktik, like the one represented by Wolfgang Klafki are indeed broad, while some approaches to General Education are mainly focused around the school as an institution. Indeed, a general education theory always theorizes institutionalised education. This said, it should be made clear that although Didaktik as theory of school teaching is considered a subdiscipline reflecting crucial parts of the teaching profession, it does not theorize the development of professional teaching, or the leading thereof (see e.g. Berliner 1989; Sandberg and Dall'Alba 2006). Another way of putting it would be that while Didaktik assumes the existence of schools, general education starts by asking how 
the generational relations in a society are organized regarding culture, politics and economy. Given that general education by definition theorizes the fields of Didaktik, currículum and leadership on a more fundamental level it makes sense, from a Nordic-German perspective, to identify General Education as a level of analysis bridging Didaktik, Curriculum theory and educational leadership studies. However, as we have seen, neither the European (German-Nordic) tradition in Didaktik or in general education educational leadership has been debated as it is understood in most contemporary research. To our knowledge any such attempt has not been made anywhere before.

\section{Epistemology or Ontology First?}

Much research in education, including curriculum theory, Didaktik and educational leadership, can be structured according to which research paradigm they primarily represent epistemologically - a critical, functional, pragmatic or hermeneutic - or some combinations thereof. The paradigm debates are no longer as engaging as they were back in the 1970s or 1980s. A reason for this is that, first, the main paradigms have influenced each other. Second, prominent positions have lost their paradigmatic position, while new approaches like post-modernism, post-humanism and others have developed. 'The linguistic turn' during late-modern high-days brought new dimensions to interpretative, contextual or hermeneutic approaches through discourse analytic approaches. Recent posthumanist ideas have aimed at redefining relations between mind and matter, merging what is subjective, socially shared, manifest, represented, and material.

A paradigmatic division among positivism, critical theory and hermeneutics reflects a theory of science perspective, focusing on ontological and epistemological positions valid for any discipline. Such argumentations regarding the epistemological nature of human knowledge are also valid for educational theory, but, epistemological theory is not theory of education or theory of learning. The dilemma in structuring educational research following epistemological positions is that conceptually human growth as Bildung and Educational activity stay underdeveloped (Benner 2005).

This critique can also be directed regarding more recent epistemologies regardless if they are discursive, critical, phenomenological or post-humanist. Seldom do these argue for or against previous theories of curriculum, Didaktik or Education. In contrast, non-affirmative education theory does not start the journey from an epistemological perspective but from theorizing education as such, ontologically, asking questions like these: What is educational interaction? How can it be identified among all other human activities? As learning does occur all the time, as well as intentional activity aiming at learning, then what is teaching and leadership about? Teaching is to lead, and leadership can be about teaching. Of what nature are then these activities interfering with other individuals' relations to themselves, to others and the world? 


\section{Ethics}

Turning the attention from an epistemological way of structuring the field towards content oriented one immediately confront us with ethical and political questions. Educational leadership as policy and practice, teaching and curriculum work are never devoid of values. A first topic regarding educational ethics has to do with is the development of learners' (including professionals') moral reasoning. If educational theory is about individuals being, becoming, and development as human beings, and that being a cultural subject indeed includes morally reasoning, then a theory of education has to answer that question.

A second, related question, is what role intentional and reflective educative activity may play for this process to occur? How are individuals' to be approached in ethical issues? In moral professions and politically regulated activities practitioners make value decisions, and these are, in a sense, critical for many reasons. Critical perspectives are important to provide analytical tools (e.g. discourse, critique) in an era dominated by a particular set of political ideologies (Ylimaki 2011). Should education, for example, be about challenging learners' cognitive-reflective capacity to reflect one's own values in relation to others' values and interests (Herbart)? A third question regarding ethics in education has to do with how intentional education is legitimized.

How then does educational theory help us to reflect on the above mentioned questions? We have seen that sociocultural reproduction and transformation theories as well as ideologically critical, functional and hermeneutic theories all deal with these questions. A non-affirmative approach with its core concepts allows for critical discussion of the values lying at the foundation of democratic education and yet avoids the normativity problems of critical theory.

\section{Education as a Discipline of Its Own}

It is relevant to pay attention to that while 'education' typically is defined as a field of research in the US it is defined as a discipline of its own in the German-Nordic tradition (Uljens 2002). It is, however, not only American research that treats education as 'a field of research' where insights from other disciplines like sociology, psychology, subject matter knowledge or ethics, are applied. In such an applied view on educational research, education would be about applying insights from psychology or ethics. It is a widespread misinterpretation that even the founding fathers of education, like Johann Friedrich Herbart, would have understood ethics as providing the aims for education and psychology the methods. Especially, given that Herbart's idea indeed was to establish education as a discipline of its own during the first decades of the nineteenth century, it makes no sense that this initiative would start by drawing implications from psychology or ethics (Benner 1995). In fact, historically seen the relation between university chairs in education, sociology 
and psychology was the opposite. Psychology and sociology were established decades after the first chair in education was established in Finland (1852), but regarding the establishment of education as an academic discipline there are huge variations between countries. In any case, this instrumental view of educational knowledge emanating from seeing educational knowledge as implicational may be the reason to why so many still today treat models of teaching as falling back on sociological theory, psychological theories of learning or ethical-philosophical ideas (Uljens 1997b).

As education in the theory tradition framing this volume is seen as a discipline of its own there is naturally an expectation to develop theory of education, theories that are not applications of sociology, psychology or philosophy. Given the dramatic expansion and differentiation of education as an academic discipline the past 50 years there is an ongoing debate if education is one and only one discipline or if it can or should be divided in sub-disciplines based on the population, contents, institution or something else (e.g. special education, adult education, mathematics education, higher education). In any case general education (Allgemeine Pädagogik) is the most foundational or general field. Contrary to philosophy of education General Education aims at developing foundational and all-encompassing theory of education trying to keep many different questions and perspectives together in a coherent system. General education typically deals with an ontological level of analysis answering questions like: what is education, where does education start and where does it stop, what makes education possible, what makes education necessary, is a universal/regional theory even in principle possible, can or should a theory be prescriptive and normative or not? Dietrich Benner is one of the absolute leading researchers of this field in Germany.

Given the profound challenges of our own time with cosmopolitanism taking new shapes we find an approach in General Education that brings us into a dialogue with the modern western classics indeed as stimulating. We think that it is only by understanding how contemporary theory in curriculum, Didaktik and leadership reflects modern education thought that we may develop a more profound dialogue across different epistemic traditions in the in a global perspective.

At one level non-affirmative theory of education is much less familiar in a North American context than in Nordic/European contexts. In this respect the present project contributes to supporting a transcontinental dialogue on theory of Bildung and related concepts of education, now including educational leadership. But we would also like to remind of that more significant similarities may in fact be exist between the historical traditions in different countries than may be recognized. A first reason is that history of ideas at most universities receive a very limited space in curricula for education as an academic subject. Another may be that educational research is expected to mainly contribute to understanding contemporary empirical problems. A third reason is that education has developed very much as a regional science. Finally, we want to point out that earlier there was not the same culture of referencing to previous research as we see today. This holds true for European and North-American Scholars. For example, knowing the modern tradition one is able to see that the nineteenth century hegelian philosopher and educational theorist 
Johan Vilhelm Snellman in Finland brought his ideas from Herder, Hegel, Herbart, and Schleiermacher (Snellman 1861/1894). The same holds true for Dewey, who seldom makes references to these original sources in his theorizing of education. Yet it is obvious that his ideas, expressed for example in My Pedagogic Creed (1992), i.e. that "education must be conceived as a continuing reconstruction of experience" reflects a view of Bildung originally developed by e.g. Herder and Schleiermacher (Schlieiermacher 1826/1983). He also is very 'modern' in acknowledging the difficulty for education following from a non-teleological societal development, according to which we have to educate for a future we do not, and cannot, know. $\mathrm{He}$ thus concludes that the aim of education is personal autonomy, in german 'Mündigkeit': "To prepare him for the future life means to give him command of himself; it means so to train him that he will have the full and ready use of all his capacities..." (p. 445). Autonomy and self-determination as the aim of education developed early to the cornerstones of modern education thought. When Dewey concludes that "education, therefore, is a process of living and not a preparation for future living" this is here taken to mean that education cannot prepare for a future living as it is not known. Yet, here Dewey comes to equate life, process of learning and education. We think it is not unproblematic to say "the process and goal of education are the same thing" (Dewey 1992) but at this point of our project, it will suffice to say that it obviously may contribute to studying Dewey to read him through the conceptual apparatus outline here and elsewhere (English 2013).

\section{Three Questions as Core Topics}

In adopting non-affirmative education theory as a point of departure for understanding curriculum, educational leadership and Didaktik, then, we asked three questions as core topics. Methodologically, in order to bring together and merge objecttheoretical discourses on Didaktik, curriculum theory and leadership in (and of) schools as historically developed societal institutions, we see it necessary to move the analysis onto a meta-theoretical level. Therefore the point of departure is taken in core questions and concepts originally developed for a modern society within classical or modern continental education theory and philosophy.

By a systematic focus on foundational questions, we point out how a uniting discourse may be grounded in and merge the previously mentioned valuable but disparate approaches and research initiatives. Finally, in light of the contemporary situation, we move the meta-analysis beyond the nation state level to consider the pedagogical dynamics and relations between states as well as networks and states. Here we remind that organisational theory, discursive institutionalism and a globopolitan view complements this non-affirmative approach. These perspectives provide us with conceptual tools and analytical methods for understanding relations within and between levels. For empirical research on leadership, curriculum and Didaktik based on non-affirmative theory of education, critical hermeneutics is a corresponding epistemological school of thought. 
The questions we propose as starting point are:

(a) How does a theory of educational leadership, curriculum or Didaktik explain the relation between individuals in terms of pedagogical interaction and influence? That is, if leadership and teaching is to influence somebody else, then what kind of influence are we addressing?

(b) How do we define the relation between education and society, i.e. the relation between institutional education and other societal forms of practice (e.g. politics, economics, and culture)? How are the dynamics between e.g. education and politics explained?

(c) How do we explain cosmopolitanism and education, i.e. (i) cosmopolitanism as an educational ideal as related to individual identity, multiculturalism, the nation-state and social cohesion and (ii) cosmopolitanism as transnational network relations between nation-states and between nation-states and various kinds of conglomerates, institutions, etc.?

The first question refers to nothing less than to the classical issue of individual's freedom in education. What does this mean? Few would accept that education would not be about influencing the Other or intervening in somebody else's experience of the world. But, how do we explain theoretically the kind of influence education has, be in terms of leadership or teaching? Obviously few would consider leadership to have causal effects, for the reason that typically the individual being influenced is considered as being able to interpret impressions, i.e. free. However, if we accept that the subject is radically free, then in what sense is influencing really possible? A radical interpretation of freedom would mean that everything was in the hands of the individual so to speak. The individual alone would determine the extent to which leadership has an influence. In educational theory, this problem is not new. In fact it belongs to the fundamental core questions in any educational theory and many attempts have been made over the centuries to establish a position between external determination and internal freedom from influence (Oettingen 2001; Uljens 2002).

So, according to e.g. Kantian transcendental philosophy of freedom, the individual is free to establish her relation to the world alone. The theoretical problem which arises from such a position is that it does not seem possible to influence somebody from the outside, rendering leadership and teaching impossible in principle. Instead, the individual would be radically free to determine the meaning of her dynamic and open relation (Bildung) to others, to the world and to herself. In this subjectivist, or subject centered, or Cartesian tradition, it becomes theoretically difficult to explain why the presence and activity of the Other would be necessary for learning to occur, for example. The alternative approach has been to decenter a subjectivist approach and start from a pure intersubjective position, meaning that the individual, from the beginning so to speak, shares something (language, practices, values) before an empirical self is established, i.e. that the subject not only comes to share the world through the process of education, but that the subjects from the very beginning shares something (Masschelein 1991). The problem following from such an radical intersubjective position is that to the extent the world is intersubjectively shared in some sense of the word reaching a shared world cannot be something education aims at. For example, educational theories could not start 
from subjects being linguistic as this is something we learn to become (Kivelä 2004). Philosophical anthropology may explain that being human is to share a language and be linguistic, that thinking is not possible without language (Herder), but educational theory must explain how we come to share the world (Uljens 2016). To the extent the world is shared education is not any necessary activity.

The second question concerns how a theory explains the relation between education and politics, economy and culture, respectively (Benner 1991). Through what processes do societal interests transform themselves into practices of schooling? What are the mechanisms and degrees of freedom involved in these transformational processes at different levels? For curriculum theory questions such as the above ones are frequent. More generally, the question concerns the reasons and aims for which (liberal) education is promoted by the political system. But the converse perspective is also crucial: what kind of education is considered necessary or valuable in order for Western democracies to survive and develop? In essence, we focus here on how societal reproduction and transformation should be understood, organized and directed as a relation between generations. It is difficult to think of educational leadership theory neglecting such a question, especially when the previous levels are widely identified as relevant. In this respect, educational not only curriculum theory but also leadership theory must communicate how the role of the school as a societal institution is defined with respect to politics, economy and culture.

The third question stems from the ongoing crisis of the nation state, due to a conglomerate of issues often discussed in terms of 'globalisation'. The idea of 'the autonomous individual in the independent nation state', most often based on language, has been an explicit organizing principle for state construction for around two centuries in many parts of the world. The legal independence of nation states as such has not been discussed but instead a number of transnational institutions and organisations as well as a global economical mechanisms, corporate interests and non-governmental organisations and agreements have come to question the autonomy of the nation state. Regarding internal ethnic pluralisation we note that the pre-modern, multi-ethnic, absolutist european monarchies operated according to economic principles of mercantilism and saw religion playing a crucial role for establishing unity. The gradually evolving modern nation state instead coordinated the idea of people as etnos (e.g. language, race) with the idea of people as demos (citizenship). Obviously education received a paramount role in such a state construction. Today, cosmopolitanism presents itself as a practical educational challenge due to global interdependencies. As we answer question c, then, we consider transnationalism in terms of the crisis of the nation state and introduce our two interrelated approaches to thinking about transnational relations as a theoretical ideal and now as an empirical reality.

Answers to these questions are derived from modern education theory/philosophy, educational leadership studies, curriculum theory/Didaktik, and discursive institutionalism as well as theories and analytical frameworks used to understand transnational relations (e.g. on Luhmann's system theory, Wallerstein's world systems theory, and theories of intercultural relations from cultural anthropology and cultural studies). 


\section{Understanding Pedagogical Interaction}

The first question concerns what kind of interaction educational leadership and teaching is about and how these activities may be related to those involved. As pointed out before, the position outlined here draws on the seminal studies of modern education theory and later developments thereof. In this tradition the concepts (a) recognition, (b) summons to self-activity, and (c) Bildsamkeit occupy a central position (Benner 1991; Mollenhauer 2014). These concepts are considered fundamental for the post-Kantian pedagogy of which the main outlines were drawn by Fichte, Herbart, Hegel, and Schleiermacher among others. In the english speaking literature the tradition these concepts reflect, has received rather limited attention although the situation is gradually changing (Uljens 1997a, 2001, 2002, 2016, 2017; Kivelä 1998; Oettingen 2006, 2016; Schaffar 2009; Siljander et al. 2012; Friesen and Sævi 2010; Friesen and Hamelock 2012; English 2013; Schaffar and Uljens 2015; Horlacher 2015; Saeverot 2016).

The development of "modern" educational theory was indirectly prepared for by renaissance to humanism and enlightenment. But not before the latter half of the eighteenth century those crucial shifts that still frame our contemporary pattern of thought were starting to develop. The period between 1760 and 1830, i.e. from Rousseau's Emile, over Kant and Fichte, Hegel, Schleiermacher and Herbart, is thus to be seen as marking the period in European theory of education when true steps to what here is called modern education theory was taken. In his Didactica Magna Comenius was still a confessional Catholic who saw the ultimate aim of education connected to the preparation for eternal life. This pre-modern cosmology was teleological in two ways. First, human individual development was to large extent seen as determined by eternal sin and, second, the future of the world was also determined. Pre-modern education was tradition-based and reproduction-oriented, it was about socialisation into existing societal patterns and practices.

Modern education theory developed as a response to the movement from a religious teleological pre-modern cosmology. During the second half of the eighteenth and first third of the nineteenth century the pre-modern teleological view of the world as created by God and heading towards its own end was replaced by a nonteleological view of both history and individual development. Teleological reasoning was abandoned in two respects. In modern education theory the future was no longer considered determined but open, education as socialisation into an existing world was therefore no longer possible. The subject was no longer seen as determined by original sin, but an unwritten page. The shift had dramatic consequences for explaining educational aims and practices as it had from now on to prepare for a future which in principle was not knowable. The new liberties introduced (freedom of speech and religion and later political liberties) required a new education concept to which the Bildung tradition was a response.

In theories of Bildung framed by Christian theology the mundane process of Bildung was about developing an innate potentiality or image of God in order to be prepared for eternal life. J.A. Comenius is a well-known representative of this view 
in his Didactica Magna in 1657 (Schaller 1995; Sousa 2015). Later, when the future was seen as dependent on our own activities, and based on autonomous thinking and ethically reflected action, rather than dictated by given, external norms or directed by some innate developmental patterns, a new kind of Self and self-awareness was required. The modernist discourse on Bildung met this need when cosmological teleology and nativism was abandoned.

As educational theory and curriculum theory works with how the question of aims should be dealt with, the change from a pre-modern closed view of the future to a modern open view of the future changed everything. Modern education theory assumed a non-teleological view of history and future. The new intergenerational question that emerged as a continuous task was "what does the older generation want with the younger" (Schleiermacher)? No given answer to that question existed any longer, it had to be negotiated and had therefore to be the topic for an ongoing public discussion. As no objective or given values existed then the individual had, by education, to be prepared and learn to live with the question of good life as an open question that can never be definitely answered. To learn to live with a question mark as one's companion, rather than an exclamation mark, was necessary as the subject that was to participate in constituting new laws to be followed by all, i.e. normative ethical relativism. Moral education could no longer be a question of leading the child to a given morality. Rather the child had to be led to the question of morality itself.

Modern education theory, then, faced a new type of pedagogical question: if the individual was free and the future was open then a theory about the learning process (Bildung) was maybe possible to develop, but what about a theory of education telling us something about what it means to educationally influence another individual? Education could no longer be about nurturing a given seed, nor could it be about formation for something predetermined. The question remained - exactly how do we theoretically explain educational interaction if the individual was radically free?

The Non-affirmative Solution to the Paradox of Education Human interactive influence has been considered as a core question in all theory of human action and interaction. However, throughout history of education the answers to these questions have been paradoxical in nature. For example, in Plato's philosophy what makes teaching meaningful for learning is not that external and eternal knowledge is communicated or transferred to the learner but rather that the learner reaches insight that he or she already possesses (nativism). To learn is, thus, paradoxically, to attain something one already possesses. Also for Kant (1992) education was paradoxical: How may education, in the sense of external influence (coercion), support the development of autonomous thought and action? (see e.g. Roth and Suprenant 2012). Differently expressed, modern education theory typically views education as an invitation or a provocation to self-reflection and autonomy. However, in order for the individual to reach autonomy in self-reflection abilities, he or she must, according to this line of reasoning, be recognized as already autonomous, free and selfreflecting (Benner 1991; Uljens 2002; Schaffar and Uljens 2015). In other words, in order for education to be possible, there must be a free subject whose reflection is 
provoked, but simultaneously it is thought that the individual becomes a free subject through the process triggered by an educational provocation.

So, in order for education to be possible, the individual must be born free, indeterminate and self-active, and simultaneously, in order for the individual to become free in a cultural sense of the word, education seems to be necessary. Using this argument for developing an understanding of educational leadership, it is assumed that the individual can reach cultural, productive freedom (the ability to act), only by being recognized and treated as if she already is free (or reflective, capable, trustworthy). Educational leadership is, therefore, understood as an recognizing invitation, intervention or provocation, a disturbance or expectation concerning the Other's relation to himself/herself, the world and others. Educational leadership is, then, to recognize somebody as if they are already capable of doing what they are supposed to become capable of - and to act accordingly (Fichte, Herbart, Schleiermacher).

Intersubjectivity Replacing Subjectivity? In order to understand post-Kantian education theory primarily initiated by Fichte and Hegel which came to lay the foundation for all relational theories emphasizing intersubjectivity and recognition, a further analysis needs to be highlighted. From a curriculum theory perspective this analysis is relevant by pointing at recent and strong critique regarding the so called Cartesian subject (Doll 1993a, b) according to which isolated individual rationality has been considered as the metaphor for human reflection. It has also been argued that the pedagogical paradox as such emanates from a belief in a transcendentally free, logocentric rational subjectivity.

There have been many attempts to decenter the subject-centered position by introducing a philosophy where intersubjectivity is made the point of departure (Masschelein 1991; Crossley 1996). Despite differences between philosophers like Arendt, Buber, Goffman, Habermas, Honneth, Mead, Merleau-Ponty, Levinas, Ricoeur and Taylor, all argue in favour of intersubjectivity as a core concept. There is no room here for a detailed analysis of how intersubjectivity is interpreted differently by each representative mentioned above, i.e. as language, as shared values and culture, as something corporeal or as shared practices. If transcendental idealism (radical freedom philosophy) was considered educationally problematic, as it may be interpreted as making educational influence impossible, other problems appear with an intersubjective position. All intersubjective positions have in common that before subjectivity, there is something that is shared. This can be language, norms, practices or culture. This seems a very reasonable point of departure as long as we talk about encultured subjects who already are in possession of e.g. language. The dialogical, collective communicative system is indeed something framing or constituting individual experience. One of the ideas here is a separation between the individual's acts and the meaning of these acts. The meaning of the individual's acts are thus partly made dependent on somebody else's interpretation. Taking part in these interpretations then helps the subject to identify herself differently. The intersubjective linguistic relation would thus be something that cannot be treated in reductionist manner explained by each individual's contribution. Instead subjectivity would be constituted through this intersubjective relation. 
The intersubjective position is attractive yet problematic as a foundation for education theory (Uljens 1997a, 2002; Kivelä 1998). The problem arises from that an intersubjective position assumes that we already share something - language, culture practices or something else. To the extent we already share something we cannot, by pedagogical means or otherwise, move into this shared world; we are already there. Obviously language cannot be made such a foundation as language. The argument that 'we are with others before we are with ourselves' (Biesta 1994) is sympathetic but problematic. It appears that we have, in the end, to accept some fundamental or rudimentary version of subjective awareness to explain how a shared world is possible.

A solution to this dilemma is to discern between different notions of subjectivity and different notions of intersubjectivity. As argued in more detail elsewhere (Uljens 2002, 2008) we may discern between pre-linguistic subjectivity, cultural subjectivity (identity, me) and (self-)reflexive subjectivity. Correspondingly we may discern between corporeally constituted (pre-linguistic) intersubjectivity, linguistic or cultural intersubjectivity and (self-)reflexive intersubjectivity. While the first two forms are given by birth the following forms are empirically established first through socialisation while the last forms of subjectivity and intersubjectivity typically require educational support in order to develop and is also something that formal education aims at starting from pre-school to university education. In this educational process the empirical Me as well as shared practices, values or communicative patterns, ways of understanding the world are made the object of reflection. There is thus no reason to substitute a subjectcentered position with an intersubjectivism or relationalism. Rather these two perspectives complete each other, especially if we identify versions of these concepts as above. Instead of defending a reductionist approach pointing either at subjectivism or relationalism a complementarist position is regarded more fruitful. Accepting complementarism within and between notions of subjectivity and intersubjectivity helps us to identify those spaces where primary socialisation and education play a role (see Uljens 2015). In line with this, the individual would be recognised as being non-determined, free, but that reaching cultural freedom, to pursue one's aims would require an empirical other. In the hegelian tradition, the Other predates the birth of self-consciousness in that the self becomes an object for herself only mediated through the Other.

Following Benner (1991), Kivelä (1998), Oettingen (2001), and Uljens (1998, 2002) the move from Cartesian-Kantian transcendental concept of freedom to an idea of the subject based on mutual recognition and mediated freedom (focusing the ethical) was proposed by educational philosophers such as Fichte, Herbart, Schleiermacher and Hegel. These philosophers herald the end of the one-sided idealist philosophy of the subject, transforming it into a position understanding relationality or intersubjectivity as constitutive, in addition to transcendental freedom. It appears to be less known that the critique of logocentric rationality and that the decentering of the Cartesian subject is not anything recent but that occurred rather early in the educational theory (Benner 1991; Uljens 2002). In the following we return to how this topic was brought on the agenda by philosophers central to the development of modern education theory. The seminal discussion also helps us to 
see where the crucial demarcation lines are drawn. Philosophy combining subjectivity and intersubjectivity emerged historically partly through attempts to explain how education was a necessary intervention in the Other's process of Bildung for the subject's reaching of cultural freedom. This position was capable of explaining both the possibility and the necessity of pedagogical interventions without this being in conflict with individual freedom or the radical openness of the future. Fichte's innovation was to see consciousness of freedom as intersubjectively mediated by the Other as the self becomes aware of itself as free, experiences herself as free, only by being recognized by another (Williams 1997). The concept of recognition was developed further by Hegel and has influenced much later developments in education theory, for example, Mead and Dewey.

Recognition The origins of the concept recognition may partly be found in a modern, classical, theory of education, i.e. within a theoretical-philosophical context of the later enlightenment. It is often associated with Fichte's and, in particular, Hegel's philosophy. Although the concept has inspired many it has nevertheless long remained on the fringes of pedagogical discussions. The past two decades, however, the situation has changed through works by and inspired by Axel Honneth, Jürgen Habermas, Charles Taylor, Nancy Fraser, Judith Butler, Emanuel Levinas, Jaques Ranciere, and many more (e.g. Honneth 1992, 1995; Fraser and Honneth 2003; Taylor 1994; Levinas 1992; Williams 1997; Cobben 2010). Yet, the relation between recognition and some basic concepts in educational theory remain unclear. Also, what exactly is referred to by recognition varies. For instance, does recognition primarily refer to assumptions behind educational activity, e.g. that the subject has to be considered free or nondetermined, thus making pedagogical activity meaningful, or does it refer to some quality or dimension of the actual activity itself, i.e. that education would be about recognizing the present state of somebody, or, still, has the concept rather to do with pedagogical objectives? In this last case, recognition would be seen as a result of an educational process, for example that the subject experiences herself as being recognized. From the above we can see that the concept may refer to the premises, to the process, or to the results of pedagogical processes.

Recognition and Intersubjectivity in Seminal Education Studies In a historical perspective a crucial step for developing the notion of intersubjectivity in educational theory was taken by J. G. Fichte in 1796 who developed a severe critique of Kant's way of explaining self-consciousness of freedom. How does such a selfawareness develop? How do individuals come to understand themselves as free agents whose action is directed by themselves? Kant's explanation was that human beings are free to make choices. Thus he assumed that the individual can follow or not follow the so called moral law he thinks humans are aware of a priori, i.e. before experience. According to the categorical imperative the individual should only act according to principles that could be made universal laws. Further, the individual should never treat other human beings only as means to one's own ends. For Fichte the critical point Kant is referring to is a given awareness of the moral law (Fichte 1796/1992). In doing this, Fichte argued, Kant thereby, in fact, assumed an intersubjective life-world. 
Thus, Fichte's innovation was to realize that consciousness of freedom was in fact intersubjectively mediated by the empirical Other. Here the Self becomes aware of itself as free (experiences herself as free) by reference to the Other, i.e. by being recognized and treated by another as having the potentiality to move beyond her present state (Uljens 2002; Williams 1997; Pinkard 1994). In his Foundations of natural right Fiche $(2000, \S 10$, p. 102) defines the original right as follows: "The principle of any judgement of right is that each is to limit his freedom, the sphere of his free actions, through the concept of the freedom of the other (so that the other, as free in general, can exist as well". Here human rights, considered as universal (natural) rights, are made the foundation for the establishment of self-awareness. The individual has the right to be recognized as free. In addition, recognition of this original freedom and these rights does not suffice according to Fichte; in addition, the individual recognised as free has to be treated accordingly. What makes Fichte's argument interesting for educational and leadership theory is that he introduces the concept of Summoning to self-activity (Aufforderung zur freien Selbsttätigkeit) or the summons to engage in free self-activity. Based on a recognition of the individual's freedom and her rights the individual is invited to put her freedom in use. To be summoned to free self-activity means that the individual is expected to express her view and make decisions on her own part, based on one's own will. It is through this the individual comes to be aware of herself as having a will that is free. We can thus see that the Kantian self-awareness of the moral law is disregarded as the point of departure, rather an empirical other is introduced to explain self-awareness. Although summons to self-activity is considered necessary it never determines the outcomes: "rather, the rational being is to determine itself in consequence of the summons" (Fichte 2000, p. 35). However, in order for the individual to determine the consequences of the summons by herself, we must assume, as Fichte explains, that the individual at some level perceives the summons, which means that we have to assume some prior cognition. Fichte (2000, p. 35) writes: "Thus the external being that is posited as the cause of the summons must at the very least presuppose the possibility that the subject is capable of understanding and comprehending; otherwise the summons to the subject would have no purpose at all". In Dietrich Benner's (1991) formulation of this position education would, then, be about to treat the other as if he or she already is capable of doing what he or she is supposed to and may become capable of. Both recognition and a summons to self-activity are fundamental categories for understanding that the empirical freedom is intersubjectively mediated.

Even if J. G. Fichte, in his lectures from 1796, defines recognition as a mutual assumptional acceptance of each other's freedom, he simultaneously introduces the concept summons to self-activity as a fundamental category for understanding a human being's becoming human. This original freedom is not a gift given to the Other that we must recognize or refuse. Yet, through his critique of Kant's transcendental freedom Fichte introduces the idea that the empirical freedom is intersubjectively mediated through recognition and a summons to self-activity. The subject's empirical autonomy and experience of him or herself as a being of free will instead becomes dependent on the empirical Other, a position that Hegel develops further 
and which today constitutes the reference point for, for instance, Charles Taylor's and Axel Honneth's work. In this spirit, Axel Honneth, for instance, identifies three hierarchically related forms of needs of recognition that correspond to three "practical self-relations." Consequently, (i) love of home/parents/caretakers is necessary for the development of a fundamental self-confidence (Selbstvertrauen). The civil society (ii) recognizing the individual as a morally responsible legal subject, i.e., as having legal rights and responsibility for his or her actions as well as being a political citizen (respect for the freedom of will, freedom of expression, ownership), leads to self-respect (Selbstachtung). Finally, (iii) the individual would strive to be esteemed and recognized (self-esteem, Selbstschätzung) for the work he or she has performed or achievement in society.

In Charles Taylor's (1994) interpretation, to recognize another person with regard to a certain feature (e.g. race/ethnicity, gender), as a free or autonomous agent, you not only admit that he/she has this feature but you embrace a positive attitude toward him/her for having that particular feature. Such recognition implies that you bear an obligation to treat him/her in a certain way. In other words, you recognize the normative status of the other person as a free and equal person, but recognition transcends normativity. Misrecognition is the opposite, a relation that hinders or destroys persons' successful relationships to themselves (Fanon 1963). Fanon (1963), for instance, demonstrated the ways in which victims of racism and colonialism have suffered severe psychological harm by being demeaned as inferior human beings. Taylor and others have recently applied theories of recognition to struggles for particular identities (e.g. politics of difference around gay rights, ethnic or religious recognition, women's' rights, rights of differently abled individuals). Here justice is not primarily concerned with material goods but rather what kind of standing other persons deserve (Young 1998).

From the perspective of a non-affirmative theory of education it makes sense to clearly include the concept of 'summoning' (Aufforderung) in relation to recognition. Without a concept for pedagogical activity the concept of recognition runs the risk of becoming too wide and why the nature of the educative act remains unclear. Now, in order to identify pedagogical and educational (leadership) actions among all possible mediating actions (e.g. care), we draw on the concepts of summoning to self-activity and Bildsamkeit (Benner 1991; Mollenhauer 2014; Uljens 2002, 2015).

\section{How Pedagogical Interaction is Explained: Summoning to Self-Activity and Bildsamkeit}

The dramatic shift to modern philosophy of freedom presented itself as a difficult problem to be solved educationally as freedom could be interpreted in two opposite ways. We could, first, assume that leaving determinism for freedom philosophy results in an unrestricted possibility to influence the learner. But also the opposite interpretation is possible: this very freedom made education as external influence impossible, because how could anybody influence such a self-constitutive subject? 
How should one navigate, i.e. theoretically explain, what educational influence was about as determinism and radical freedom were educational unacceptable? Siljander (2008) draws attention to that Herbart's contribution was to introduce the idea of pedagogical causality to overcome the antinomy between freedom and coercion, between the causality of nature and the causality of freedom. The concepts Bildsamkeit and summons to self-activity have a bridging function for Herbart.

Summoning to Self-Activity The concept of summoning explains how a teacher or a principal has a mediating role with respect to the Other in the maintenance and development of the Other's self-relations. In order to identify pedagogical and educational leadership actions among all possible mediating instances, we also draw on the concept of summoning to self-activity. This concept explains how the school, teacher or a principal has a mediating role between the culture and the individual in the maintenance and development of the Other's self-relations. According to Fichte (1796), summons should be understood in a very specific meaning; we cannot summon somebody to gain an original state of consciousness. Rather, summoning assumes there is a somebody to be summoned before. Summoning should be understood only as an invitation to the Other's self-activity. An act of summons is the impulse to cultural self-reflection made on the part of a reasonable human being in developing into a culturally reasoning subject. In terms of school leadership, the act of invitation or summons is directed to toward a teacher or student's potentiality and invites the latter to become through own activity to become aware of his own freedom as a cultural and political being and ability to realize his own aims.

Bildsamkeit For Herbart Bildsamkeit was "ein Übergehen von der Unbestimmtheit zur Festigkeit", i.e. a movement from non-determinedness to firmness, a process through which the individual develops a personality. While Bildsamkeit often has been translated with referring to the learning ability or developmental capacity, also plasticity, it rather refers to that the individual is first recognized as being nondetermined (Bildsam), but second, being invited or summoned to make use of this freedom taking action during the pedagogical process (Benner 1991). Thus Bildsamkeit refers more to a process than to a state of mind (capacity). Bildsamkeit is about the learner's own intentional but relational activity rather than a process that happens to the individual. Studying, in terms of trying to move beyond one's present state, is an intentional activity, that the learner is invited to engage in, while 'learning' is something that 'happens' with us. Learning is something we typically experience when it has happened. Finally, Bildsamkeit is thought of as making possible that very activity of the learner that is occasioned by a corresponding act of teaching, leadership or education. Due to the close connection between educative activity and the learner's own activity Bildsamkeit has been conceived of as a relational concept that is connected to teaching (Mollenhauer 2014; Benner 1991; Uljens 1997a; Siljander et al. 2012).

While 'summoning' may be seen as a teacher's invitation of the learner to become engaged in a self-constituting and self-transcending process, Bildsamkeit refers to those latent capabilities made real through intentional efforts which individuals aim at making sense of the world and their experiences, given the summon- 
ing. The point is thus that this summons to free self-activity contributes to the establishment of a shared and mutual sphere, or a space wherein the subject may come to see the world in another light. The principle of Bildsamkeit, then, also means that the learner is recognized as a subject with a current potentiality for selftranscendence. But this potentiality is realized by the learner in and through the pedagogical space that is created through the summons to self-activity. The principle of Bildsamkeit refers to individual's own processing of one's experiences - ones relation to the world, others and oneself - through their own activity (Benner 1991, 2005; Uljens 2002). Pedagogical activity or summons to self-activity, then, means that the subject's potentiality for empirical freedom and world-relations are recognized (the principle of recognition, Anerkennung) and then intervened by a pedagogical act so that learners become aware of themselves as free to make use of their autonomy to become and develop as cultural beings.

This reasoning emphasizes that self-understanding in a wide sense is essentially dependent on social recognition, as for instance Honneth (1995) argues, while social recognition does not determine anything. If the individual's self-image is dependent on and is established through interaction with others, and if these dimensions of self are viewed as rights, it follows that pedagogical activity can be viewed as a response to the moral and political demands resulting from the recognition of these rights (Uljens 2016). The self is thus simultaneously both free and dependent, both as regards itself and others. Therefore, it is apt to say that the continuous selfforming (Bildung) process is about having learned to answer continuous questions of who I am, what I can do, know, and want.

It may be good to observe that pedagogues in their summons cannot assume or presuppose a shared life-world or some form of mutuality (symmetry) between the Self and the Other (intersubjectivity) as a starting point for education. Symmetry, or the negation of asymmetry, in the form of establishing a shared life-world, is rather something that is sought after to make real through the pedagogical process. But also the opposite is true. In their summons of the learner, teachers cannot exclusively take for granted there being a radical difference (asymmetry) between the Self and the Other, partly because corporeal intersubjectivity is accepted and partly because an asymmetry (individuation) is, in fact, something which is also sought through the pedagogical process. A "sought-for asymmetry," that is, the negation of symmetry, refers to the aim of the pedagogical process, namely that the individual develops uniqueness in a cultural sense, a uniqueness that did not originally exist.

Non-affirmative Summons A difficult question in all educational theory and practice is the question of norms and normativity. Few accept that educational practice and school development is value-neutral. On the other hand, if education would about socialisation of learners into given sets of values the freedom of the individual is violated and education would be counter-productive with respect to the aims of democratic society. The normativity dilemma is present and has to be solved both regarding constructing national curricula, in evaluation practices, in leadership and in teaching. The question is then how a theoretical position may look like in order to avoid turning education into technology or normative socialisation? As we have 
seen conservative theories tend to promote socialising into something existing for reproductional reasons while theories led by ideals for the future for transformational reasons both run the risk of turning education into a technology. Yet the challenge is there. Education must prepare for the world as it stands and for a future one. How can this be done without violating the learners' self-determination?

We defend a so-called non-affirmative position with respect to norms (see e.g. Benner 2005; Uljens 2002). This means that existing knowledge, values or ideals are definitely taken seriously but not necessarily affirmed. Non-affirmative education also means then, in the pedagogical situation, to focus on the questions to which existing practices, norms or knowledge are seen as answers. Through this the learner is thought to acquire a relation not only to given answers (positive knowledge), but also to the questions behind the answers. Of equal importance is the ability to learn to formulate new answers to old questions as well as new questions to be answered.

Affirmative education means that the practitioner confirms, in a rather unproblematic fashion, either the present situation or the learners' life-worlds, or the aims and content of schooling, reflecting the contemporary needs of society. Affirming a given reality, given values or future ideals can mean to uncritically relate one's professional practice to these. A version of affirmative teaching would have to be concerned with an expectation that learners absorb the given content of teaching, without teachers paying attention to the fact that curricular content in educational settings primarily serves as an example or means to support the development of principled insight, something for which the content is exemplary as such.

An affirmative attitude ends up having a fundamental dilemma: to the extent that aims are given and accepted, educational leadership and teaching is expected to follow a technical rationale. Such a (Tyler) rationale measures quality in terms of efficiency and efficacy. Non-affirmative summons involves a critique of both socializing and normative education. In accordance with this, in, for instance, emancipatory pedagogy, also called critical pedagogy, pedagogues tend to think they know and have the right to decide what students should be liberated for. A non-affirmative summons to self-activity, in contrast, highlights that the education process is dependent on an experiential address, but that when this provocation is a pedagogical the pedagogue consciously refrains from naively confirming either a prevailing or ideal future condition. With such a self-reflecting pedagogical discernment, the pedagogue is thought to be better able to create a space for an education process that recognizes the learner's self-activity and right to exercise conscious independence of thought so important in and for a democratic society and for developing oneself and one's culture in other respects. Also, in a non-affirmative view what "democracy" means, is or should be is an open question. Therefore, if democratic education aims to prepare the learners for democratic participation by mimics of such practices, one must understand the limitation of such methods.

Non-affirmative education that seeks to allow the learner to identify and deal with those problems to which existing knowledge is the answer (and also to assess the value of the existing problems) thus aim at preventing or restricting learners from unreflectively dedicate themselves to cultural content, practices, specific skills 
or concepts. In this limited sense, education is about hindering learning. A pedagogical activity which is educationally reflective presupposes that the school as a social institution is allowed enough free space for the establishment of necessary pedagogical fields of action in relation to other social interests.

The Paradoxical Nature of Non-affirmative Education With respect to the dichotomy between curriculum models emphasizing either learning of contents as such or curriculum models emphasizing learning of generic skills or concepts, a non-affirmative position would start from not affirming any of these ambitions as such. Instead, the educational activity would aim at working on the relation between the above curricular aims in connection to the learner's experiences. In nonaffirmative theory learning contents always also aims beyond itself. Working on the contents typically aims at a cultivation of more general capacities (self-concept, will, moral reasoning, identity, etc.) but also at identifying the principled meaning that a specific content exemplifies (Klafki 1994). That is, the modern tradition holds that selection and treatment of contents should also serve educative purposes beyond learning the subject matter itself (for Herbart's 'educative teaching' see Siljander 2000; Somr and Hrušková 2014). Learning generic skills or knowledge in turn occurs through working with contents, but focusing on generic knowledge can also work as a selection criterion for choosing curricular contents. Here the teacher's task is to extrapolate the educative power or qualities (Bildungsgehalt) of the selected contents (Bildungsinhalt).

The reason to why non-affirmative pedagogy reminds of pragmatism (Dewey), neo-pragmatism and deliberative democracy (Habermas) consist of their common roots. Both positions argue that there is an interdependent relation between education and politics. Also deliberative democracy requires individuals capable of participation in such a democracy. However, from a non-affirmative education theory perspective, a theory of how deliberative democracy works is something else than a theory of educational preparing for participation in such a democracy. If this distinction is not identified there is a risk of ending up in socialization pedagogy again, now with deliberative democracy as the directing norm. Education theory would then be about drawing implications and developing prescriptive recommendations for how teaching should be organized.

Non-affirmative approaches to educational leadership would be focused on creating a professional school culture where individual learners learn about what it means to find a voice of his/her own and what it means to develop towards democratic citizenship. Here the learner learns to make use of his/her own productive freedom. Insofar as district leaders and school principals act accordingly, they mediate between governance mechanisms, interpreting and translating them in dialogue with teachers. In such a process, the use of positive knowledge of e.g. new legislation or curricula may be focused towards not only understanding them as such but also towards reaching the questions or interests to which existing policies, norms, or practices are seen as answers or responses. An educational leader in this case invites (summons) colleagues or even the public to engage in reflective self-activity (Bildsamkeit) in order for them to transcend what is given. A non-affirmative sum- 
mons to self-activity highlights that the education process is dependent on an experiential address, but that when this provocation is a pedagogical the pedagogue consciously refrains from naively confirming either a prevailing or ideal future condition. With such a self-reflecting pedagogical discernment the pedagogue is thought to be better able to create a space for an education process that recognizes the learner's self-activity and right to exercise conscious independence of thought. Nonaffirmative education that seeks to allow the learner to identify and deal with those problems to which existing knowledge is the answer (and also to assess the value of the existing problems), thus aims at preventing or restricting learners from unreflectingly dedicate themselves to cultural content, practices, specific skills or concepts. In this limited sense education is about hindering learning. A pedagogical activity which is educationally reflective presupposes that the school as a social institution is allowed enough free space for the establishment of necessary pedagogical fields of action in relation to other social interests (Uljens 2016).

An educational leader who supports the identification of questions behind provided answers may result in the development of an ability to formulate alternative questions and agendas. Finally, it is to be observed that "summoning to self-activity" operates within (horizontally and between (diagonally and vertically) in institutional settings. Thus, we consider leadership as occurring within and across multiple institutional levels.

Using this argument for developing an understanding of educational leadership and curriculum work as they operate in educational/societal institutions, it is assumed that the individual can reach cultural, productive freedom (the ability to act), only by, paradoxically, being recognized and treated as if they are already free (or reflective, capable, trustworthy). Educational leadership is, therefore, understood as a recognizing invitation, intervention or provocation, a disturbance or expectation concerning the Other's relation to himself/herself, the world and others.

Following Dietrich Benner's (1991) theory of education, educational leadership would, then, be to recognize somebody as if they are already capable of doing what they are supposed to become capable of - and to act accordingly (Fichte, Herbart, Schleiermacher). This may result in learning on the part of the Other, but this is an open question. Teaching or educational leadership is not causal in nature. The nonaffirmative alternative argues that the growing individual is treated as though he or she is already capable of doing that to which he or she is summoned, and as someone who realizes his or her empirical freedom through his or her activity (Benner 1991). To say that pedagogical activity is to treat somebody if she already would be capable of that very thing one expects somebody to become capable of may at first sight be odd. A simple but strong example is when children learn the language or practical things like riding the bike. Parents and caretakers talk to the child as if she already would understand what he or she may start to realized through the process itself. The child only learns her being an individual with a name by being addressed as an individual having this name.

In this case, recognition is not only about recognizing a specific ability or competence, but about behaving toward the Other in an opportunity-identifying way. When Herbart refers to the concept of pedagogical tact, the intention is to demon- 
strate that summons not only falls back on the recognition of the freedom of the Other or the Other as worldly subject, but that summons must, in order to work, be experienced as reasonable by the Other. Through such a thought-provoking but sensitive activity, the educator recognizes the subject's empirical reality, life situation, as well as his or her self-expression and potentiality. However, nothing of this is affirmed, but rather challenged. Education more often aims at creating a headache, rather than at curing it.

The non-affirmative position (Benner 1991) outlined here must be further discussed but this theorizing shows that we in our educational theory tradition find ideas how to avoid the dichotomies between conservative reproduction oriented and normative transformation oriented curriculum theory, as well as descriptivetechnological approaches to teaching and curriculum work.

As we have seen from the above, curriculum theory and educational leadership cannot be limited to dealing with a theory of Bildung alone, but must explicitly and in parallel deal with a theory of education (pedagogical influence) leading us to different versions of the pedagogical paradox.

An act of summons is the impulse to cultural self-reflection made on the part of a reasonable human being in developing into a culturally reasoning subject. In terms of school leadership, the act of invitation or summons is directed to toward a teacher or student's potentiality and forces the latter to become aware of his own freedom as a cultural and political being and ability to realize his own aims. Education works with this double openness; the educator lives with the unanswerable question.

These concepts refer to a modern tradition of relational theory of education and form core concepts for educational acts in terms of summoning (inviting) the Other to self-activity (Bildsamkeit). 'Summoning' may be seen as the leader's or teacher's invitation of the Other to become engaged in a self-transcending process. In terms of school leadership, the act of invitation or summons is directed to toward a teacher or student's potentiality and forces the latter to become aware of his own freedom and ability to realize his own aims. In sum, the very same core concepts may be laid out as foundational for both teaching and educational leadership as human interpersonal practice. In fact, educational leadership as culture building or curriculum management, as example, is a process of intentionally creating professional working conditions and circumstances for colleagues to reconstruct their professional identities and capacities.

\section{Non-affirmative Theory and Critical Hermeneutics}

The non-affirmative education theory outlined here may also be clarified in relation to hermeneutics and phenomenology. Hermeneutics is relevant for non-affirmative general education theory for at least three reasons. First, the process of Bildung is traditionally perceived as the subject's dynamic relation to the world, to others and to herself. It includes an experiential (Ge. Erlebnis), a reflexive dimension and communicative dimension (cf. Ricoeur 1976; Kristensson Uggla 2010; Kemp 2010). 
In this process the subject develops both a personal and a cultural identity, i.e. a sense of self (Me) and sense of belonging (We). In English 'experience' refers to both the sensations one has and the experiences resulting from reflecting upon these sensations. In many other languages this difference is denoted by different concepts. The process of Bildung can now be seen as a change in one's experiences and identity. A change in experience may, with e.g. Gadamer (1975) be described as a loss, inasmuch it may be described as reaching of something. In the process of learning the negativity of experience may refer both to experiencing a dissonance between one's perception (Fi. elämys, Ge. Erlebnis) of the world and one's experiences (Fi. kokemus, Ge. Erfahrung), or to the actual loss of a previous way of understanding the world requiring a possible reorientation (Uljens 1992; Benner and English 2004; Marton 2014). Second, all of the above regarding Bildung as an interpretative process is equally valid for the leader and teacher. The leader and teacher stand in the very same position as any learner. Here the teacher/pedagogue, as an interpreting subject, also stands in an open relation to the world, others and herself requiring continuous interpretation of experiences. This is the teachers' or leaders' interpretative, meaning making process -process of Bildung. Third, the leaders and teachers are, however, expected not only to interpret the world for themselves, but also to explicate or communicate their understanding with the learners - the culture is mediated by the educationalist. When this mediation is carried out by the leader or teacher, it has to be done with the learners contemporary experiences and experiencing in mind, but also the learner's future. This explication is thus carried out and guided by pedagogical intentions. Educative leadership and teaching requires simultaneous awareness and recognition of many things, e.g. curricular expectations, the surrounding culture, and the learner's experiences - especially the learners' (phenomenologically seen) intentional object of awareness and her intentional activities aiming at reaching insight, i.e. the teaching-studying-learning process. Following the idea of a non-affirmative summoning the leader's and the teacher's intention would thus be to reconstruct or to open up for what is believed to be "educative" qualities of a selected learning contents in an invitational way from the learner's perspective. The truly educative qualities are therefore an emergent dimensions of the relations established, rather than something essential inherent in the contents as such (Klafki 1963). In a peculiar way the concept of Bildung aims at connecting the individual experience, the subjective, and the cultural contents, the objective, in ways that makes this contents accessible for the learner, yet in an interpretational way connected by the concept of meaning.

Non-affirmative leadership and teaching features not only the interpretative but also the mediating moment as developed in hermeneutics. The interpretative, sometimes mimetic, moment includes a reflective dimension, or rather is reflection, given in and through the non-affirmative act. Differently expressed, leaders and teachers experience external expectations, curricular interests and the like, but are not necessarily expected to affirm these interests. The 'tradition' exerts a normative force but in a non-affirmative light the individual interpreters are regarded able, not to stand out of the tradition but to making it an object for educative purposes. The tradition is recognized yet not affirmed. Would contemporary interests and the tradition be 
expected to be affirmed, the result might be manipulation and indoctrination rather than educative leadership and teaching. The explicative moment in hermeneutics, or, in other words, mediational, communicative re-contextualisation of understanding, corresponds to the concept of situational non-affirmative summoning to selfactivity reminiscent of Herbart's 'educative teaching' (Benner 1997; Uljens 2000). Educative leadership thus directs the followers attention and reflection to the problems at hand not only for seeking perhaps a practical solution for a problem at hand but also in order to support the development of discerning thought, which, in turn may orient the actor's future activity. Educational leadership that is educative in nature engages the learner in a process aiming at developing her professionality.

It is not much of an innovation to point out similarities between hermeneutics and Bildung, either as philosophical anthropology or as a language for interpretative processes in human learning or as an epistemological position for empirical research. Here the point is rather to observe that both theory of Bildung and hermeneutics typically starts from the perspective of the individual doing the interpretation or learning - there is always a somebody, a who. If the connection between hermeneutics and Bildung is more developed, a corresponding concept of hermeneutic teaching or leadership is much less studied. Therefore the contribution here is to remind of teaching as being congruent not only with the process of interpretation and understanding, which indeed is required, but the process of explication, which is also to be seen as a interpretative, but reconstructive initiative. Let us take one step back to see the logics of the above argument.

Important steps regarding hermeneutics were made since the eighteenth century in Germany as during the first half of the nineteenth by e.g. Friedrich Daniel Ernst Schleiermacher (1768-1834). His Hermeneutics and critique (Hermeneutik und Kritik) from 1838, published by his students 4 year after his death, significantly contributed to the development of hermeneutics as an empirical method, making hermeneutics a study of any texts, not only those connected to jurisprudence (law), linguistics and theology (Uljens and Mielityinen 2004). The view that hermeneutics is about studying texts is still widely supported (Palmer 1969). Being located between enlightenment and romanticism Schleiermacher was influenced by Hegel's dialectic, however without accepting Hegel's teleological view of historical development. It is vital to understand that Schleiermacher also was one of the major contributors to modern education theory, most famous for his Lectures in Education from 1826 (Schleiermacher 1826/1983). For him, as for Humboldt, Bildung was a concept referring to a dynamic relation between the individual and the world where the individual was by 'spontaneity' always directed to the world but simultaneously experiencing the world through 'receptivity'. The task of humanity, as Herder and Humboldt also argued, was to be involved in a continuous self-forming process. This tradition of theorizing beingness in the world constitutively including interpretation was later, in different ways, continued by e.g. Heidegger and also Gadamer.

Theory of Bildung and hermeneutics may include ideas about being from a philosophical anthropology perspective as well as theorizing what it means to interpret the world. From a Bildung perspective interpretation and understanding are then constitutive in defining human being and becoming, essentially connected to judg- 
ment, a view shared by also american philosophers like Charles Pierce, John Dewey and William James as well as Richard Rorty.

Theory of education includes the task of explaining how we think educational or pedagogical activity is related to a process of Bildung. Turning to hermeneutics is helpful for two reasons. First, obviously, also the leader is a subject interpreting the world. The process of Bildung, i.e. the unfinished or ongoing interpretative process in which the individual stands in an active position regarding herself, and the surrounding world ('spontaneity') as well as in an experiencing relation ('receptivity') is equal for all. However, in order to conceptualize educative activity we turn our attention towards our attention to the second moment of hermeneutics. This second moment or step of hermeneutics refers generally taken to explication, communication or the justification side of the interpretative process, methods and its results, understanding. In hermeneutics it has been disputed whether this second moment should be included in the act of hermeneutic interpretation or not. While Schleiermacher defined the task of hermeneutics primarily to be about the act and methods of understanding this corresponding to the process of Bildung, many hermeneutic theorists both before and after have, in addition, emphasized both moments of interpretation: understanding and clarification (Gallagher 1992).

From an educational perspective this second moment of hermeneutic interpretation, i.e. clarification, makes sense in that it does emphasize that e.g. a teacher or a school leader is not only carrying out an interpretative act in his or her own interest. Instead, the educational value of an (re)interpretation lies in what sense an this understanding arrived at may be helpful in supporting designing and carrying out a process aiming at enabling others in reaching beyond their experiences. This second moment of interpretation is closer to a pedagogical task despite the obvious differences between communicating one's results from empirical research within a "context of justification", which is driven by epistemological argumentation regarding validity and truth rather than by pedagogical motives.

Carrying out educative activities may be seen as a mediation between the learner and the world. The leader or the teacher stands in an interpretative relation to the learner, to the world and to herself. Within an already existing intersubjective space or shared world, the pedagogical leader reconstructs given cultural contents in a communicative interaction with the Other, aiming at establishing a second, "pedagogical space' (Uljens 1997a, 2002, 2016). Seeing pedagogical leadership in this way connects to earlier theorists in hermeneutics having emphasized the two moments of interpretation, namely understanding and explication. With some reservations, we can talk about a context of discovery for developing an understanding and a context of situated pedagogical justification where the contents is conveyed with educative intentions. Carrying out educational leadership or teaching the situation is radically open. As the responses and the outcome is not knowable in advance the leader and teachers are making continuous reinterpretations along the way, asking for the Other's intentions, experiencing, reflections, experiences (Uljens 1997a). In 'pedagogical explication', creating a space for Bildung, also continuous interpretative activity is present. Non-affirmative leadership is therefore both experiential and experimental. 
Teaching, according to Schleiermacher, was about protecting the child from outer less positive influences so that the inner good qualities could develop. 'Counteracting education' in turn was about working against individuals' less positive initiatives. In addition the teacher had to support reflection and development of competencies. Regarding ethics, Schleiermacher's idea was primarily about helping the subject to learn with the question of good life as an open one. Although education was an intentional act, it was not about being normatively closed, bringing the learner to a predefined understanding.

\section{The Other and Summons as Responsible Response}

As has been argued elsewhere this reconstruction of the modern education theory includes intersubjectivity and subjectivity as parallel non-excluding or complementary categories (Uljens 2001, 2015). Instead of making either intersubjectivity or subjectivity the ultimate point of departure it is possible and meaningful to accept both simultaneously. This requires, first, that different notions of both subjectivity and intersubjectivity are identified and, second, that we see how they are related to each other.

There is, however, a widespread understanding that this modern tradition represents a kind of subjective idealism which must be replaced by accepting intersubjectivity as the first philosophy or then replaced by some other way of decentering the so called Cartesian subject. Indeed a radical subjectivist epistemology is problematic in that the Self subordinates the Other, reducing the Other into being experienced by the Self. This is the fundamental problem of phenomenology. A decentering of such a view is represented by Emmanuel Levinas. Levinas turns around this subject-centered position in two ways by replacing epistemology with ethics and the primacy of the Self with that of the Other. As a result, by experiencing the Other the Self is awakened to awareness of one's responsibility. As formulated by Levinas, the face of the Other appeals to the Self to welcomingly open up for the Other, whereby the impregnable 'otherness of the Other' is simultaneously recognized. Here it is the Self that is summoned by the Other, through the Other's mere presence. The advantage with Levinas's position is that it draws attention to the Self as depending of the Other, but at the same time, this is interpreted as a reversed onesidedness in relation to the subject-centered tradition that Levinas critiqued. From a pedagogical perspective, Levinas's position is also limited.

Against this background, pedagogical activity, summons, can nevertheless be interpreted as the way in which the Self handles the responsibility to which we awaken through the presence or address of the Other. With Levinas, also the Self/ pedagogue is reminded of its/his or her "infinite" responsibility to respond to how the Other should be treated. Levinas's suggestion that the Other awakens the Self to responsibility simultaneously means that a reflective behavior is demanded of the pedagogue. How should I conduct myself? What does my responsibility involve? What constitutes a reasonable summons? 
It is possible here to discern a similarity or a point of convergence with the nonaffirmative summons: the non-affirmative summons is a reflected pedagogical act in the form of a full expression of a responsibility, and as such aware of its fundamental opportunity for affirmative or socializing teaching as well as prescriptive education, that is, freedom-depriving rather than freedom-developing pedagogy. The non-affirmative pedagogy that seeks to allow the Other to deal with the problems to which existing knowledge is the answer (and also to assess the value of the existing problems), and with issues about the good life, thus works to prevent the learner from unreflectingly dedicate to him or herself cultural content, and therefore represents a kind of restrictive pedagogy. A pedagogical activity which is ethically reflective presupposes that the school as a social institution is allowed enough free space for the establishment of necessary pedagogical fields of action in relation to other social interests.

Educational awareness could then be defined as the Self recognizing the unapproachable "Otherness" of the Other, but simultaneously viewing herself as an Other for the Other. The self-reflectivity of pedagogical thinking therefore means that the Self is forced to reflect on its I-ness and ask for its otherness from the perspective of the Other (who am I, what do I want, how does the other experience me?). In this way, the Self is and becomes both free and dependent on the Other.

According to this advocated perspective, there is also a pedagogical paradox, but in a new version. It implies that the growing individual is treated as though he or she is already capable of doing that to which he or she is summoned, and as someone who realizes his or her freedom through his or her activity (Benner 1991).

\section{A Non-hierarchical Relation Between Education and Politics, Economy and Culture}

The second question concerns how a theory explains the relation between education and politics, economy and culture, respectively, as non-hierarchical. How do we define the relation between education and society, i.e. the relation between institutional education and other societal forms of practice e.g. politics, economics, and culture? How are the dynamics between e.g. education and politics explained? In the attempt to understand how education (and leadership thereof) is related to politics, economy and culture, we must first negotiate a path through the various extant explanations in the history of education.

First, a pre-modern mode of thought understands education as being located within the existing society or culture (see Benner 1991; Uljens 2002, 2007; Uljens and Ylimaki 2015a; Ylimaki and Uljens 2017). This socialization-oriented model of education emphasizes the task of education as preparing the individual for an existing society and culture wherein societal practices and norms function as the guiding principles. In this model, educational leadership is subordinated to societal practices. Here education is not expected to have any particular developmental or trans- 
formative role with respect to the existing society, but rather education is preparatory in character. The power of societal transformation lies beyond education, and as a consequence, education is reduced to socialization.

Secondly, as described above, in contrast to the reproduction-oriented model, since Rousseau education theory has learned to conceptualize education as a revolutionary force with respect to societal practices (Uljens 2007; Rousseau 2002). In its most radical or critical form, revolutionary or transformation-oriented education is not only disconnected from society, but also allows itself to be positioned as superordinated with respect to societal interests (Benner 1991). According to Rousseau, there is not much point in educating individuals for an existing society, since education would then only reproduce unacceptable constellations (Rousseau 1979). Rather, the role of education would be to develop something new, something that does not yet exist. Education would work towards ideals, which may, in the future, become realities as a new generation enters society after having undergone education. In this model, education is superordinated with respect to societal interests. More specifically, social transformation theories critique the status quo and seek to explain, either through 'subjective', (e.g. Lukacs; Frankfurt School) or 'objective' (e.g. Althusser) ontologies, how radical change occurs is society. These "critical" theories do not place any critical distance between the values and norms they themselves represent. The similarity between these three positions is their normativity, meaning that a predetermined set of values guides educational practice. In addition, these values are defined irrespective of the educational leader's own interests.

Both the reproduction- and the transformation-oriented models are prescriptive while the first accepts existing norms of the society as guing for educating, the second starts from an ideal for the future, an idea that education should strive at. Then how might curriculum theory and educational leadership deal with value questions? How can they relate to ethics and politics? One of the founding fathers of modern education theory, was Johann Friedrich Herbart, Kant's follower on his philosophy chair. One of Herbart's ideas was that education should be conceptualised as an independent academic discipline of its own, not just a 'field of research'. Contrary to a widespread misinterpretation of Herbart's pedagogy he did not think that ethics could provide education the aims and psychology the methods of teaching as the individual is born neither good nor bad, nor was ethical realism taken seriously. If the modern human being is assumed to be the creator of laws as well as subjected to follow these laws, then moral principles are to be constantly negotiated. In addition, if humans are borne without eternal sin then moral thinking is rather something to be learned.

From a curriculum theory perspective the question is how such a (curriculum) theory may avoid being identical with the prevailing ideology or representing an ideologically opposite position to a politically agreed curriculum? In either case, curriculum theory would function as an instrument for either positive socialization or as a counter-hegemonic ideological discourse. Although educational theory is never value neutral there is reason to keep up the difference between politics and educational theory (Uljens 2016). Another problem with the previously described 
models is that they runs the risk of not leaving room for the principal's, teacher's or learner's to decide upon what is to be considered valuable and meaningful.

In the tradition of modern education theory education is therefore not subordinated to ethics, politics or psychology. If it were, the only remaining question would be from where and from whose ethics, politics and psychology the aims and methods are to be derived. Generally taken, throughout history we have seen two such normative positions: (a) in pre-modern thinking education is equated with normative socialization and the ideals for education stem from the values and practices of contemporary society, and (b) according to reformatory or transformative theories the ideals for education stem from how we envision the future of society (Uljens 2002 , 2007). The first position can be called sociocultural reproduction and the second sociocultural transformation.

A third line of reasoning opposes the above-mentioned ones by criticizing them for subordinating och super-ordinating education in relation to society and societal development (Benner 1991). Since the future is thought to be undetermined and the question of morality is something that cannot ultimately be decided in advance, the individual's reflective ability - self-awareness and self-determination - is seen as an ability that must be developed.

In this last model, education is seen in a non-hierarchical relation to politics, culture and economy. Education is not solely placed either "outside" or "inside" the society and is thus not either super or subordinated with respect to society, but attempts to mediate between the two. In this non-hierarchical conceptualization, educational institutions are given relative independence with respect to societal and other interests. It is this space that both allows for and requires reflective, professional educational leaders on each level of the education system.

It should be observed that a non-hierarchical understanding acknowledges that hegemonic political interests influence education, but recognizes that if educational leadership were to be reduced in the service of some political ideology, it would be in conflict with democratic principles. Thus, political democracy requires a certain form of critical educational leadership, that is, relative independence should be guaranteed by the political system itself. From a non-affirmative education theory perspective, a theory of how deliberative democracy works is something else than a theory of educational preparing for participation in such a democracy (Masschelein 2004). If this distinction is not identified there is a risk of ending up in socialization pedagogy again, now with deliberative democracy as the directing norm. Education theory would then be about drawing implications and developing prescriptive recommendations for how teaching should be organized (Uljens 2016).

From a non-hierarchical perspective, educational leadership is leadership that sustains democracy, related to an image of citizenship. From this point of view, education is allowed to critically examine the political system within which it operates, but it also leaves room for politics to be reflective and critical about contemporary education and educational leaders. The same relation occurs between education and economics: education must prepare individuals for an existing working life, but in such a way that the individual may transcend existing ways of working. In sum, the non-hierarchical position to the relation between school and society accepts 
that: (a) School prepares individuals for an existing world - though it does so in a problematizing, non-affirmative fashion, not confirming a present state of affairs; (b) Democratic ideals are defended: education prepares individuals for participation in societal political practices and change; (c) Human freedom is assumed - from provocation (intervention) to self-activity; (d) The question of the good life remains an open question; and (e) A relative degree of freedom is guaranteed for the state, district, principal, teacher, and ultimately, for the student. Valuable or ideal in society is decided upon in advance. Therefore, it is supposed that the previous models, taken seriously, in fact run the risk of indoctrination and of turning educational leadership into a technological profession.

\section{Organizational and Institutional Theories: Leaders and Actors}

For our theoretical framing, we put education theory in the foreground but also recognize that educational activity occurs within schools and other educational organizations as societal institutions. We appreciate the aspect of open systems theories that explains the interplay between schools/educational organizations and the broader environment, including neoliberal policies, centralization and decentralization trends, and related societal trends (e.g. globalization, cosmopolitanism) and internal dimensions of the system (e.g. school culture, technical requirements, structures, politics, formal and informal leadership). Yet we see the need to retheorize open systems organizational theory with its rational systems/mechanistic legacy combined with natural systems/human relations approaches. Further, we work from a non-hierarchical ideal of education (including organizations) in relation to the broader environment (e.g. politics, culture, economy) and a nonaffirmative education theory. Educational leadership scholars Hoy and Miskel (2005) remind us that open systems theories draw attention to the transformation of organizations through an interplay between the external environment and the schools, but their application give little attention to educational activity. In other words, open systems theories do not consider principles from educational theory or curriculum theorizing as we do here.

In our approach to educational organizations and institutions, we appreciate Greenfield's (1986) theory of organizations as the context of ideas by which we understand our experiences, Habermas' (1984) communicative approach, and Weick's (1995) sensemaking approach to systems that remind of hermeneutics and phenomenology. We find Greenfield (1986) Habermas (1984) and Weick (1995) particularly relevant as they argued that consensual meaning is created through iterative and adaptive communication (e.g. rational discourse, double interacts), referring to social norms and values as well as experiences and ideas. These theories of organizations grounded in hermeneutics and phenomenology are less prevalent in educational leadership literature than recent literature from business grounded in hermeneutics from philosophy and research. 
As we noted earlier, we recognize the challenges of integrating distinct theoretical traditions but suggest the relevance of an organizational context to educational activity. Here we recognize the contributions of various thoughts on how we organize in society to education but rather than a functionalist approach to systems theory, we conceptualize organizations through hermeneutics and phenomenology in relation to education theory whereby people form interpretations and develop understandings in a shared space for reflection and educational activity. Within organizations and institutions, Macdonald's (1995) perspectives are also important here as he advanced a broad understanding of curriculum to include hermeneutics, critical perspectives, and technical perspectives, such as the technical aspects of systems emphasized in much of the organizational theory literature. With Moos et al. (2016), Schmidt and others we also find a broader framework for understanding how the school system is governed and how knowledge is transmitted, selected, valued, and organized in an educational context. Closely related, taking a hermeneutic-phenomenological perspective, we appreciate Greenfield's (1986) educational organizations are the context of ideas, including an internal culture, by which we understand our experiences; however, like Lundgren (1972), we see goals and aims in terms of societal aim. That is, we also see organizations as societal institutions. Here institutional theory and actor network theory may fill a gap in open systems theory, arguing that much of that environment consists of social and cultural forces, not merely production resources and task-related information as some open systems theorists would suggest (e.g. McGregor). Actor network theory (e.g. Czarniawska and Sevón 1996, 2005; Czarniawska 2014; Latour 2005; Law 1986; Koyama 2011; Nyvaller 2015; Fenwick and Edwards 2010) has been utilized recently for studying how socio-technological conglomerates operationalize and technologize educational policies into governable practises asking for new forms of professional leadership competencies.

Along with actor network theory, new and neo-institutional perspectives from sociology extend our understandings of organizations and provide an opening for a multi-level perspective on educational leadership in relation to curriculum. As noted earlier, new institutionalism explains how structures like curriculum policy replicate between related organizations through isomorphism and leadership as a power dynamic. Institutional theories, thus, go beyond open systems theory in explaining the influence of policies and other dimensions of the external environment on organizational homogeneity. In particular, neo-institutionalism has influenced on scholars who seek to explain the transnational level and literature on global social change (Meyer 2010). Meyer and colleagues, for example, have developed world society theory to consider the relations among global institutions and culture and the structures and behaviors of individuals and organizations at nation state and transnational levels.

Organizational theories and related institutional theories, thus, apply to transnational organizations, including NGOs and organizations like OECD that oversee evaluations and other policies. Indeed, increasing complexity of multinational and transnational organizations has created the necessity of new structures, including federal decentralization (Drucker 1974). In federal decentralization, a company is 
organized so that there are a number of independent units operating simultaneously; each unit has its own management, which in effect runs its own autonomous unit. This structure has been utilized in large conglomerates with divisions in various countries and also in large school districts. There are many hybrid forms of transnational organizations, but classical organizational theories apply in established patterns of relationships among parts of these organizations (e.g. differentiation, structure of hierarchical relationships, formalized policies, organizational cultures and norms), but here the focus is on governance in various polities and the movements of ideas as discourses. This is where we need discursive institutionalism to analyze and understand policy discourses within and between levels.

\section{Discursive Institutionalism}

Above it was acknowledged that every theory of educational leadership must deal with three fundamental questions as well as their internal relations. These questions concern, first, how institutional education is related to politics, economy and culture in a democratic society and, second, how leadership as a professional, moral practice is explained in terms of power and influence, that is, as an ethical-political and epistemological relation between individuals in professional settings. On the first issue, this approach argues for a non-hierarchical view of the relation between societal forms of practice, thus holding to a western democratic tradition of citizenship and social transformation, allowing evolution and revolution. Thus a non-hierarchical view of leadership emphasizes the interdependent relation between modern democracy, dynamic culture and education that are each mutual preconditions. The claim that educational leadership is simultaneously a dynamic institutional, multilevel, diagonal, horizontal and vertical process, operating between different epistemologies and value-spheres, where the intersections between levels and interests may be described as negotiated discursive spaces, ultimately returns us to a theoretical definition according to which education stands in a non-hierarchical relation to politics, economy and culture. The very same structure explains how curriculum works, since educational leadership is meaningful as a dynamic relation between different levels.

So-called first order educational leadership refer here to teachers' leading the students' study activities in the teaching-studying-learning process. Second-order educational leadership shifts level and focus to principals' leadership of teachers' teaching activities and the school as a collective organization. Third order educational leadership again shifts level and focus to leaders who lead other leaders (e.g. municipal superintendents leading principals). Fourth order leadership involves developing and deciding about new national/state policies and curricula on a level authorized to establish laws - clearly a very different kind of educational leadership. As a result of recent political and economic aggregation processes, globalization, a transnational, fifth level of analysis as well as a cosmopolitan perspective has accentuated (Beck 2006). Typically contemporary Didaktik, varieties of curriculum stud- 
ies, leadership research and policy analysis and governance research have turned their main focus on typical one or two levels.

Accepting a multi-level approach to educational leadership and curriculum turns our attention not only to interaction between these levels but also interaction within them. Thus, the answer previously provided, i.e. the non-affirmative problem concerning the kind of influence educational leadership has, a non-affirmative approach was adopted. Educational leadership as non-affirmative summons to self-activity highlights that the education process is dependent on an experiential address, but that when leadership as summons is pedagogical the leader should consciously refrain from naively confirming either a prevailing or ideal future condition. With such a self-reflecting pedagogical discernment the leader is thought to be better able to create a space for an education process that recognizes the co-worker's selfactivity and right to exercise conscious independence of thought.

As we can see educational leadership as curriculum work, as evaluation, as school development etc. occurring within and between different levels this means that it is important to highlight mechanisms through which the political will formation and its results (ideas) transform or find their way, in cooperation with professional expertise, into a 'pedagogical agenda' by being communicated to practitioners. Curriculum/Didaktik typically identify several levels of activity, considered relevant for understanding the direct and indirect top-down/bottom-up dynamics between, within and across these levels. Leadership research has increasingly developed similar approaches since the 1970s (Meyer and Rowan 2006).

The question is now how to approach a multi-level, multi-centered and multiprofessional educational governance system given the fundamental theoretical positions developed above? Given the answers provided by a non-hierarchical view on the relation between politics and education as well as the non-affirmative approach of educational interaction we perceive of discursive institutionalism as offering a complementary and fruitful approach to understanding how educational policies, ideas and values (curriculum) relate to administrative processes on different levels beyond schools and districts/municipalities. As we see it, discursive institutionalism itself presupposes a non-hierarchical understanding of societal forms of practice.

According to Schmidt, discursive institutionalism aims at understanding how cognitive ideas (problems identification) and normative ideas (values that legitimize problems) are developed and communicated across societal, philosophical, policy, and program levels. This point is important for our framework in that it explains the interplay among societal values and aims, policies, and program interactions. The term 'discourse' refers not only to structure (what is said, or where or how) but also to agency (who said what to whom). Specifically, Schmidt argues that ideas operate as coordinative and communicative discourses. Coordinative discourses refer to policy construction among policy actors while communicative discourse refer to policy legitimization between policy actors and the general public.

These discourses operate within and between levels and in one of four directions. The first direction is top-down, meaning that policy elites generate and communicate ideas to the public, creating a master discourse, which inspires public debates and requires mediation. Second, discourses move bottom up, such as when social 
activists inspire mass protest against a policy or program, creating a counter discourse in mass media. Third, discursive interaction may remain solely at the level of civil society in the public sphere. Finally, there may be no "arrows" between coordinative and communicative discourses. Important questions are related to which way the arrows go-top-down, top-to-top, or bottom-up - and who is seen as the carrier of ideas (Schmidt). Schmidt's work on discursive institutionalism, thus, enhances our understandings about how curriculum as ideas and discourse may be communicated (and by whom) within and across macro (e.g. societal, policy) and micro (program, school) institutional levels.

Through vertical negotiations, political will transform into a 'pedagogical agenda' (policy) by being communicated to practitioners but agents' perceptions and enactments are also communicated back to the policy formulating process. The vertical discourses sometimes passes levels in between, like when transnational organizations like OECD communicate learning results directly to the schools without communicating these results to national authorities. The PISA process also demonstrates how result of evaluation is intended as influencing future curriculum work. Horizontal dialogues occur one all levels, including cooperative discourses within each level, but also between politicians and the administration.

Schmidt's discursive institutionalism provides a new point of departure to consider the "institutional" or "structural" dimensions, particularly those that are evidentinlaterdeliberative and discourse-oriented curriculum theory. Discourse-oriented curriculum theory provides a language for talking about the human interactive and interpersonal dimensions of any level, from classroom to transnational. Discursive institutionalism acknowledges the system-laws, policy documents, task descriptions, financing systems - that lies beyond individuals' everyday leadership practices. This position is coherent with the non-hierarchical view of the relation between societal practices in a democracy. The non-hierarchical point of departure offers us the principled position or rationale to approach both interactionalindividual and institutional structural levels from a discursive perspective. At the same time, with its grounding in public administration, Schmidt's discursive institutionalism does not have an underlying educational language or theory of education. Thus, we consider deliberative and discourse-oriented curriculum theory and classic concepts from educational philosophy described previously (recognition, summoning, Bildsamkeit,) as well as discursive institutionalism in our framework.

Coherent with discursive institutionalism, discourse-oriented curriculum theory, and the core concepts of modern educational theory described above, a curriculum includes the view of a curriculum as text as a systematic interruption in the practitioner's way of understanding herself and carrying out one's professional tasks. We see curriculum work as an interruption in the Other's relation to herself, other persons and the world (Honneth 1995).

This recognition-based Hegelian philosophy provides a general frame for understanding how the curriculum itself as well the construction process, works, and is used, as a pedagogical intervention in order to influence. Here leadership influence does not mean support for implementation of ready-made ideas but invitation to dialogue. In doing so, educational leadership as curriculum work recognizes the 
subject as radically free as this makes him/her able to transcend what is given. But the position also acknowledges the necessity of the subject's own agency as a necessary requirement for transcending a given state. The effects of a curriculum activity are, obviously, also in the hands of the receivers enacting these intentions. The curriculum making discourse as invitation to self-activity and self-formation creates spaces within and between institutional levels. By introducing these concepts, we create a more coherent language for school/district and curriculum work, educational leadership and school development activity, using the very same concepts that are relevant in describing the core object of curriculum theory and Didaktik, the teaching-studying-learning process. At the same time, we recognize that Schmidt's discursive institutionalism has been developed and applied to multiple levels of institutions and their structural dimensions within the nation state. Thus, we need to consider transnational organizations and relations through a combination of lenses, including organizational theory, new and neo-institutional theory, actor network theory, and world society theory.

\section{Cosmopolitanism as an Educational Ideal and as Transnational Relations in an Increasingly Plural World}

The third topic relates to cosmopolitanism and its necessary counterpart, i.e. individual and national identity, and citizenship. In the beginning of our chapter, we observed that we live through an era where the majority of nations worldwide internally have developed towards increasing plurality while being simultaneously framed by challenges that call for a cosmopolitan view. From being an abstract idea the relevance of a cosmopolitan perspective has developed into an everyday and self-evident issue through globalisation. However, educational theory, leadership and curriculum research has only recently and still to a very limited extent developed a reflected position in this matter. The nation-state perspective have dominated.

With this twofold challenge, how should we conceptualise education, leadership and curriculum in order to make sense of these phenomena in a contemporary cosmopolitan perspective including increasing local diversification? Further, how should we establish a notion of education, leadership and curriculum simultaneously relevant both for local, national and global citizenship in a post-national, neocosmopolitan era? In our understanding this dilemma mainly falls into two different parts: cosmopolitanism as an educational ideal and cosmopolitanism as transnationalism reflecting dynamics between states and between states and transnational aggregations or various kinds.

While the first has long historical tenets, the second presents itself as a rather recent topic. While cosmopolitanism as an educational ideal points at aims, contents and methods of education, i.e. curricular questions, cosmopolitanism as trans- 
nationalism points towards new features of contemporary educational leadership. Just to mention a too obvious example, transnational organisations like OECD influences and directs educational practices through the initiation and organization of international evaluations. New mechanisms and governance forms force traditional educational leadership research to develop new languages for dealing with the situation.

In the first part of the problem we meet the dilemma of cosmopolitanism as an educational ideal. A first dimension of this is what it means to have or accept cosmopolitanism, or world-citizenship, as an educational ideal? A second dimension of this problem is how cosmopolitanism relates to differences between nation states and the various educational aims they promote? Is it possible to unite different nation-state policies with a single cosmopolitan ideal? Do different versions of cosmopolitanism presuppose different versions of nation state education policies, or the other way around, is any version of nation state policy congruent with any version of cosmopolitanism? A third dimension related to increasing plurality within each nation state. How do national education systems approach increasing intrastate ethnic, religious, linguistic and ethnic/racial plurality - by differentiation/ diversification or unification and coherence making? As before religions unite peoples and individuals beyond nation state borders.

The second part of the problem concerning cosmopolitanism and education, curriculum and leadership is both practical and principled. It concerns how we conceptualize and empirically describe educational relations between and among nation states. Here we ask: How do we explain curriculum making and educational leadership relations within and between nation states, i.e. transnational, in an increasingly plural world? What kind of relation are we addressing?

Contemporary educational policy research has been active in approaching globalisation and the drivers in this process. This research has been successful pointing out globalized economy supported by technology and neo-liberal politics as driving forces in globalization. Often educational policy research has pointed out counterproductive consequences and other worrying effects of these developments. We highly appreciate this research although approaching the issue differently. The policy oriented literature is not always explicit concerning education theory. In curriculum theory, on the other hand, we see more clearly that the connections between globalization, cosmopolitanism and education tradition is much more present (Autio 2013; Hopmann 2015; Pinar 2011, 2013). Sociologists and philosophers of education were also early in bringing the cosmopolitanism anew (Beck 2006; Kemp 2010; Roth and Burbules 2007; Biesta 2009). In explaining educational leadership and curriculum work at a transnational level, our position again takes a non-affirmative position and draws upon the core concepts from Hegelian traditions, modern education theory, and later developments based upon subjectivity and intersubjectivity at the nation state level (i.e. recognition; summons to self-activity and Bildsamkeit) as well as discursive institutionalism. At the same time, we explicitly consider the contemporary globalized situation, looking at how these concepts apply in a drastically different context of relations between and among international organizations and increasingly pluralistic nation state. 
Cosmopolitanism as Universalism in Educational Research and Theory When saying that cosmopolitanism, as a version of universalism, always goes together with particularism, it is a proposition that is relevant for epistemology of education, i.e. the assumptions featuring our theories. Do we, for example, imagine our theories being of universal validity over time and cultures or do we see them as regionally limited? Now and then we still meet characterizations of the Western scientific tradition, obviously including social sciences, representing unreflected universalist knowledge ambitions as well as cultural insensitivity demonstrating versions of naïve ontological realism and representational epistemology. This view would have decentered recently, first in the 1960s with new insights developed in relation to the concept of paradigm (Kuhn, Lakatos, etc) and later with postmodern epistemology (Lyotard, etc.). However, in education, a non-foundationalist approach was developed early on by those classics being referred to here. In his classic lectures on education of 1826 Friedrich Daniel Ernst Schleiermacher asked the question concerning how far educational theory can be culturally universal. Being both one of the founders of modern hermeneutics, recently rediscovered, translated into english and today not only read through Dilthey, and a crucial contributor to culturalhumanistic pedagogical theory, it is not surprising that his own conclusion was negative: a theory of education is always relative to its own cultural context (Schleiermacher 1998), a position later supported by Dilthey (1883) and all subsequent anti-essentialist theories. A cultural space is thus dynamic, a map is a reconstruction of experiences given discourses and interests, rather that a representation (Saari 2012). In fact, according to Schleiermacher conceptual development and reflection takes off with life-world experiences. On the other hand, accepting the impossibility of a universally valid position does not have to mean we accept a view of theoretical pluralism where all theories are of equal value. Accepting epistemological pluralism rather changes the nature of the dialogue: it requires from participants even greater sensitivity to alternative views. With this must come an openness to different contemporary forms of discourse but also engagement in historical contributions in order not to loose the sight of historical roots. In this sense theorizing is reconstructive in nature.

Cosmopolitanism as an Educational Concept Cosmopolitanism as a theoretical idea has gone through many phases since it was introduced by the greek philosopher Diogenes (412-323 b.Chr). Diogenes conceived of himself not coming from any specific place but that his worth as human was not connected to from where he came. Before and after the Greeks cosmopolitanism and universalism has appeared in different shapes (Papastephanou 2016). Today being a cosmopolitan has an empirical, concrete meaning attached to it, intensified by the most recent globalization movement and related societal trends as well as technology (e.g. neoliberalism, population migrations, demographic shifts toward increasing plurality). In other words, we can, so much more easily than the greek Stoics for which cosmopolitanism was merely an abstract idea, think about the world as a real, common place in which we all are included. Kemp (2010) points at three core issues for today's cosmopolitanism: how does economic globalisation relate to democratic control of 
economy and technology, how to deal with conflicts between national or culturally related interests and challenges connected to sustainable development and, finally, how to deal with global responsibility?

Kant defended what he termed the universal cosmopolitan condition as comprised of two fundamental rights: the right of a state (Staatsrecht), which lays down the fundamental norms of rational political authority in the form of a rightful civil constitution and international right (Volksrecht), which sets out the basic principles that govern relations between states. The "right of peoples" (Volksrecht, international right) expressed a wish for peace, i.e. to avoid wars. Further, in addition to international right regulating conflicts between states Kant also defended the need of cosmopolitan right in terms of basic ethical existence. Cosmopolitan right defined an ideal equal for all. It was claiming that all rational beings, irrespective of their origin or race (some allusion to culture), should be regarded as ends in themselves and as also as lawgiving members of the universal kingdom. For Kant, cosmopolitanism was a moral orientation that provided the rationale for states to enter into a permanent peace treaty and confer rights of universal hospitality. In other words, all citizens would still belong to and reside in their own republics. Thus, while Kant sought to extend republican political philosophy into a wider framework beyond the relatively limited modern notion of the nation state, he did not completely abandon the importance of the nation state role. So recognized by a nation state any human being could therefore not be made use of by anybody else and their interests.

In his seminal work Cosmopolitanism and the Nation State, Meinecke (1970) captured the decline of the nineteenth-century cosmopolitan idea with the rise of the national idea. Meinecke captured Kantian cosmopolitanism and the so-called cultural cosmopolitanism of Enlightenment intellectuals and elites who did not succeed in translating their vision into a viable political order for the time. Further, Kantian cosmopolitanism did not explicitly address interculturality and other cultural dynamics (e.g. background, habitus) involved in relations between different cultures.

Education and the Establishment of the Nation-State As observed previously, the roots of European Didaktik are typically traced back to Comenius and his Didactica Magna from 1657. The establishment of modern Didaktik may be seen as a response to a need of the embryonal developments of a new school system providing the state with new competencies, but also resulting from new technology enabling mass schooling, i.e. the printing press. The format of the state before the modern nation state coming to existence was based upon an absolutist view of power demonstrated in monarchies. Mercantilism was the dominating economic paradigm primarily designed to securing the incomes for the state, military power being one of the main drivers. These earlier states were typically multi-ethnic although often one cultural group was the dominating. While territorial issue were central borders could change with marriage between monarchies. The teaching of reading cared for by the church started more systematically during mid seventeenth century in European countries, was very much connected to developing a capacity to perceive the meaning of (holy) texts. Teaching to write, i.e. productive communi- 
cative capacity around texts, was developed 200 years later, with the establishment of elementary schools. During the seventeenth century also significant expansion of universities occurred, with the aim to provide the state with workforce.

Herder was one of the first modern cultural theorists to use the plural version of cultures, considering particularly issues related to language (Herder 2002). In Herder's view, the movement toward the establishment of modern nation-states (eighteenth to nineteenth century) required a new approach to establish and sustain a relation among national, collective unity (sense of belonging) and individual and regional plurality. On the one hand, in the eighteenth and nineteenth centuries, this involved the task of building a single, new identity called the nation, encompassing several identities and affirmations. The relationship of new nations to pre-existing cultural identities was in part to be one of transcendence from cosmopolitanism to 'nation'. On the other hand, in agreement with Hegel, Herder argues that this very conception of encompassing diverse identities - social and regional, linguistic and cultural-meant giving a key role to the state through which the composite nation was to be created. These foundational social philosophers, then, lay the groundwork for understanding policy relations between nation states and basic human relations; however, they do not explicitly discuss the role of habitus or the ethical dilemmas that emerge from curriculum work across nation-state borders.

In a recent project exploring ethics in international curriculum work, Helfenbein (2010) explicitly considered ethical dilemmas in curriculum work occurring in various projects across borders defined by nation states, ethnicity, culture, and class. Helfenbein (2010) draws on Blackburn's (1996, p. 126) notion of ethics (i.e.the study of moral judgments and actions), Foucault's (1997) turn to ethics in his later writing, as well as critical geography to pose new questions revolving around ethical concerns about spacial relations, including power and identity. In our view, Helfenbein (2010) raises an important argument that while geographic borders have materiality associated with them, geographic places and spaces are socially constructed with real effects on lived experiences that are ethical in nature.

Hegel, in turn, defended the necessity of the nation state as the embodiment of ethical existence. For Hegel, the state is the last of three ethical components-the family, civil society, and the state, which together constitute the normative order known as ethical life. As the third ethical component, according to Hegel, the State should be seen as the pinnacle and as following logically from the other components. The state, then, is what allows human beings to take their place in the historical development of universal mind, and, hence, to make them capable of ethical living. Hegel also writes about the actual state where aims toward unity are viewed as a necessary evil. Hegel, thus, saw the state and its institutions, as part of the ongoing historical process of actualizing freedom, a kind of teleological philosophy of history.

Drawing on his Hegelian roots, John Dewey (1959) wrote about a similar harmony between people's particular and universal interests. For Dewey, as for Hegel, one must act in absolute cultural freedom; work, community, and the nation state must not confront an individual as alien but rather should be integrated with the self. Although not explicit, Hegel and Dewey use the term culture as singular for all 
humans, toward in Hegelian terms, the development of universal mind or the nation state. At the same time, Hegel argued that the nation state reconciles particularism (the individual) with the universal.

To conclude, today we do not have any global parliament or global state for which education would prepare. However, would some predefined idea of worldcitizenship be considered an ideal for education to strive towards this might result in an affirmative position, making contemporary education a tool for aiming at and reaching of a future state of art. Yet, what we do have is an increasingly strong awareness and understanding of sharing the planet or the globe as a place where we all live. Among other things, our increasing knowledge about the universe, cosmos or solar system has made us more aware of this than ever before in human history. While there is no global political state in which we would own or have citizenship the human population on earth form, to various degrees, a 'global community' that exceeds the borders of existing nation-states. Making use of Ferdinand Tönnies' (1855-1936) differentiation in 1887 between Gemeinschaft (community) and Gesellschaft (society), we may see Gemeinschaft as "a social group united by common beliefs" and Gesellschaft "a social group held together by practical concerns, formal and impersonal relationships". Given such definitions we can see that the experience of sharing the world as a common place for all known human life is certainly a concern of practical nature, but so is it about holding together with respect to common beliefs, let this be on a very general level. Now, given that contemporary institutional education aims at preparing the individual for a life in community and in society, i.e. for different "citizenships", this is valid also from a global or cosmopolitan perspective. Educating for globopolitan life is thus relevant although no global state exist. Educating for a life and living together on the earth exceeds traditional education for community and society framed by a notion of the nation-state. From an education theory perspective our general point of departure in this issue is not to make use any positive definition of globopolitanism as an ideal that narrows down how the future should look like. Rather, following e.g. Schleiermacher's definition of ethics, we have to learn to live with the question of globopolitanism as an open one.

Universalism and Particularism: Multiculturalism Philosophers and education scholars have long considered issues of identity in terms of the Bildung process occurring through 'experience', a conflict ridden process in the course of which a spiritual being discovers her own identity or selfhood while striving to actualize the selfhood. In many countries, scholars and educators have responded to the contemporary dilemma of increasingly culturally diverse student identities and universalism vs. particularism with multicultural education. Both US and European versions of multicultural education are frequently rooted in transformative sociological perspectives whereby schools play a role in overcoming social and political struggles against racism and other related 'isms'. By some contrast, European versions of multicultural education are often grounded in issues of nationality and language more than race and ethnicity; nonetheless, at a conceptual level, this literature is similar in that it is grounded in a social transformation perspective and a modernist 
critique of educational norms and values that privilege dominant groups and disadvantage traditionally marginalized groups (e.g. Gundara 2000; Portera 1998). Both North American and European scholars offer similar typologies and a range of pedagogical forms or approaches directed primarily toward either a particularist approach aimed at students from specific ethnic/cultural groups or a universalistic approach for all students irrespective of ethnic/cultural origin. The particularist approach is often supported by acceptance of positive discrimination, allowing for differentiation in favour of individuals or groups.

Drawing on critical theory notions of oppression, Sleeter and Grant (1985) posited four educational programs now popular in the United States and elsewhere (Human Relations, Teaching the Culturally Different, Single Group Studies, and Multicultural Education), all of which are grounded in an assumption that society will eventually change if we change the consciousness of individuals (children) through multicultural education and culturally responsive pedagogy. Within these approaches, then, there is also a range of emphasis on particularity over universality. For example, Single Group Studies support traditionally marginalized students as future citizen who will be educated to bring about structural and cultural changes in society for the benefit of "their historically oppressed group". This approach includes such programs as Black Studies, Chicano Studies and Women's Studies; it explicitly teaches students about the history of the group's oppression, how oppression works today, and how the culture the group developed within oppressive circumstances. Although embraced as particularized struggles within multicultural education, such single group studies can have a separatist emphasis and lead to dependency or tribalism.

In response to the separatist problem, Banks (2002) proposed multicultural education that teaches all children about cultural pluralism and diversity, as well as making sure all achieve well. Similarly, from a European perspective and responses to the needs of increasing immigration and population migrations, Gundara (2000) explained, multicultural education can be directed at all pupils (a universalistic approach). Across European multicultural education literature, scholars focus on the idea of nation and citizen as well as language diversity (e.g. Banks and Banks 2009; Gundara 2000; Portera 1998). In the wake of population shifts and more open immigration policies in many countries, the ideas of nation and citizen have to be revisited, in order to clarify not only rights, but also duties, and to develop social democratic norms for all citizens of a country (Schnapper 1994).

Multicultural education approaches have been recently tested or described empirically, examining various ways in which teachers respond to the needs of culturally diverse students in classrooms. For instance, Ladsen-Billings (1994) coined the term "culturally responsive pedagogy" in her now classic study of eight exemplary teachers of African American students. This 'pedagogy of opposition' drew on anthropological theories that noted a mismatch between students from culturally diverse backgrounds and their teachers, particularly in terms of language and verbal participation structures. Building on Ladson-Billings' study, Cooper (2003) investigated the practices of effective White teachers of African American students who had been nominated by the Black administrator and parents of their predominately 
African American schools. She found that they adopted many of the practices of effective African American teachers, including being "warm demanders" who held high expectations for academic achievement and became second mothers or "othermothers' to the children in their classrooms. In a similar project focused on Latino(a) children, Moll et al. (1992) referred to funds of knowledge as "the historically accumulated and culturally developed bodies of knowledge and skills essential for household or individual functioning and well-being" (p. 133).

While we noted differences in approaches to multicultural education from one country to another and from one area of focus to another, an ongoing harmonization of multicultural education may be identified. Across national contexts, discussions of multicultural education are frequently centered on questions of how far cultural diversity threatens the unity of society, and to what degree multicultural education programs for an increasingly pluralistic population of students hampers or encourages the realization of equality of opportunity for all students. However, these more universalistic approaches come to the same point of struggle: how to respond to increasing student plurality and yet retain a human relations approach that recognizes national and global unity for all students and perhaps dependency for some? As Helfenbein (2010) reminds us, we have to think simultaneously at the scale of the universal and the particular. While multicultural education research has provided important pedagogical understandings, these scholars have not used recognition and other modern educational concepts that may be helpful in the contemporary situation. At the same time we ask, what kind of postnational pedagogy might be important to educate for an aim of recognition? In our view, Benner's (1991) approach to recognition emphasizes initiative as well as need, an approach that may overcome concerns about inequities and dependency in particularist approaches.

In educational leadership studies, a growing number of scholars have applied multicultural education perspectives and culturally responsive pedagogy to leadership. (e.g. Johnson 2006; Scanlan and Lopez 2012). According to Johnson (2006), culturally responsive school leaders support academic achievement, work to affirm students' home cultures, empower parents in culturally and economically diverse neighborhoods, and act as social activists who advocate for societal change to make their communities a better place to live. Using a broader lens about culturally responsive leadership, Scanlan and Lopez (2012) conducted a narrative synthesis that examined 79 empirical studies related to best practices to promote equity and excellence for culturally and linguistically diverse students. Scanlan and Lopez (2012) concluded that principals serve a role as policy mediator; they need to "cultivate language proficiency, provide access to high-quality teaching and learning, and promote the socio-cultural integration of all students" (Scanlan and Lopez 2012, p. 149). Similarly, in a Nordic/European context, Moller (2009b) and Kalantzis and Cope (1999) write about leadership for democratic education arising from research at the intersection of educational leadership, critical theory, and critical multiculturalism. Such theories are rooted in social justice, equity, and the common good (e.g. Dewey 1916; Freire 2000). In Moller's (2009) view, most definitions of education for culturally responsive practice and democracy include themes such as recognizing the basic value and rights of each individual, taking the standpoint of 
others into consideration, deliberation in making decisions, embracing plurality and difference, and promoting equity and social justice. Multicultural education literature, culturally responsive pedagogy, and its application in culturally responsive leadership deal with social interactions and empirical realities around universalism versus particularism in schools. In the next section, we move back to empirical realities in literature on interstate relations in policy research.

Interstate Relations in Policy Research: Empirical Cosmopolitanism Current debates regarding international relations in policy research draw attention to the revival of a Kantian ideal as relevant in the present context of globalization, the socalled crisis of the nation state, and the need for a global, civil society (Bohman and Lutz-Buchmann 1997). The notion of cosmopolitanism put forward empirically in transnational relations is responsive to internal nation-state policy dynamics and responsive to a world system (Wallerstein), world society (Luhmann) or world polity (Meyer). Closely related, Rudd and Goodson (2016) developed a concept of 'refraction' as a holistic approach to understanding the empirical interconnectedness among structure, agency, ideology, history and individual beliefs. Here Rudd and Goodson (2016) highlight the areas of foci evident in particular historical moments of educational reforms across the UK.

Policy scholars have been studying recent globalizing curriculum policies through varying (and often Western) epistemologies and theoretical logics, frequently drawing on Luhmann's (1996) self-referential social systems theory and Wallerstein's (1974, 2006) world systems theory. According to Luhmann (1996), society can be interpreted as a functional integration of systems that follow an internally independent regulation that must accommodate the external requirements of other systems. Here society as a whole is defined by the medium of communication. Luhman extended his theory to the global level when he argued that communication had become globalized, meaning that society had to be analyzed on a global level within which states and other systems operate and regulate relations (Luhmann 1996, 2012). For Luhmann, then, educational theorizing is understood largely as a self-referential system of reflection rooted in distinct contextual conditions, intellectual traditions and value systems with respective systems of reference and contexts. Applying Luhmann (1996) to policy borrowing and lending, Steiner-Khamsi (2004) argues that borrowing (e.g. increasingly global core curricula) does not imply an exact duplication of reform; it draws our attention to processes of local adaptation and modification. Here contextual conditions are emphasized in policy communications, but there is little attention to critical geography and interculturality or communication between different cultures in these contexts.

While Luhmann based his theory of world society on Parsons, another seminal theorist Immanuel Wallerstein (1974) developed his world system theory out of a critical reading of Marx. For Wallerstein, the 'world system' is essentially the world economy emerging out of the rise of the west and the dominance of a single center over the periphery. Here cosmopolitanism concerns less the homogenizing capital world economy than the different combinations of periphery and centre. Wallerstein claimed that any social phenomenon of the present had to be studied in the context 
of the world system. However, instead of a functional theory, Wallerstein proposed a structural theory of power, extending Marx's distinction between capital and labor to the global level. Specifically, Wallerstein (1974) conceived of a world system as a multicultural territorial division of labor that leads to the existence of three interdependent regions: core, semi-periphery, and periphery. The core-periphery relationship is structural, one with a power hierarchy in which powerful and wealthy "core" societies dominate and exploit weak and poor (e.g. colonized) peripheral societies. The semi-periphery is supposed to mediate conflicts and to give the periphery hope for upward social mobility. Luhmann's functionalist systems theory and Wallerstein's world systems theory have both provided significant, if differing, theories and logics for understanding the structural dynamics between systems and their differential power structures, but these theories are not explicit regarding the discursive nature of relations, particularly as these may apply to education in a plural world.

Schmidt's (2016) discursive institutionalism as an analytical framework has largely been considered within nation states; however, her most recent conceptualization of DI focuses on the EU as a 'region-state', providing an important discursive strategy for understanding dynamics and relations between states as well as between states and networks. Again, discursive institutionalism aims at understanding how cognitive ideas (problems identification) and normative ideas (values that legitimize problems) are developed and communicated across societal, philosophical, policy, and program levels. Using discursive institutionalism, Schmidt argues that the substantive content of the idea 'region-state' serves as a lens to illuminate the EU in its current (emergent) development as a new international organizational form, one that has never been observed before as well as in relation to a line of development from existing supranational entities organized by and above the nationstate. Here discursive institutionalism frames Schmidt's conceptualization of the EU as a region-state in terms of the concept itself along with its discursive use of that concept to propose new ways of engaging in the EU based on the insights about the EU that emerge from the region-state concept" (p. 4). What the concept 'regionstate' offers for the EU is a new, readily understandable term capable of encompassing what it has become and what it is becoming" (Schmidt 2016, p. 2). Specifically, in the example of the EU emerging as a new international organization, Schmidt examines the substantive content of the EU as it is being and becoming a concept of 'region-state' characterized by shared sovereignty, variable boundaries, composite identity, highly compound governance, and fragmented democracy in contrast to sovereignty, boundaries, identity, governance, and democratic legitimacy as the main markers of the nation state. With Schmidt's approach in re-naming the EU as a 'region-state' we find a discursive strategy to understand the development of new ideas and global discourses within a new international organization and between nation states, a strategy that we argue is relevant to understand relations and dynamics regarding transnational curriculum policies. Still, we argue that Schmidt's discursive institutionalism does not have an underlying educational language or theory of education to explain pedagogical relations amidst increasing cultural plurality at all levels, including the transnational level. 
We see points in all of these theories that make a valuable contribution to understanding the current empirical realities as well as important missing dimensions. First, what is missing is a dialogue among these three perspective, all of which are valuable where the cosmopolitan moment may be conceived of as a creative combination of different forces-centre, periphery, and semiperiphery, the local and the global, and discursive institutionalism within and between institutions. While Luhmann's systems theory and Wallerstein's world system theory have contributed important, if differing, approaches to understanding relations within and between nation states and social systems generally, we also find a lack of attention to an educational language or the cultural dimensions of relations. This is where the nonaffirmative framework makes a valuable contribution. We recognize the structural and processual contributions of world society and world systems theories and position ourselves in relation to these. Further, we draw upon interculturality and discursive institutionalism especially as it emphasizes the cultural and ideational dimensions of discourses, respectively.

\section{Educational Core Concepts for Understanding Intercultural and International Relations}

We have discussed the core concepts of modern education theory at length in response to our first question regarding educational and pedagogical influence. In this section, we revisit these core concepts as well as interculturality concepts from cultural anthropology (e.g. Mead, Geertz, Wimmer) as these may provide an educational language for transnational and international relations beyond the language from policy studies. Again the core concepts from modern educational theory (Benner 1991) are:

1. Recognition - how the Self is aware of the Other as being free,

2. Summoning to self-activity - how a teacher or a principal has a mediating role with respect to the Other in the maintenance and development of the Other's self-relations;

3. Bildung (Bildsamkeit) - realization of the individual's possibilities through own conscious efforts aimed at making sense of the world and her experiences.

Recognition, summons to self-activity, and Bildsamkeit are fundamental categories for understanding intersubjectivity or what it means to become human (Fichte, Hegel). Interculturality, or communication between individuals (e.g. policymakers) from two distinctly different cultures, derives its role from the sphere of intersubjectivity According to Fichte, man should understand that, starting out from his own transcendental subjectivity, he discovers another self-consciousness in a process in which he is 'summoned' by 'the other' to jointly produce a third, a medium of the 'mind' in which both his own and his other's subjectivity are suspended. Hegel (1807) also theorized about intersubjectivity, arguing that 'self-con- 
sciousness exists because it is a self-consciousness in and by itself to another, meaning that it exists only if recognized by another.' In Fichte's view, adopted by Hegel, when attempting to view itself as an independent entity, the self must recognize the other as an equal subject so that, in turn, may be recognized by the other. Habermas (1981) expanded on Hegel's modern philosophy by drawing attention to the dialogic character of recognition and how communicative relations and actions can be distorted by force. Interculturality, grounded in cultural anthropology, furthers these theoretical propositions of intersubjectivity by considering the cultural dimensions of intersubjectivity. Specifically, interculturality focuses on relations among different cultural groups where the life-world is culturally different or not permanently shared (e.g. Mead et al.).

In a lecture connecting culture with intersubjectivity and recognition, Wimmer (2013) expanded upon Geertz' notion of culture as a system expressed through symbols that allow groups of people to communicate within and between cultures. Specifically, he conceptualized culture as an open and unstable process of negotiating meanings with three closely connected concepts: (1) the internalized culture of an individual, which forms the basis for processes of negotiation or habitus; (2) the common perceptions of the nature of the world as a result of those processes of negotiation (public-cultural-collective representation); and (3) cultural practices that represent the limits to social groups within which the processes of negotiation take place (cultural distinction). In other words, Wimmer (2013) argued that interculturality involves recognition; recognition is a foundational basis for multiculturalism and the coexistence of different ethnic or cultural groups in one country (nation state) as well as between individuals from two different countries with varying levels of cultural capital and power (p. 407). Here Wimmer's conceptualization reminds of Bourdieu's (1977) theories of cultural capital, habitus, and fields of power. Cultural capital and habitus affect intercultural relations as individuals use their own cultural capital as well as dominant societal norms to navigate policy relations and the education process. In our view, these perspectives on culture and interculturality have implications for educational relations at the transnational level as well as within nation states and their institutions.

At the same time, application to educational relations at the transnational level may be a hybrid version of both affirmative and non-affirmative perspectives. This means that, within a more mandated circumstance, educators/policymakers/international organization leaders' direct their own and others' (e.g. policy counterparts in other nation states or international organizations, state or region leaders, school/ district leaders, teachers) attention toward the relation between the experiential structure and dimensions of the policy ideas, requirements, and other content. In some similarity and contrast to the other four levels (classroom through nation state levels), educational leadership involves recognition and other human interpersonal practices. At a transnational level, recognition and interculturality are foundational to these relations. Again drawing on Benner's (1991) proposition, education would, then, be to recognize each leader or policy-maker in other countries as if he or she is already capable of doing what he or she is supposed to become capable of - and to act accordingly, Yet in the circumstance of transnational relations, there is also a 
potentially coercive relation or dynamic to these relations. From a non-affirmative approach, educational leadership and curriculum work may be focused on creating transnational policy cultures where international organization members/learners learn about what it means to position him or herself as both national and global citizens of democracy. Here the organizational member/learner learns to make use of his/her own productive freedom.

In some instances, one nation state organization and its results may "summon" another member to reflect its curriculum or evaluation system. Such relations, as a special form of curriculum (culture), are not directive or normative, but they contribute to global curriculum dialogue. Here discursive institutionalism also becomes important in, for instance, in international organization members' use of knowledge (ideas and content in transnational curriculum and evaluation policies) about curriculum and evaluation policies that may support mutual understandings or raise questions between nation states members with their differing cultural backgrounds, underlying values, and interests. Using the example of Schmidt's (2015) conceptual naming of the EU as a region-state, the very naming of transnational policy interests, knowledge and values (e.g. OECD), can illuminate concepts that support understanding transnational curriculum and evaluation policies, summoning activities grounded in affirmative and non-affirmative perspectives, and the development of international organizations around these. Such discursive relations may result in learning on the part of the Other as policymaker or international organizational leader or educational leaders at other levels within nation states, but this is an open question. At the same time, we recognize that transnational organizations in particular ways.

While we argue for the relevance of an educational language for transnational relations in a plural world, we must ask if these modern educational concepts are sufficient to understand the dynamics and relations at the transnational level. Such questions require a comparative study and, in our view, a new methodology. In a Hegelian tradition, the state guarantees that you are recognized so subjectivity is possible. In other words, the state expresses who people are. We ask: is this Hegelian tradition sufficient to understand human (e.g. educational) relations between nation states?

\section{Toward a Non-affirmative Hermeneutic Approach for Studying Educational Leadership, Curriculum and Didaktik}

In this section, we conclude our initiative by some reflections regarding epistemology and research methodology for studying educational leadership in a broad understanding of the concept. In this chapter we initially pointed out that large portions of research into leadership, curriculum and Didaktik have been framed by and grounded in various epistemological positions (critical theory, versions of positivism, and hermeneutics, postmodern positions). Often research is also profiled by 
identifying it representing certain methodology (discourse analysis, phenomenology, narrative research, etc.). It is indeed vital to establish a clear understanding regarding epistemological and methodological issues. However, as we have argued, research may also be guided by theory regarding its object. What do we understand by education in the first place? From our argumentation in this chapter it should be clear that we think we have been able to identify a very fundamental level of theorizing not only educational leadership, but also Didaktik and curriculum studies. We also think there has been several reasons to why re-theorizing these fields have been motivated.

The level at which we locate the non-affirmative theory of education is both foundational, and it is general, yet non-foundational in its epistemological attitude. The strength is obviously that we take our point of departure in the question of public and institutional schooling in our globalized world. We have also shown how we locate ourselves in the western, modern tradition without assuming any epistemological primacy of it (Paraskeva 2016). We have pointed out that the modern classics speak to us with convincing arguments, but that some of these connections have become forgotten. We also recognize the visionary qualities of these classics: while these theories were developed parallel or in relation to establishing modern nation states, these were years still far from anything like political democracies. The seminal ideas of modern education we have laid out were developed around a century before the introduction of the any early introduction of democratic popular vote (e.g. in 1906 in Finland) and it is still relevant more than 100 years after its introduction.

When saying that this position is epistemologically non-foundational it is not an acceptance of relativism nor that the theory advocated is a universal one. Universal theories might be necessary, but they are considered, in principle, impossible to achieve in education (Uljens 2002). This insight in the relative validity of education theory is not anything that has resulted from late-modern thinking (Rorty 1989), rather it has been understood within the discipline since long. Still we want to acknowledge that the late-modern period in philosophy helped us to clearly realize the limited validity of such a theory across cultures, partly representing other epistemologies. We see possibilities with critical hermeneutics for understanding Bildung and education in a globalized world (Kristensson Uggla 2010).

We think there is a value in engaging in an as-if foundational thinking in education theory given that foundational theorizing may be non-foundationalist regarding its epistemology stance. Maybe even more today than before. With the rapid expansion and differentiation of the pure quantity of research in addition to the urgent need for educational leadership research, curriculum studies, and policy research to support societal developmental work at different levels, combined with high pressure on publishing activity may have resulted in loss of theoretical groundwork and anchoring. We hope to some extent have met this need with this volume. Also we want to recognize the yet high quality of research on the various fields we reviewed. The task has not been easy and we hope we have succeeded in doing justice for work done. 
This project was initially driven by an European-American comparative interest (Uljens and Ylimaki 2015). We believe having pointed out that this theoretical framework recognizes common roots to American and European education theory and research, this hopefully for its part will enhance future dialogue. In a global perspective, for European and American research on curriculum, Didaktik and leadership to be able to communicate with e.g. Asian or Chinese traditions requires profound insights in one's own tradition.

We have also pointed out limitations we feel this foundational theory approach has for empirical research. The limitation does not consist in a conceptual weakness, although many aspects may be developed further. Rather, the position lacks conceptual structures for grasping the organisational dimension of institutionalized education. Second, we feel that discursive institutionalism offers us a policy language that does not emanate from education theory, but through which educational phenomena may be more easily understood. Third, increasing pluralisation of cultures within nation states across the world require us to develop a sensitivity which certainly was not present among philosophers of education 200 years ago, although the principles developed make sense as a foundation for this research. Fourth, as so much theory construction also education theory development has been carried out with the nation-state as the frame of reference. By our analysis of cosmopolitanism, and as we have called it, globopolitanism, we address questions and invite readers to rethink the relation between the global, the state and the local from an education theory perspective. Finally, we see educational leadership as truly a multi-level phenomenon where leaders mediate between and across levels.

We have also pointed out that an organizational perspective is required to grasp both educational leadership and teaching. In addition historical and cultural awareness and a policy perspective is considered necessary. In this respect we support a Habermasian awareness of both the systems-perspective and a life-world perspective. Throughout arguing for the non-affirmative position we have pointed out that at all levels of the education system there are individuals involved. Education cannot be understood without ethics, as supporting growth of ethical reasoning among learners is a topic of education but also as ethics is constitutive for educative activity itself. For these reasons we think that Ricoeur's (1989, pp. 114ff.) view of the relation between phenomenology and hermeneutics is valuable i.e. critical hermeneutic phenomenology. This position accepts the problem of meaning as the fundamental one both in interpretation theory or hermeneutics and phenomenology, but also in policy and education in general as well as in leadership. As Ricoeur (1989, p. 114) notes, in order for meaning to become a hermeneutic problem "the central question of phenomenology must be recognized as a question of meaning".

The problem of meaning in phenomenology refers to the nature of an experience, which again has a political, historical, cultural and a lingual aspect as discussed in Ricoeur (1989, p. 115). A second perspective on the relation between phenomenology and hermeneutics advocated by Ricoeur and conceived of as relevant here, is the distanciation from the "experience of belonging" (ibid., p. 116). That is, there is a connection between the hermeneutic concept of distanciation and the phenomenological epoché (bracketing), as long as the epoché is conceived of as "the intentional 
movement of consciousness towards meaning". In other words, to distance us from lived experience means to "interrupt lived experience in order to signify it" (ibid., p. 116). As previously pointed out we think this is close to what non-affirmative educational leadership and teaching is about, but in education the interruption in the Other's experiencing is done through the educative act. The relevance of this position for empirical research is first it helps us to define the relation between theory and practice as pedagogical practice and as empirical descriptions of this practice. Let us explain.

Sometimes it is claimed that pedagogical practice is primary in relation to educational theory, i.e. that practice is not dependent on theory. Schleiermacher's widely referred position from 1826 may exemplify this: "Still, it is nevertheless a fact that in every domain that goes under the name of Art, in a narrower sense, practice is much older than theory, so that it can simply not be said that practice gets its own definite character only with theory. The dignity of practice is independent of theory; practice only becomes more conscious with theory." Naturally the educational practice (Bildungswirklichkeit) is much older compared with a contemporary understanding of theory. Educational practice also continues to exist regardless of our description of it in the naive sense that it does not cease to exist if we stop talking about it. At least it would continue to exist as past "lived experience" (Van Manen 1991). However, in such past lived experience the meaning of the experience is not always evident. Therefore, precisely as Schleiermacher argues, a fundamental feature of theory is that it helps us to deepen our understanding of pedagogical reality. However, a deepening of our understanding must not be compared with a more detailed description of practice. To deepen our understanding is more; every description always has a constitutive function as well. Taken for granted that some kind of reflection is always connected with practice in a constitutive fashion, i.e. that practice gets its meaning only by virtue of this reflection, then practice is, exactly as Schleiermacher claims, not independent of theory (Bowie 1998). In this respect educational theory would now be primary in relation to practice; practitioners' theories contributes to defining the essence or the meaning of educational reality for the actor. In describing these core elements related to research, Max van Manen (1991) argued that phenomenological research is a lived experience for researchers as they relate with the ontological nature of the phenomenon while learning to "see" prereflective, taken-for-granted and essential understandings through the lens of their always already pre-understandings. van Manen (1991) posits principles for research activities: commitment to an abiding concern, oriented stance toward the question, investigating the experience as it is lived, describing the phenomenon through writing and rewriting, and consideration of parts and whole.

The conclusion defended here is that instead of claiming that theory is secondary to practice or that practice is secondary to theory, we should ask: "What kind of reflection is present in practice?" This position represents critical realism (or "epistemic" realism, Putnam 1988). In this view the world itself does not contain the limits for how it may be described. Only the describers themselves may decide upon which rules are to be followed, since the description is made in relation to previous 
knowledge and with certain interests in a given cultural and historical context. This means that models can be tested empirically, provided that the assumptions behind them are accepted.

One of the main roles non-affirmative theory has, with respect to empirical research, is that it offers us a framework for an empirical research programme regarding leadership and teaching practice including policy analysis, curriculum analysis and research supported school development. The non-affirmative theory also provide us with a thought model for teachers, principals, superintendents, officials at the national and transnational levels. The actual conceptual structure is a theory in the sense that it offers us a conceptual structure for our observations of the pedagogical reality. It is a constitutive theory defining what institutionalized education is about in the first place. Differently expressed, the analysis carried out is an ontological one as it asks about the fundamental nature of the institutionalized leadership-teaching-studying-learning process. Non-affirmative theory of education presents itself as a third position beyond traditional critical theory and functionaltechnological Tylerian models. The position is by no means valuefree or -neutral as it is a theory in and for a western democratic tradition as this has developed the past century. It criticality is visble in its non-affirmative stance demanding ethical, political, cultural and conceptual awareness from the practitioner. However, the practitioner must understand the difference between indoctrination and support for developing critical thinking among students but also professionals. At its core the position is a critical reminder that politics is not allowed to make use of education in its own interest, violating the possibility of contemporary and future democratic forms of social and societal life.

Comparative Inquiry Cross-national comparativists have long considered contextual differences within nation states, including cultures and language that affect categorical definitions; however, current challenges to the nation state raise new methodological dilemmas. Processes of transnationalization, such as the development of the European Union, have challenged the foundations of comparative social sciences methods as well as curriculum-leadership work itself with regards to the sovereign state and autonomous society. We agree with Charles Tilly (1984), who has written extensively about globalization movements, criticized the modern tendency for use of nation states as bounded units of comparative analysis because a strict focus on the nation state has run its course in a world characterized by vast population movements and vertical plurality which undermine the ideal of cultural solidarity. Further, neoliberalism, with its accompanying movements of capital, and the increasing relevance of transnational institutions may subvert formal procedures of inquiry with the nation-state as a strict, bounded analytical unit of comparison. In the contemporary situation, comparative inquiry approaches have also come under recent scrutiny because of the contradiction between different time-scales of different cultures and the linear conception of time (e.g. Abbott 1991; Sztompka 1990). As Sztompka (1990) has argued, globalization of the social world with its increasing plurality has reversed the cognitive and societal situation from one where a century ago heterogeneity and societal isolation was the reality. 
In our view, there will continue to be nation states with leadership and curriculum making occurring at school, district/municipal, state and nation state levels; however, in light of the contemporary situation, our methodological use of the nation state will be dynamic rather than static. We will compare similarities and differences within and between levels from classrooms to transnational levels amidst the current globalization moment. We will, thus, examine the ways in which globalization binds nation states/societies together along many dimensions, but simultaneously, illuminates diversity. Further, in our sampling and data analysis processes, we acknowledge the significance of diversity in terms of individual educators' and/or policymakers' habitus to interculturality or relations between individuals/subjects from distinct cultures. As noted earlier, in light of globopolitanism with its population migrations between nation states and increasing cultural plurality within nation states, interculturality is critically important to any human relations.

Thus, our research project seeks an alternative form of comparative inquiry for a multi-level examination of curriculum guides, leadership education standards or aims, policies, curriculum work-leadership within and between levels from classrooms to transnational levels. Specifically, we propose a formative comparative approach with an emphasis on contemporary moments that are informed by historical and cultural roots as well as the rapidly changing contemporary situation at the nation state and transnational levels, all of which are also shaped in certain ways by individuals with varying cultural backgrounds or habitus and epistemologies. This does not mean that we embrace plurality and diversity for its own sake. Rather, we address diversity, using comparison reflexively to situate diversity in the encounter of curriculum documents and inherent aims, policies, principal development documents, and educational relations amidst contemporary cosmopolitanism as an empirical reality and related dilemmas of universalism versus particularism.

In our view, a comparative research project examining curriculum workleadership must also entail a reflexive relation among fundamental social philosophy and its strength in pedagogical relations with more contemporary, postmodern philosophy (e.g. Deleuze) and its strength in identity. In our view, this reflexive relation involves simultaneously differentiating globalizing cultural times cognitively in policy and subject relations where the subject is considered, with some variation between the nation state curriculum/evaluation policy and leadership preparation level and the transnational policy level. At the nation state level (and states within these), we have curricula (e.g. content, methods) as well as policies. For our project, we ask: How do nation states initiate, develop, and mediate curriculum changes or reforms? If appropriate, we also ask how do states within nation states initiate, develop, and mediate curriculum changes or reforms? How are various nation states, with their differing cultural and historical traditions, responding to global, common changes and dilemmas? What are the conceptions of citizens' Bildung, skills, and learning of each nation state and how are these promoted through policies and the process of education? At the transnational level, we do not have curricula; rather, we have transnational curriculum and evaluation policies that could be compared. We ask: What curriculum and evaluation policies are promoted by transnational organizations as members of continuously evolving configurations 
of nation state systems and how is this promotion carried out? Here we may consider curriculum as a culture emerging in relations within and between new forms of governance. At school and district/municipality levels, we then ask: What notions of curriculum are promoted by transnational organizations, nations, and states, and how do they mediate among these and their students? How, if at all, did their principal and superintendent preparation support their curriculum work? At all levels, we acknowledge that categories are discursive, dynamic, and evolving within and between nation states.

A Note on Methods It is important to note that a refined version of critical discourse analysis or CDA (Fairclaugh 2005) is necessary because CDA begins with a normativity problem in clear social transformative ideal and an aim to correct a societal wrong. Our framework, rather, supports a non-hierarchical, non-affirmative perspective on criticality as well as an institutional perspective (Schmidt 2008a), and these combined perspectives necessitate a refined view of criticality to ground our discursive analyses. We also note, however, that some relations within and between levels may be affirmative and others may be non-affirmative, with for example, evaluation policies and legislations that are mandatory necessitating perhaps more affirmative perspectives and mediational approaches. Thus, we seek comparisons of connected segments that reveal emergent and, at times, contradictory discursive dynamics within classrooms, schools, districts, municipalities and/ or states, as well as in transnational relations between these nation states. Our framework will form the basis for data analysis of interview transcripts, including attention to discursive institutionalism (Schmidt) that may illuminate similarities, distinctions, old and new paradoxes, and emergent new constructions (Schmidt 2015). In so doing, we draw on discursive institutionalism for understanding how cognitive ideas (problems identification) and normative ideas (values that legitimize problems) are developed and communicated across societal, philosophical, policy, and program levels as well as how discursive constructions shape human educational/pedagogical relations. Going beyond Schmidt $(2009,2016)$, then, we analyze data, looking for a language of education, beginning with modern education theory and its core concepts (Benner 1991). From this foundational theoretical framing and methodological possibilities, we now introduce the remaining chapters in this volume.

\section{Overview of Book Structure}

This opening chapter presented a common general framework that brings two significant but yet unfortunately disparate fields (curriculum theory, leadership studies) closer together along with critical understandings from discursive institutionalism. Our framework moves beyond the limitations of curriculum theory/Didaktik (i.e. the lack of attention to the interplay between aims, contents, methods and leadership roles at various levels, the normative nature of dominant curriculum theories 
and their regulatory and transformational aims and underlying epistemologies and ontologies; limited language to talk about various systems). Discursive institutionalism, combined with classic educational philosophy concepts (recognition, summoning, Bildsamkeit), creates a language for curriculum work and other human-institutional interactions, including those concerning the broader system (e.g. law, policy documents). In our framework, then, curriculum theory/Didaktik (societal aims, content, methods, planning), leadership/institutional studies (structure) and policy (ideas) now complete each other conceptually. Educational leadership, including curriculum work is, thus, conceptualized as:

a non-affirmative, critical-interpretative and cultural-historical distributed multiprofessional practice carried out on different levels of the educational system, operating between different cultures, epistemologies (knowledge practices) and value-spheres (ethics and politics) where professional actors, through their roles (tasks) and persons, based on a recognition of the Other's potentiality, reality and possibility, aim at supporting teachers/ principals/students by summoning (inviting, intervening, demanding, supporting provocation) to engage in the transcendence of one's current pedagogical work.

As such, educational leadership may be accomplished through activities such as developing routines and cultures of change as well as post-national pedagogies, in order to create dynamic and reflected teaching opportunities, so that students become able to grow into an existing world while being prepared to change it according to their interests as related to others in a deliberative democracy. At the same time, we recognize that much of the theoretical and empirical work on educational leadership has been constructed for relations within the nation state.

Thus, we posed a third question derived from the ongoing crisis of the nation state, due to what we have termed globopolitanism. For over 200 years, in many parts of the world, independent nation states have developed education based upon the idea of culturally uniting 'the autonomous individual', most often through a common language. In the contemporary empirical reality, nation states remain legally and politically; however, new transnational and international institutions and organisations challenge the autonomy of nation states. Today, cosmopolitanism presents itself as a practical educational challenge due to global interdependencies as well as increasing internal, horizontal, ethnic plurality. Thus, while we see modern education theory and its core concepts essential for relations within and between levels of the nation state, we must consider the extent to which these core concepts are sufficient for understanding increasing transnational level of educational leadership and curriculum work relations. Moreover, in line with our non-affirmative position, we must continually live with the future as an open question, thus leaving our own framework a living, dynamic project open to question and revision. We hope our general framework may inform a new education field for theorizing curriculum/Didaktik and leadership according to which leadership and teaching professions may be conceptualized in a coherent way, not following different theoretical logics. Such a new research field requires a new comparative methodology. Further, we argue that our research agenda may also be productive for schools and new forms of governance at all levels as reflective professional learning communities being critically policy aware in their curriculum content and pedagogical develop- 
mental work amidst globopolitanism with perennial and contemporary tensions between unity and plurality.

\section{An Invitation to a Cross-National Dialogue}

The remainder of the book is organized into four additional parts. The first part provides a review of curriculum theory and Didaktik in the U.S. and Europe from authors who have been leaders in these traditions, including Stefan Hopmann and his colleague Mariella Knapp from Europe and Walter Doyle from the United States. In the second part, Lejf Moos, Gert Biesta, Tero Autio, and Joao Paraskeva further consider the societal and policy context for contemporary educational leadership and curriculum work. The third part brings leadership in closer dialogue with curriculum theory/Didaktik with chapters from Ira Bogotch, Dilys Schoorman, and Daniel Reyes-Guerra considering multicultural education and leadership, Daniel Castner, Rosemary Gornik, James Henderson and Wendy Samford with a constructive alternative to the Tyler Rationale in teacher leadership, Bill Pinar's chapter on rethinking authority in educational leadership, and Eva Forsberg, Elisbet Nihfors, Daniel Petterson and Pia Skott considering the commodification of the Swedish curriculum, leadership, and the need for a new code. Finally, in Part V, we explore discursive and multi-level perspectives with Michael Uljens and Helena Rajakaltio's chapter on national curriculum reform in Finland and Kirsten Sivisend and Ninni Wahlström's chapter on curriculum-leadership in transnational reform policy in Norway and Sweden.

One of the recurring themes across the chapters is a call for a renewed crossnational and cross-field/disciplinary dialogue on curriculum theorizing/Didaktik and leadership in an era of what we term globopolitanism. We hope that readers of this volume will approach the reading of this text as an opportunity to challenge their thinking and a space for dialogue as well, bringing their own theoretical backgrounds, experiences, thoughts, aims, and values to bear on the propositions and challenges that are raised and considered. We acknowledge that some authors and readers may be left with questions and ideas more than answers as cosmopolitanism and globalization challenge us to consider curriculum and leadership beyond the nation state level; however, we believe that the non-affirmative framework and this volume opens a space for a renewed and thoughtful dialogue on these issues. Future directions may include further cross-national dialogue toward new theoretical possibilities, a further consideration of cosmopolitanism as an empirical ideal and empirical reality, new comparative studies as well as new, less normative, approaches to educational leadership and curriculum work/leadership practice within and between levels. We hope that our framework and the kind of cross-field/disciplinary and cross-national dialogue initiated here will ultimately construct a foundation for the kind of curriculum-leadership work those of us who participated in this project seek to foster. This volume, thus, concludes with our own final thoughts about moving forward as well as commentaries from William Pinar, Carolyn Shields, and 
Thomas Englund, who contribute to this new cross-national dialogue from a North American context and a Nordic/European context as well as from curriculum and leadership perspectives.

\section{References}

Abbott, A. (1991). The order of professionalization: An empirical analysis. Work and Occupations, $18(4), 355-384$.

Althusser, L. (1970/2006). Ideology and ideological state apparatuses (notes towards an investigation). The Anthropology of the State: A Reader, 9, 86.

Anderson, G. L. (2009). Advocacy leadership: Toward a post-reform agenda in education. New York: Routledge.

Anyon, J. (2006). Social class and the hidden curriculum of work. Childhood Socialization, 162, 369.

Anyon, J. (2008). Social class and school knowledge. In The way class works: Readings on schools, family and the economy (pp. 189-209). London: Routledge

Apple, M. W. (1992). The text and cultural politics. Educational Researcher, 21(7), 4-19.

Apple, M. W. (2004). Ideology and curriculum. New York: Routledge.

Apple, M. W. (2005). Education, markets, and an audit culture. Critical Quarterly, 47(12), 11-29.

Apple, M. W. (2008). Knowledge, power, and education: The selected works of Michael Apple. Shanghai: East China Normal University Press.

Apple, M. W. (2014). Official knowledge: Democratic education in a conservative age. New York: Routledge.

Apple, M. W., \& Weis, L. (1986). Seeing education relationally: The stratification of culture and people in the sociology of school knowledge. Journal of Education, 168, 7-34.

Arnot, M., \& Whitty, G. (1982). From reproduction to transformation: Recent radical perspectives on the curriculum from the USA. British Journal of Sociology of Education, 3(1), 93-103.

Aronowitz, S., \& Giroux, H. (1985). Radical education and transformative intellectuals. CTheory, 9(3), 48-63.

Autio, T. (2006). Subjectivity, curriculum and society: Between and beyond the German Didaktik and Anglo-American Curriculum Studies. Mahwah: Lawrence Erlbaum Associates.

Autio, T. (2009). Globalisation, curriculum and new belongingness of subjectivity. Beyond the nexus between psychology (curriculum) and the nation-state (Didaktik). In E. Ropo \& T. Autio (Eds.), International conversations on curriculum studies (pp. 1-20). Dordrecht: Sense.

Autio, T. (2013). Subjectivity, curriculum, and society: Between and beyond the German Didaktik and Anglo-American Curriculum studies. Mahwah: Lawrence Erlbaum Associates.

Avolio, B. J., Bass, B. M., \& Jung, D. I. (1999). Re-examining the components of transformational and transactional leadership using the Multifactor Leadership. Journal of Occupational and Organizational Psychology, 72(4), 441-462.

Banks, J. A. (2002). Race, knowledge construction, and education in the USA: Lessons from history. Race, Ethnicity and Education, 5(1), 7-27.

Banks, J. A., \& Banks, C. A. M. (2009). Multicultural education: Issues and perspectives. New York: Wiley.

Barnard, C. I. (1968). Functions of an executive. Cambridge, MA: Harvard University Press.

Bass, B. M. (1985). Leadership and performance beyond expectations. London: Free Press/Collier Macmillan.

Bass, B. M., \& Avolio, B. J. (1990). Developing transformational leadership: 1992 and beyond. Journal of European Industrial Training, 14(5), 21-27.

Beck, U. (2006). Cosmopolitan vision. Cambridge: Polity Press.

Bengtsson, J. (2003). Possibilities and limits of self-reflection in the teaching profession. Studies in Philosophy and Education, 22(3/4), 295-316. 
Benner, D. (1991). Allgemeine Pädagogik. Weinheim: Juventa.

Benner, D. (1993). Die Pädagogik Herbarts. Weinheim: Juventa.

Benner, D. (1995). Wilhelm von Humboldts Bildungstheorie: Eine problemgeschichtliche Studie zum Begründungszusammenhang neuzeitlicher Bildungsreform. Weinheim: Juventa.

Benner, D. (1997). Johann Friedrich Herbart. Systematische Pädagogik Band 2: Interpretationen. Weinheim: Deutschen Studien Verlag.

Benner, D. (2005). Tekster til dannelsesfilosofi-mellem etik, paedagogik och politik. (Essays on philosophy of Bildung - between ethics, pedagogics and politics). Århus: Klim.

Benner, D. (2015). Allgemeine Pädagogik (8. upplagan). Weinheim: Beltz Juventa.

Benner, D., \& English, A. (2004). Critique and negativity: Towards the pluralisation of critique in educational practice, theory and research. Journal of Philosophy of Education, 38(3), 409-428.

Bennett, J. V., Ylimaki, R. M., Dugan, T. M., \& Brunderman, L. A. (2014). Developing the potential for sustainable improvement in underperforming schools: Capacity building in the sociocultural dimension. Journal of Educational Change, 15(4), 377-409.

Berliner, D. C. (1989). Implications of studies of expertise in pedagogy for teacher education and evaluation. In J. Pfleiderer (Ed.), New directions for teacher assessment: Proceedings of the 1988 ETS invitational conference (pp. 39-67). Princeton: Educational Testing Service.

Berman, P., \& McLaughlin, M. W. (1976). Implementation of educational innovation. The Educational Forum, 3(40), 345-370.

Bernstein, B. (1975). Class and pedagogies: Visible and invisible. Educational Studies, 1, 23-41.

Biesta, G. (1994). Education as practical intersubjectivity. Towards a critical- pragmatic understanding of education. Educational Theory, 44(3), 299-317.

Biesta, G. (2009). Good education in an age of measurement: On the need to reconnect with the question of purpose in education. Educational Assessment, Evaluation and Accountability, 21(1), 33-46.

Blackburn, S. (1996). Securing the nots: Moral epistemology for the quasirealist. In New readings in moral epistemology. Oxford: University Press.

Blankertz, H. (1982). Die Geschichte der Pädagogik. Von der Aufklärung bis zur Gegenwart. Wetzlar: Pandora.

Blossing, U., Imsen, G., \& Moos, L. (2014). The nordic education model: "A school for all" encounters neo-liberal policy. Dordrecht: Springer.

Bobbitt, J. F. (1918). The curriculum. Boston: Houghton Mifflin.

Bogotch, I. (2002). Educational leadership and social justice: Practice into theory. Journal of School Leadership, 12, 138-156.

Bohman, J., \& Lutz-Bachmann, M. (1997). Perpetual peace: Essays on Kant's cosmopolitan ideal. Cambridge: The MIT Press.

Boske, C. (2014). Critical reflective practices: Connecting to social justice. In International handbook of educational leadership and social (in) justice. Dordrecht: Springer.

Bourdieu, P. (1977). Outline of a theory of practice (Vol. 16). Boston: Cambridge University Press.

Bourdieu, P. (2011). The forms of capital (1986). Cultural Theory: An anthology, 1, 81-93.

Bourdieu, P., \& Passeron, J. C. (1990a). Reproduction in education, society and culture (Vol. 4). Newbury Park: Sage.

Bourdieu, P., \& Passeron, J. C. (1990b). Reproduction in education, society and culture (Vol. 4). London: Sage.

Bowie, A. (1998). Introduction. In F. D. E. Schleiermacher (Ed.), Hermeneutics and criticism. And other writings. Cambridge: Cambridge University Press.

Bowie, A. (2003). Aesthetics and subjectivity. Manchester: Manchester University Press.

Bowles, S., \& Gintis, H. (1975). Schooling in capitalist America (Vol. 57). New York: Basic Books.

Bowles, S., \& Gintis, H. (1976). Schooling in capitalist America: Educational reform and the contradictions of economic life. New York: Basic Books.

Braun, A., Maguire, M., \& Ball, S. J. (2010). Policy enactments in the UK secondary school: Examining policy, practice and school positioning. Journal of Education Policy, 25(4), $547-560$.

Brincat, S. (2009). Hegel's gesture to radical cosmopolitanism. Journal of Critical Globalisation Studies, 1, 47-65. 
Bromme, R. (1995). What exactly is 'pedagogical content knowledge'? Critical remarks regarding a fruitful research program. In S. Hopmann \& K. Riquarts (Eds.), Didaktik and/or curriculum (pp. 2015-2216., Report 147). Kiel: Institut für die Pädagogik der Naturwissenschaften an der Universität Kiel.

Brooks, J. S. (2012). Black school, White school: Racism and educational (mis)leadership. New York: Teachers College Press.

Brooks, J. S., Jean-Marie, G., Normore, A. H., \& Hodgins, D. W. (2008). Distributed leadership for social justice: Exploring how influence and equity are stretched over an urban high school. Journal of School Leadership, 17(4), 378-408.

Brown, A., Collins, A., \& Duguid, P. (1989). Situated cognition and the culture of learning. Educational Researcher, 18(19), 32-42.

Brunner, C. (1998). Women superintendents: Strategies for success. Journal of Educational Administration, 36(2), 160-182.

Brunner, C. C., Opsal, C., Oliva, M. (2006). Disrupting identity: Fertile soil for raising social consciousness in educational leaders. In Leading for social justice: Making revolutions in education (pp. 214-232). Boston: Allyn \& Bacon.

Bu, Y., Xu, J., \& Deng, Z. (2016). The new basic education and the development of human subjectivity. In G. Zhao \& Z. Deng (Eds.), Re-envisioning Chinese education: The meaning of person-making in a new age (pp. 201-2012). New York: Routledge.

Burns, J. M. (1978). Leadership. New York: Harper \& Row.

Burrell, G., \& Morgan, G. (2003). Sociological paradigms and organisational analysis (Vol. 248). London: Heinemann.

Caldwell, B. J. (1998). Strategic leadership, resource management and effective school reform. Journal of Educational Administration, 36(5), 445-461.

Callahan, R. E. (1962). Education and the cult of efficiency. Chicago: University of Chicago Press.

Callon, M. (1980). Struggles and negotiations to define what is problematic and what is not. In The social process of scientific investigation (pp. 197-219). Dordrecht: Springer.

Capper, C. A. (1989). Students with severe disabilities in the general education program: A conceptual and practical framework for rural school administrators. Journal of Rural and Small Schools, 41(1), 52-59.

Capper, C. A. (1993). Educational administration in a pluralistic society. New York: State University of New York Press.

Capper, C. A., Frattura, E. M., \& Keyes, M. W. (2000). Meeting the needs of students of all abilities: How leaders go beyond inclusion. Newbury Park: Corwin Press.

Cerny, P. G. (1997). Paradoxes of the competition state: The dynamics of political globalization. Government and Opposition, 32(02), 251-274.

Chi-Kin Lee, J., \& Kennedy, K. J. (2017). Theorizing teaching and learning in Asia and Europe: A conversation between Chinese curriculum and European didactics. London: Routledge.

Claesson, S., Hallström, H., Kardemark, W., \& Risenfors, S. (2011). Ricoeurs kritiska hermeneutik vid empiriska studier. Pedagogisk Forskning i Sverige, 1(16), 18-35.

Clarke, S., \& Wildy, H. (2009). The Europeanisation of educational leadership. European Educational Research Journal, 8(3), 352-475.

Cleve, Z. J. (1884). Grunddrag till skolpedagogik (Foundations of School Pedagogics). Helsingfors: Edlunds.

Cobben, P. (2010). Institutions of education, then and today: The legacy of German idealism. Leiden: Brill.

Cole, M., \& Engeström, Y. (1993). A cultural-historical approach to distributed cognition. In G. Salomon (Ed.), Distributed cognitions: Psychological and educational considerations. Cambridge: Cambridge University Press.

Coleman, J. S., \& National Center for Educational Statistics. (1966). Equality of education opportunity. Washington, DC: U.S. Department of Health, Education and Welfare.

Comenius, J. A. (1907). The great didactic. (M. W. Keatinge, Transl.). London: Adam and Charles Black. https://archive.org/stream/cu31924031053709\#page/n11/mode/2up 
Cooper, P. M. (2003). Effective White teachers of Black children teaching within a community. Journal of Teacher Education, 54(5), 413-427.

Cooper, C. W. (2009). Performing cultural work in demographically changing schools: Implications for expanding transformative leadership frameworks. Educational Administration Quarterly, $45,694-724$.

Crossley, N. (1996). Intersubjectivity. The fabric of social becoming. London: Sage.

Crow, G., Day, C., \& Møller, J. (2016). Framing research on school principals' identities. International Journal of Leadership in Education, 1-13.

Czarniawska, B. (2014). A theory of organizing (2nd ed.). Cheltenham: Edward Elgar.

Czarniawska, B., \& Sevón, G. (1996). Translating organizational change. Berlin: Walter de Gruyter.

Czarniawska, B., \& Sevón, G. (2005). Global ideas. How ideas, objects and practices travel in the global economy. Malmö: Liber.

Dahllöf, U. (1967). Skoldifferentiering och undervisningsförlopp. Stockholm: Almqvist \& Wiksell.

Dall'Alba, G., \& Sandberg, J. (2006). Unveiling professional development: A critical review of stage models. Review of Educational Research, 76(3), 383-412.

Damgaard Knudsen, L. E., \& Andersson, M. (2008). Skab dig! Paedagogisk filosofi. Köpenhamn: Forlaget Unge Pedagoger.

Devos, G., Ekholm, M., Kofod, K., Louis, K. S., Moos, L., Schratz, M., \& van Velzen, B. (2012). Political culture and educational reform. In Educational policy in an international context (pp. 5-27). Palgrave Macmillan US.

Day, C. (2005). Sustaining success in challenging contexts: Leadership in English schools. Journal of Educational Administration, 43(6), 573-583.

Deleuze, G., \& Guattari, F. (1988). A thousand plateaus: Capitalism and schizophrenia. London: Athlone.

Deng, Z. (2016). Rethinking and re-envisioning Chinese didactics. Implications from the German Didaktik tradition. In G. Zhao \& Z. Deng (Eds.), Re-envisioning Chinese education: The meaning of person-making in a new age (pp. 183-199). New York: Routledge.

Dewey, J. (1916/2008). Democracy and education. Boston: Seven Treasures (Original work published in 1916).

Dewey, J. (1938). Experience and education (The Kappa Delta Pi Lecture Series). New York: Collier Books.

Dewey, J. (1959). The child and the curriculum (No. 5). Chicago: University of Chicago Press.

Dewey, J. (1990/1915). The school and society and the child and the curriculum. Chicago: University of Chicago Press.

Dewey, J. (1992). The structure of experience. Chicago: Chicago University Press.

Dewey, J. (2008). Democracy and education. Boston: Seven Treasures. Original work published in 1916.

Dewey, J., \& Small, A. W. (1897). My pedagogic creed (No. 25). Chantilly: EL Kellogg \& Company.

Diederich, J. (1988). Didaktisches Denken. Weinheim: Juventa.

Dillard, C. B. (2000). The substance of things hoped for, the evidence of things not seen: Examining an endarkened feminist epistemology in educational research and leadership. International Journal of Qualitative Studies in Education, 13(6), 661-681.

Dilthey, W. (1883). Einleitung in die Geisteswissenschaften. Versuch einer Grundlegung für das Studium der Gesellschaft und der Geschichte. Leipzig: Duncker \& Humblot.

DiMaggio, P. J., \& Powell, W. W. (1983). And collective rationality in organizational fields. American Sociological Review, 48(2), 147-160.

DiMaggio, P. J., \& Powell, W. W. (1991). The new institutionalism in organizational analysis. Chicago: University of Chicago Press Books.

Dimitriadis, G. (2009). Performing identity/performing culture: Hip hop as text, pedagogy, and lived practice (Vol. 1). New York: Peter Lang.

Dolch, J. (1965). Lehrplan des Abendlandes (2nd ed., orig. 1959). Ratingen: Aloys Hann Verlag. 
Doll, W. E. (1993a). Curriculum possibilities in a "post-future". Journal of Curriculum and Supervision, 8(4), 277-292.

Doll, W. E. (1993b). A post-modern perspective on curriculum. New York: Teachers College Press. Doyle, W., \& Carter, K. (1984). Academic tasks in classrooms. Curriculum Inquiry, 14(2), 98.

Dreyfus, H. L., \& Dreyfus, S. E. (1986). Mind over machine: The power of human intuition and expertise in the era of the computer. New York: The Free Press.

Drucker, H. M. (1974). The political uses of ideology. Dordrecht: Springer.

Drysdale, L., Bennett, J. T., Murakami, E., Johansson, O., \& Gurr, D. (2014). Heroic leadership in Australia, Sweden, and the United States. International Journal of Educational Management, 28(7), 785-797.

DuFour, R., \& Eaker, R. (1998). Professional learning communities at work: Best practices for enhancing student achievement. Bloomington: Solution Tree.

Durkheim, E. (1997). Suicide. New York: Free Press. (Original work published 1893).

Edmonds, R. (1979). Effective schools for the urban poor. Educational Leadership, 37(1), 15-24.

Engeström, Y. (1987). Learning by expanding. Orienta: Helsinki.

Engeström, Y. (2000). Activity theory as a framework for analyzing and redesigning work. Ergonomics, 43(7), 960-974.

Engeström, Y., Miettinen, R., \& Punamäki, R.-L. (1999). Perspectives on activity theory. Cambridge: Cambridge University Press.

English, A. (2013). Discontinuity in learning. Dewey, Herbart, and education as transformation. Cambridge: Cambridge University Press.

English, A. (2014). Herbart, Johann F. In D. C. Phillips (Ed.), Encyclopedia of educational theory and philosophy (pp. 373-376). Thousand Oaks: Sage.

Englund, T. (1986). Curriculum as a political problem. Changing educational conceptions with special reference to citizenship education (p. 25). Uppsala: Uppsala Studies in Education.

Englund, T. (1997). Undervisning som meningserbjudande (Teaching as meaning construction). In M. Uljens (Ed.), Didaktik (pp. 120-145). Lund: Studentlitteratur.

Englund, T. (2006). Deliberative communication: A pragmatist proposal. Journal of Curriculum Studies, 38(5), 503-520.

Fairclough, N. (2005). Analysing discourse. Textual analysis for social research. London: Routledge.

Fanon, F. (1963). The wretched of the earth. New York: Grove Press.

Fayol, H. (1949). General and industrial management. London: Pitman.

Fenwick, T., \& Edwards, R. (2010). Actor-network. New York: Routledge.

Fichte, J. G. (1796/1992). Foundations of transcendental philosophy (D. Breazeale, Trans.). New York: Cornell University Press.

Fichte, J. G. (2000). Foundations of natural right (F. Neuhouser (Ed.), M. Bauer, Trans.). Cambridge: Cambridge University.

Fichte, J. G. (2009). Fichte: Addresses to the German Nation. Cambridge: Cambridge University Press.

Follett, M. P. (1918). The new state: Group organization the solution of popular government. University Park: Penn State Press.

Follett, M. P. (1949). The essentials of leadership. In L. Urwick (Ed.), Freedom and coordination, Lectures in business administration by Mary Parker Follett (pp. 47-60). London: Management Publications Trust.

Follett, M. P., Metcalf, H. C., \& Urwick, L. F. (1942). Dynamic administration. New York: Routledge.

Forsyth, P. B., \& Hoy, W. K. (1978). Isbridge University preolation and alienation in educational organizations. Educational Administration Quarterly, 14(1), 80-96.

Foster, W. (1986). Paradigms and promises: New approaches to educational administration. Prometheus books.

Foucault, M. (1991). Governmentalité. In G. Burcell, C. Gordon, \& P. Miller (Eds.), The Foucault effect: Studies in governmentality (pp. 87-104). Hempel Hempstead: Harvester Wheatsheaf. 
Foucault, M. (1997). Ethics. Subjectivity and truth. New York: The New Press.

Frank, M. (1977). Das individuelle Allgemeine. Textstrukturierung und-interpretation nach Schleiermacher. Frankfurt am Main: Suhrkamp.

Fraser, N., \& Honneth, A. (2003). Redistribution or recognition? A political-philosophical exchange. London: Verso.

Freire, P. (1993). Pedagogy of the oppressed. 1970. New York: Continuum.

Freire, P. (2000). Pedagogy of the oppressed. New York: Bloomsbury (Original work published 1979).

Freire, P. (2004). Pedagogy of indignation. Boulder: Paradigm.

Friesen, N., \& Hamelock, M. (2012). Augustine, Wittgenstein, and "the Call" in Mollenhauer's forgotten connections: On culture and upbringing. Phenomenology \& Practice, 6(2), 94-107.

Friesen, N., \& Sævi, T. (2010). Reviving forgotten connections in North American teacher education. Klaus Mollenhauer and the pedagogical relation. Journal of Curriculum Studies, 142(1), 123-147.

Frontini, S. (2009). Global influences and national peculiarities in education and training: The Finnish case. In I. H. B. Holmarsdottir \& M. O’Dowd (Eds.), Nordic voices. Teaching and researching comparative and international education in the Nordic countries. Rotterdam: Sense Publishers.

Fullan, M. (2007). The new meaning of educational change. London: Routledge.

Gadamer, H.-G. (1975). Truth and method. London: Sheed and Ward.

Gallagher, S. (1992). Hermeneutics and education. New York: SUNY Press.

Gauthier, D. P. (1963). Practical reasoning. Oxford: Clarendon Press.

Genschel, P., \& Seelkopf, L. (2015). The competition state. In: S. Leibfried, E. Huber, M. Lange, J. D. Levy, \& J. D. Stephens (Eds.), The oxford handbook of transformations of the state. Oxford Handbooks Online. doi:10.1093/oxfordhb/9780199691586.013.12.

Giroux, H. (1980). Critical theory and rationality in citizenship education. Curriculum Inquiry, 10(4), 329-366.

Giroux, H. A. (1983). Theory and resistance in education: A pedagogy for the opposition. South Hadley: Bergin \& Garvey.

Gooden, M. A. (2012). What does racism have to do with leadership? Countering the idea of colorblind leadership: a reflection on race and the growing pressures of the urban principalship. Educational Foundations, 26, 67-84.

Goodlad, J. (1966). The development of a conceptual system for dealing with problems of curriculum and instruction. U.S. Department of Health, Education, and Welfare, Office of Education Cooperative Research Project No. 454. Los Angeles: Institute for the Development of Educational Activities, UCLA.

Gough, I. (2001). Globalization and regional welfare regimes. The East Asian case. Global Social Policy, 1(2), 163-189.

Gramsci, A. (1996). Prison notebooks (Vol. 2). New York: Columbia University Press.

Greene, M. (2001). Educational purposes and teacher development. In Teachers caught in the action: Professional development that matters (pp. 3-11). New York: Teachers College Press.

Greenfield, T. B. (1986). The decline and fall of science in educational administration. Interchange, $17(2), 57-80$.

Greenfield, W. (1987). Instructional leadership: Concepts, issues, and controversies. Newton: Allyn and Bacon.

Greenwood, R., \& Hinings, C. R. (1996). Understanding radical organizational change: Bringing together the old and the new institutionalism. The Academy of Management Review, 21(4), $1022-1054$.

Grek, S. (2008). From symbols to numbers: the shifting technologies of education governance in Europe. European Educational Research Journal, 7(2), 2018-2218.

Grek, S. (2009). Governing by numbers: The Pisa "effect" in Europe. Journal of Education Policy, 1(24), 23-37.

Grogan, M. (1996). Voices of women aspiring to the superintendency. New York: SUNY Press. 
Gronn, P. (2000). Distributed properties a new architecture for leadership. Educational Management \& Administration, 28(3), 317-338.

Guba, E., \& Lincoln, Y. (1994). Competing paradigms in qualitative research. In N. Denzin \& Lincoln (Eds.), Handbook of qualitative research (pp. 105-177). SAGE: Thousand Oaks.

Gudmundsdottir, S. (1988). Knowledge use among experienced teachers: Four case studies of high school teaching. Unpublished Doctoral Dissertation. Stanford: School of Education.

Gudmundsdottir, S., \& Shulman, L. (1987). Pedagogical content knowledge in social studies. Scandinavian Journal of Educational Research, 31, 59-70.

Gulick, L. (1937). Notes on the theory of organization. Classics of organization theory, 3, 87-95.

Gundara, J. (2000). Interculturalism, education and inclusion. London: Paul Chapman.

Gundem, B. B. (1995). Historical roots and contemporary foundations. In S. Hopmann \& K. Riquarts (Eds.), Didaktik and/or curriculum (pp. 43-56). Kiel: IPN.

Gundem, B. B. (2010). European curriculum studies. Continental overview. In C. Kriedel (Ed.), Encyclopedia of curriculum studies (pp. 354-358). London: Sage.

Gundem, B., \& Hopmann, S. (1998). Didaktik and/or curriculum: An international dialogue. New York: Peter Lang.

Gunter, H. M., Grimaldi, E., Hall, D., \& Serpieri, R. (2016). New public management and the reform of education: European lessons for policy and practice. London: Routledge.

Gustavsson, B. (1996). Bildning $i$ vår tid. Om bildningens möjligheter och villkor $i$ det moderna samhället. Stockholm: Wahlström \& Widstrand.

Habermas, J. (1981). New social movements. Telos, 49, 33-37.

Habermas, J. (1984). Theory of communicative action (Vol. 1). Boston: Beacon Press.

Habermas, J. (1996a). The European nation state. Its achievements and its limitations. On the past and future of sovereignty and citizenship. Ratio Juris, 9(2), 125-137.

Habermas, J. (1996b). Between facts and norms: Contributions to a discourse theory of law and democracy (W. Rehg, Trans.). Cambridge: Polity Press.

Hallinger, P. (2003). Leading educational change: Reflections on the practice of instructional and transformational leadership. Cambridge Journal of Education, 33(3), 329-352.

Hallinger, P. (2004). Meeting the challenges of cultural leadership: The changing role of principals in Thailand. Discourse Studies in the Cultural Politics of Education, 25(1), 61-73.

Hallinger, P. (2005). Instructional leadership and the school principal: A passing fancy that refuses to fade away. Leadership and Policy in Schools, 4(3), 221-239.

Hallinger, P., \& Murphy, J. (1985). Assessing the instructional management behavior of principals. The Elementary School Journal, 86(2), 217-247.

Hamilton, D. (1995). Order and structure in Didaktik and curriculum. In S. Hopmann \& K. Riquarts (Eds.), Didaktik and/or curriculum (pp. 71-84., Report 147). Kiel: Institut für die Pädagogik der Naturwissenschaften an der Universität Kiel.

Hamilton, D. (2000). The pedagogic paradox (or why no didactics in England?). In M. Uljens (Ed.), Pedagogikens problem. Kulturella utvecklingslinjer och teoretiska spörsmål (pp. 57-76). Vasa: Åbo Akademi, Department of Education.

Hamilton, D., \& Gudmundsdottir, S. (1994). Didaktik and/or curriculum? Curriculum Studies, 2(3), 345-350.

Hargreaves, A., Moore, S., Fink, D., Brayman, C., \& White, R. (2003). Succeeding leaders? A study of principal succession and sustainability. Toronto: Ontario Principals' Council. Retrieved February, 20, 2008.

Hargreaves, A., Halász, G., \& Pont, B. (2007). School leadership for systemic improvement in Finland. A case study report for the OECD activity improving school leadership. Paris: OECD.

Harris, A. (1992). Effective leadership in schools facing challenging contexts. School Leadership and Management, 22(1), 15-26.

Harris, A. (2007). Distributed leadership: Conceptual confusion and empirical reticence 1. International Journal of Leadership in Education, 10(3), 315-325.

Hegel, G. W. F. (1807/1977). The phenomenology of spirit. Oxford: Oxford University Press.

Helfenbein, R. (2010). Thinking through scale: Critical geography and curriculum spaces. In Curriculum studies handbook: The next moment (pp. 304-317). New York/London: Routledge. 
Heller, A. (1999). A theory of modernity. New York: Columbia University Press.

Henderson, J. G., \& Gornik, R. (2007). Transformative curriculum leadership. Upper Saddle River: Prentice Hall.

Herbart, J. F. (1908). The science of education. Its general principles deduced from its Aim, and the aesthetic revelation of the world. Cambridge: D.C. Heath \& Co.

Herbart, J.-F. (1914). Umriss pädagogischer Vorlesungen [1841]. In O. Willman \& T. Fristch (Eds.), Johann Friedrich Herbarts pädagogische Schriften (Vol. 2). Oesterwieck: Verlag von U. W. Zickfeldt.

Herder, J. G. (2002). In M. N. Forster (Ed.), Philosophical writings. Cambridge: Cambridge University Press.

Honneth, A. (1992). Integrity and disrespect: principles of a conception of morality based on the theory of recognition. Political Theory, 20, 187-201.

Honneth, A. (1995). The struggle for recognition. The moral grammar of social conflicts. Cambridge: Polity.

Hopmann, S. (1992). Starting a dialogue. Roots and issues of the beginning conversation between European Didaktik and the American curriculum tradition. Paper presented at the annual meeting of the American Educational Research Association in San Francisco, April 1992.

Hopmann, S. (1997). Wolfgang Klafki och den tyska didaktiken (Wolfgang Klafki and the German Didaktik). In M. Uljens (Ed.), Didaktik: teori, reflektion, praktik (pp. 213-226). Lund: Studentlitteratur.

Hopmann, S. (2003). On the evaluation of curriculum reforms. Journal of Curriculum Studies, $4(35), 459-478$.

Hopmann, S. (2015). Didaktik meets Curriculum' revisited: Historical encounters, systematic experience, empirical limits. Nordic Journal of Studies in Educational Policy.http://dx.doi. org/10.3402/nstep.v1.27007.

Hopmann, S., \& Riquarts, K. (1995). Didaktik and/or curriculum: Basic problems of comparative Didaktik. In S. Hopmann \& K. Riquarts (Eds.), Didaktik and/or curriculum (pp. 9-40). Kiel: IPN.

Hopmann, S., Riquarts, K., \& Westbury, I. (2000). Teaching as a reflective practice: The German Didaktik tradition. Hove: Psychology Press.

Hord, S. M. (Ed.). (2004). Learning together, leading together: Changing schools through professional learning communities. New York: Teachers College Press.

Horlacher, R. (2015). The educated subject and the German concept of bildung. A comparative cultural history. London: Routledge.

Hoy, W. K., \& Miskel, C. G. (2005). Educational leadership and reform. Chicago: IAP.

Huber, S. G. (2004). School leadership and leadership development: Adjusting leadership theories and development programs to values and the core purpose of school. Journal of Educational Administration, 42(6), 669-684.

Hudson, B., \& Meyer, M. (Eds.). (2011). Beyond fragmentation: Didactics, learning and teaching in Europe. Opladen: Barbara Budrich Publisher.

Hultman, G., Löfgren, R., \& Schoultz, J. (2012). Subject didactics in practice - hidden in the process a study of teaching logics and classroom cultures. Education Inquiry, 3(1), 3-18.

Hutchins, E., \& Klausen, T. (1990). Distributed cognition in an airline cockpit. Paper presented at the 2nd international congress for activity theory, Lahti, Finland, May 21-25, 1990.

Jackson, S. (2000). A qualitative evaluation of shared leadership barriers, drivers and recommendations. Journal of Management in Medicine, 14(3/4), 166-178.

Jank, W., \& Meyer, H. (2002). Didaktische Modelle. Berlin: Cornelsen-Scriptor.

Johnson, L. (2006). "Making her community a better place to live": Culturally responsive urban school leadership in historical context. Leadership and Policy in Schools, 5(1), 19-36.

Johnson, L. (2007). Rethinking successful school leadership in challenging US schools: Culturally responsive practices in school-community relationships. International Studies in Educational Administration, 35(3), 49-57. 
Kalantzis, M., Cope, B. (1999). Multicultural education: Transforming the mainstream. In Critical multiculturalism: Rethinking multicultural and antiracist education (pp. 245-276). Milton Keynes: Lightning Source.

Kansanen, P. (1995) The Journal of Curriculum Studies, 27(4), 347-352.

Kansanen, P. (2009). Subject-matter didactics as a central knowledge base for teachers, or should it be called pedagogical content knowledge? Pedagogy, Culture \& Society, 17, 29-39.

Kant, I. (1915). Avhandlingar om fred och rätt. Stockholm: Albert Bonnier.

Kant, I. (1992). Kant on Education [Über Pädagogik]. Translated by Annette Churton. London: Kegan Paul, Trench, Trubner, 1899. Bristol: Thoemmes Press.

Kelley, C., \& Halverson, R. (2012). The comprehensive assessment of leadership for learning: A next generation formative evaluation and feedback system. Journal of Applied Research on Children: Informing Policy for Children at Risk, 3(2), 4.

Kemp, P. (2010). Citizen of the world: The cosmopolitan ideal for the twenty-first century. New York: Humanity Books.

Kennedy, K., \& Chi-Kin Lee, J. (Eds.). (2016). European didactics and Chinese curriculum: Curriculum thoughts in dialogue. London/New York: Routledge.

Kesson, K. R., \& Henderson, J. G. (2010). Reconceptualizing professional development for curriculum leadership: Inspired by John Dewey and informed by Alain Badiou. Educational Philosophy and Theory, 42(2), 213-229.

Kivelä, A. (1998). Gibt es noch eine Theorie pädagogischen Handelns? Zeitschrift für Pädagogik, 44(4), 603-616.

Kivelä, A. (2004). Subjektifilosofiasta pedagogisen toiminnan teoriaan. Oulu: Acta Universitatis Ouluensis.

Klafki, W. (1963). Studien zur Bildungstheorie und Didaktik. Weinheim: Beltz.

Klafki, W. (1994). Neue Studien zur Bildungstheorie und Didaktik. Weinheim: Beltz.

Klafki, W. (1995). On the problem of teaching and learning contents from the standpoint of critical-constructive Didaktik. In S. Hopmann \& K. Riquarts (Eds.), Didaktik and/or curriculum (pp. 187-200). Kiel: IPN.

Klar, H. W. (2012). Fostering department chair instructional leadership capacity: Laying the groundwork for distributed instructional leadership. International Journal of Leadership in Education, 15(2), 175-197.

Kliebard, H. M. (2004). The struggle for the American curriculum, 1893-1958. London: Routledge.

Koyama, J. P. (2010). Making failure pay: For-profit tutoring, high-stakes testing, and public schools. Chicago: University of Chicago Press.

Koyama, J. (2011). Principals, power, and policy: Enacting "supplemental educational services". Anthropology \& Education Quarterly, 42(1), 20-36.

Kristensson Uggla, B. (1999). Kommunikation på bristningsgränsen. En studie i Paul Ricœurs projekt. Stockholm: Symposion.

Kristensson Uggla, B. (2010). Ricoeur, hermeneutics, and globalization. New York: Continuum.

Kroksmark, T. (1989). Introduktion. In J. A. Comenius (Ed.), Didactica Magna. Göteborg: Daidalos.

Ladson-Billings, G. (1994). What we can learn from multicultural education research. Educational Leadership, 51(8), 22-26.

Ladson-Billings, G. (1995). Toward a theory of culturally relevant pedagogy. American Educational Research Journal, 32(3), 465-491.

Lahdes, E. (1977). Peruskoulun uusi opetusoppi. Otava: Helsinki.

Latour, B. (1986). The powers of association. In J. Law (Ed.), Power, action and belief. A new sociology of knowledge? (pp. 261-277). Keele: Sociological Review Monograph.

Latour, B. (2005). Reassembling the social: an introduction to actor-network-theory. Oxford: University Press.

Lave, J. (1988). Cognition in practice. Cambridge: Cambridge University Press.

Law, J. (1986). Power, action, and belief: A new sociology of knowledge. London: Routledge \& Kegan Paul. 
Lawn, M., \& Grek, S. (2012). Europeanizing education: Governing a new policy space. Oxford: Symposium Books.

Leithwood, K. (1994). Leadership for school restructuring. Educational Administration Quarterly, 30(4), 498-518.

Leithwood, K. A., \& Riehl, C. (2003). What we know about successful school leadership. Nottingham: National College for School Leadership.

Leithwood, K., \& Seashore-Louis, K. (2011). Linking leadership to student learning. San Francisco: Wiley.

Leithwood, K., Seashore, K., Anderson, S., \& Wahlstrom, K. (2004). Executive summary: Review of research: How leadership influences student learning.

Levinas, E. (1992). Jenseits des Seins oder anders als Sein geschieht. München: Verlag Karl Alber.

Lewellen, T. C. (2002). Anthropology of globalization, the: Cultural anthropology enters the 21st century. London: Bergin \& Garvey.

Lezotte, L. W. (1979). A policy prospectus for improving urban education. Hartford: Connecticut State Board of Education.

Lezotte, L. W. (1986). School effectiveness: Reflections and future directions.

Lick, D. W., \& Murphy, C. U. (2004). Whole faculty study groups (3rd ed.). Thousand Oaks: Corwin Press.

Lindgard, B., \& Rizvi, F. (2009). Globalizing education policy. London: Routledge.

Lindgard, B., Wayne, M., Rezai-Rashti, G., \& Sellar, S. (2015). Globalizing educational accountabilities. London: Routledge.

Linné, A. (2015). Curriculum theory and didactics towards a theoretical rethinking. NordSTEP 2015(1), 27002. http://dx.doi.org/10.3402/nstep.v1.27002.

Louis, K. S., \& van Velzen, B. (2012). Educational policy in an international context. Political culture and its effects. New York: Palgrave.

Luhmann, N. (1996). Social systems. Stanford: Stanford University Press.

Luhmann, N. (2012). Theory of society (Vol. 1). Stanford: Stanford University Press.

Luke, A. (2010). Defining critical literacy. In Moving critical literacies forward: A new look at praxis across contexts (pp. 19-31). New York: Routledge.

Lumby, J. (2008). Disappearing gender: Choices in identity. In H. Sobehart (Ed.), Women. Leading education across the continents: Sharing the spirit, fanning the flame (pp. 29-38). Lantham/ Toronto: Rowman \& Littlefield.

Lundgren, U. P. (1972). Frame factors and the teaching process. Stockholm: Almqvist \& Wiksell.

Lundgren, U. P. (2015). When curriculum theory came to Sweden. NordSTEP 2015, 1: 27000 http://dx.doi.org/10.3402/nstep.v1.27000. The postmodern condition. Manchester University Press.

Lyotard, J. F. (1979). Describing conceptions of the world around us. Instructional Science, 10, $177-200$.

MacBeath, J. (2006). School inspection \& self-evaluation: Working with the new relationship. London: Routledge.

MacBeath, J. (2012). Future of teaching profession. Cambridge: Educational International Research Institute and University of Cambridge.

MacDonald, M. J. (1971). Rigorous mortis: Allegory and the end of hermeneutics. Studies in the Literary Imagination, 28(2), 107.

MacDonald, M. J. (1995). Rigorous mortis: allegory and the end of hermeneutics. Studies in the literary imagination, 28(2), 107.

Marks, H., \& Printy, S. (2003). Principal leadership and school performance: An integration of transformation and instructional leadership. Educational Administration Quarterly, 4(4), 293-331.

Marton, F. (1981). Describing conceptions of the world around us. Instructional Science, 10, $177-200$.

Marton, F. (2014). Necessary conditions for learning. London: Routledge.

Marx, K. (1946). Kritik des Gothaer Programms. 
Mason, T. C., \& Helfenbein, R. J. (2012). Ethics and international curriculum work. The challenges of culture and context. Charlotte: IAP.

Masschelein, J. (1991). Kommunikatives Handeln und pädagogisches Handeln. Weinheim: Deutscher Studien Verlag.

Masschelein, J. (2004). How to conceive of critical educational theory today? Journal of Philosophy of Education, 38(3), 351-367.

Matusov, E. (2011). Authorial teaching and learning. In E. J. White \& M. Peters (Eds.), Bakhtinian pedagogy: Opportunities and challenges for research, policy and practice in education across the globe (pp. 21-46). New York: Peter Lang Publishers.

Mayo, E. (1933). The human problems of an industrial organization. New York: McMillan.

McGregor, D. (1960). The human side of enterprise. New York: McGraw-Hill.

McKenzie, K. B., Christman, D., Hernandez, F., Fierro, F., Capper, C., Dantley, D., ... Scheurich, J. (2008). From the field: A proposal for educating leaders for social justice. Educational Administration Quarterly, 44(1), 111-138.

McKernan, J. (2008). Curriculum and imagination. Process theory, pedagogy and action research. London: Routledge.

McLaren, P. (1998). Life in schools. An introduction to critical pedagogy in the foundations of education. Reading: Addison-Wesley.

McLaren, P. (2000). Che Guevara, Paulo Freire, and the pedagogy of revolution. Lanham: Rowman \& Littlefield Publishers.

Mead, G. H. (1967). Mind, self and society. Chicago: University of Chicago Press.

Meinecke F. (1907/2015). Cosmopolitanism and the national state. New Jersey:Princeton University Press.

Meinecke, F. (1970). Cosmopolitanism and the national state (trans: Robert B. Kimer) (Princeton, 1970), 10.

Menck, P. (1995). Anmerkung som Begriff der "Didaktik" in Deutschland. In S. Hopmann \& K. Riquarts (Eds.), Didaktik und/oder Curriculum. Grundprobleme einer international vergleichenden Didaktik. Zeitschrift für Pädagogik, 33. Beiheft. Weinheim: Beltz Verlag.

Merton, R. K. (Ed.). (1968). Social theory and social structure. New York: Simon \& Schuster.

Metcalf, H. C., \& Urwick, L. (1942). Dynamic administration: The collected papers of Mary Parker Follett. London: Routledge.

Meyer, H. (1997). Schulpädagogik (Vol. Bd. 1). Berlin: Cornelsen Scriptor.

Meyer, J. W. (2010). World society, institutional theories and the actor. Annual Review of Sociology, $36,1-20$.

Meyer, J. W., \& Rowan, B. (1977). Institutionalized organizations: Formal structure as myth and ceremony. American Journal of Sociology, 83(2), 340-363.

Meyer, H. D., \& Rowan, B. (Eds.). (2006). The new institutionalism in education. New York: SUNY Press.

Meyer-Drawe, K. (1984). Leiblichkeit und Sozialität: Phänomenologische Beiträge zu einer pädagogischen Theorie der Inter-Subjektivität. Munich: Fink.

Michelfelder, D. P., \& Palmer, R. E. (1989). Dialogue and deconstruction: The Gadamer-Derrida encounter. New York: SUNY.

Miller, C., \& Martin, B. (2015). Prinicipal preparedness for leading in demographically changing schools: Where is social justice training? Educational Management, Administration and Leadership, 43(1), 129-151.

Mittelstrass, J. (1979). The Philosopher's conception of Mathesis Universalis from Descartes to Leibniz. Journal of Annals of Science, 36(6), 593-610. http://dx.doi. org/10.1080/00033797900200401.

Moland, L. L. (2011). Hegel on political identity. Patriotism, nationality, cosmopolitanism. Evanston: Northwestern University Press.

Moll, L. C., Amanti, C., Neff, D., \& Gonzalez, N. (1992). Funds of knowledge for teaching: Using a qualitative approach to connect homes and classrooms. Theory Into Practice, 31(2), 132-141.

Mollenhauer, K. (2014). Forgotten connections. On culture and upbringing. (N. Friesen, Ed. \& Trans.). London: Routledge. 
Moller, J. (2009a). Approaches to school leadership in Scandinavia. Journal of Educational Administration and History, 41(2), 165-177.

Moller, J. (2009b). School leadership in an age of accountability: Tensions between managerial and professional accountability. Journal of Educational Change, 10(1), 37-46.

Moller, J., Eggen, A., Fuglestad, O. L., Langfeldt, G., Presthus, A. M., Skrøvset, S., \& Vedøy, G. (2005). Successful school leadership: The Norwegian case. Journal of Educational Administration, 43(6), 584-594.

Molnar, A., \& Zahorik, J. A. (1977). Curriculum theory. Selected Papers from the Milwaukee Curriculum Theory Conference (University of Wisconsin, Milwaukee, November 11-14, 1976).

Moos, L. (Ed.). (2013). Transnational influences on values and practices in Nordic educational leadership: Is there a Nordic model? Dordrecht: Springer.

Moos, L., Möller, J., \& Johansson, O. (2004). A Scandinavian perspective on educational leadership. The Educational Forum, 68(3), 200-210.

Moos, L., Johansson, O., Merok Paulsen, J., Strand, M., \& Risku, M. (2016). Democracy in complex networks: Political leaders and administrative professionals. In L. Moos, E. Nihlfors, \& J. Merok Paulsen (Eds.), Nordic superintendents: Agents in a broken chain (pp. 177-205). Dordrecht: Springer.

Muijs, D., \& Harris, A. (2006). Teacher led school improvement: Teacher leadership in the UK. Teaching and Teacher Education, 22(8), 961-972.

Myhre, R. (1976). Pedagogisk idéhistorie fra oldtiden till 1860. Oslo: Fabritius.

National Commission on Excellence in Education. (1983). A nation at risk: The imperative for educational reform. The Elementary School Journal, 84(2), 113-130.

Norberg, K., \& Johansson, O. (2010). The ethical dimensions of curriculum leadership in Scandinavian countries. Journal of Educational Administration, 48(3), 327-336.

Nordin, A., \& Sundberg, D. (Eds.). (2014). Transnational policy-flows in European education: The making and governing of knowledge in the education policy field. Oxford: Symposium.

Nordkvelle, Y. (2003). Didactics: From classical rhetoric to kitchen-Latin. Pedagogy, Culture \& Society, 11(3), 315-330.

Normand, R. (2016). The changing epistemic governance of European education. The fabrication of the Homo Academicus Europeanus? Dordrecht: Springer.

Normand, R., \& Derouet, J.-L. (2017). A European politics of education. Perspectives from sociology, policy studies and politics. London: Routledge.

Nyvaller, M. (2015). Pedagogisk utveckling genom kollegial granskning, Gothenburg studies in educational sciences 372 . Gothenburg: University of Gothenburg.

Oelkers, J. (2000). Democracy and education: About the future of a problem. In J. Oelkers \& H. Rhyn (Eds.), Dewey and european education: General problems and case studies. Dordrecht: Springer.

von Oettingen, A. (2001). Det pedagogiska paradoks. Et grundstudie i almen pedagogik. Århus: Klim.

von Oettingen, A. (2006). Pedagogisk filosofi som reflektert omgang med pedagogiska antinomier. Aarhus: Klim.

von Oettingen, A. (2016). Almen didaktik. Köpenhamn: Munksgaard.

Ong, W. J. (2002). Orality and literacy: The technologizing of the word (2nd ed.). New York: Routledge.

Orr, M. T., \& Pounder, D. (2011). Teaching and preparing school leaders. In Finding, preparing, and supporting school leaders: Critical issues, useful solutions (pp. 11-39). Lanham: Rowman \& Littlefield Education.

Palamidessi, M., \& Feldman, D. (2003). The development of curriculum thought in Argentina. In W. Pinar (Ed.), International handbook of curriculum research (pp. 109-122). Mahwah: Lawrence Erlbaum.

Palmer, R. E. (1969). Hermeneutics. Evanston: Northwestern University Press.

Papastephanou, M. (Ed.). (2016). Cosmopolitanism: Educational, philosophical and historical perspectives. Dordrecht: Springer. 
Paraskeva, J. M. (2016). Curriculum epistemicides. Towards an itinerant curriculum theory. New York: Routledge.

Paraskeva, J. M., \& Steinberg, S. (Eds.). (2016). Curriculum: Decanonizing the field. New York: Peter Lang.

Parsons, T. (1963). On the concept of political power. Proceedings of the American Philosophical Society, 107, 232-262.

Pedersen, K. O. (2011). Konkurrencestaten. Copenhagen: Hans Reitzels Forlag.

Pedroni, T. C. (2007). Market movements: African American involvement in school voucher reform. London: Routledge.

Perander, J. J. F. (1883). Herbartianismen i pedagogiken. Helsingfors: J. C. Frenckell \& Son.

Perrow, C. (1970). Organizational analysis: A sociological view. Belmont: Wadsworth Publishing.

Peterson, K. D., \& Deal, T. E. (1998). How leaders influence the culture of schools. Educational Leadership, 56, 28-31.

Pinar, W. (1978). The reconceptualization of curriculum studies. Journal of Curriculum Studies, 10(3), 205-214.

Pinar, W. F. (Ed.). (2000). Curriculum studies: The reconceptualization. Troy: Educator's International Press.

Pinar, W. F. (2004). What is curriculum theory? New York: Routledge.

Pinar, W. F. (2009). The worldliness of a cosmopolitan education: Passionate lives in public service. New York: Routledge.

Pinar, W. F. (2011). The character of curriculum studies: Bildung, currere, and the recurring question of the subject. New York: Palgrave Macmillan.

Pinar, W. F. (2012). What is curriculum theory? London: Routledge.

Pinar, W. F. (2013). International handbook of curriculum research. New York: Routledge.

Pinar, W. F., Reynolds, W. M., Slattery, P., \& Taubman, P. M. (1995). Understanding curriculum. An introduction to the study of historical and contemporary curriculum discourses (Vol. 17). New York: Peter Lang.

Pinkard, T. (1994). Hegel's phenomenology. The sociality of reason. Cambridge: Cambridge University Press.

Portera, A. (1998). L'educazione interculturale nella teoria e nella practica: Stereotipi pregiudizi e pedagogia interculturale nei libri di testo della scuola elementare. Padua: CEDAM.

Porter, A. C. (2002). Measuring the content of instruction: Uses in research and practice. Educational Researcher, 31(7), 3-14.

Powell, W. W., \& DiMaggio, P. J. (1991). The new institutionalism in organizational analysis. Chicago: Chicago University Press.

Purkey, S. C., \& Smith, M. S. (1983). Effective schools: A review. The Elementary School Journal, 83(4), 427-452.

Purpel, D. E. (1989). The moral \& spiritual crisis in education: A curriculum for justice and compassion in education. Westport: JF Bergin \& Garvey.

Putnam, H. (1988). Representation and reality. Cambridge, MA.: MIT Press.

Ravitch, D. (2010). Why I changed my mind about school reform: Federal testing has narrowed education and charter schools have failed to live up to their promise. Wall Street Journal. http:// online.wsj.com/news/articles/SB10001424052748704869304575109443305343962.

Reid, W. (1994). The pursuit of curriculum: schooling and public interest. Norwood: Ablex.

Ricœur, P. (1976). Interpretation theory: discourse and the surplus of meaning. Fort Worth: Texas Christian University Press.

Ricoeur, P. (1989). Phenomenology and hermeneutics. In P. Ricoeur (Ed.), Hermeneutics and the human sciences (pp. 101-128). Cambridge: Cambridge University Press.

Risk, A. N. A. (1983). National commission on excellence in education. Washington, DC: National Academy Press.

Rizvi, F. (2009). Towards cosmopolitan learning. Discourse: Studies in the cultural politics of education, 30(3), 253-268.

Robertson, S. L. (2006). The politics of constructing (a competitive) Europe(an) through internationalising higher education: Strategies, structures, subjects. Perspectives in Education, 24(4), 29-44. 
Robinsohn, S. B. (1972). Bildungsreform als Revision des Curriculum und eine Strukturkoncept für Curriculumentwicklung (4th ed.). Neuwied am Rhein: Luchterhand Vorlag.

Roethlisberger, R. C., Dickson, W. J., \& Wright, H. A. (1943). Management and the worker: An account of a research program conducted by the Western Electric Company, Hawthorne Works, Chicago. Cambridge, MA: Harvard University Press.

Rogers, E. M. (2010). Diffusion of innovations. New York: Simon and Schuster.

Rogoff, B. (1990). Apprenticeship in teaching. Oxford: Oxford University Press.

Rorty, R. (1989). Contingency, irony, and solidarity. Cambridge: Cambridge University Press.

Roth, K., \& Burbules, N. C. (2007). Changing notions of citizenship education in contemporary nation-states. Journal of Moral Education, 37(2), 257-270. doi:10.1080/03057240802009678.

Roth, K., \& Surprenant, C. W. (Eds.). (2012). Kant and education: Interpretations and commentary. London: Routledge.

Rousseau, J. J. (1979). Emile, or on education (A. Bloom, Trans.). New York: Basic Books, 54, $108-170$.

Rousseau, J. J. (1762/2002). The social contract and the first and second discourses. New Haven: Yale University Press.

Rövik, K. A., Eilertsen, T. V., \& Moksnes Furu, E. (2014). Reformideer i Norsk skola. Spredning, oversettelse, implementering. Oslo: Cappelen Damm.

Rudd, T., \& Goodson, I. F. (2016). Refraction as a tool for understanding action and educational orthodoxy and transgression. Revista Tempos e Espaços em Educação, Special Issue: Curriculum, Orthodoxy and Transgression, 9(18), 99-110.

Ryan, J. (2003). Leading diverse schools (Vol. 2). Berlin: Springer.

Ryan, J. (2006). Inclusive leadership and social justice for schools. Leadership and Policy in Schools, 5(1), 3-17.

Saari, A. (2012). The map is the territory: Educational evaluation and the topology of power. European Educational Research Journal, 11(4), 586-600.

Sadler, J. E. (2007). J. A. Comenius and the concept of universal education. New York: Routledge.

Saeverot, H. (2016). Revitalising Bildsamkeit? Studies in Philosophy and Education, 35(1), 1-16.

Saeverot, H., \& Werler, T. (2017). Pedagogikkens språk - Begreper i pedagogisk vitenskap (Language of education - Concepts in education as a science). Oslo.

Säfström, C. A., \& Östman, L., (1999). Textanalys: Introduktion till syftesrelaterad kritik. Lund: Studentlitteratur.

Sahlberg, P. (2015). Finnish lessons 2.0. New York: Teachers College Press.

Säljö, R. (1994). Minding action. Conceiving of the world versus participating in cultural practices. Nordisk Pedagogik, 14, 71-80.

Salovaara, P. (2011). From leadership-centricity toward leadership. A hermeneutic-narrative study. Tampere: University of Tampere.

Scanlan, M., \& López, F. (2012). ¡Vamos! How school leaders promote equity and excellence for bilingual students. Educational Administration Quarterly, 48(4), 583-625.

Schaffar, B. (2009). Allgemeine Pädagogik im Zwiespalt. Würzburg: Ergon.

Schaffar, B., \& Uljens, M. (2015). Paradoxical tensions between Bildung and Ausbildung in Academia. Moving within or beyond the modern continental tradition? In E. Westergaard \& J. Wiewiura (Eds.), On the facilitation of the academy (pp. 1-16). Rotterdam: Sense. https:// www.sensepublishers.com/media/2288-on-the-facilitation-of-the-academy.pdf.

Schaller, K. (1995). The Didactic of J. A. Comenius between instruction, technology and pansophy. In S. Hopmann \& K. Riquarts (Eds.), Didaktik and/or curriculum (pp. 57-71). Kiel: IPN.

Scheurich, J. J. (1998). The grave dangers in the discourse on democracy. International Journal of Leadership in Education Theory and Practice, 1(1), 55-60.

Schleiermacher, F. D. (1826/1983). Ausgewählte Pädagogische Schriften. Besorgt von Ernst Lichtenstein. Paderborn: Schöningh.

Schleiermacher, F. D. E. (1998). Hermeneutics and criticism. Cambridge: Cambridge University Press.

Schmidt, V. A. (2008). Discursive institutionalism: The explanatory power of ideas and discourse. Annual Review of Political Science, 11, 303-326. 
Schmidt, V. A. (2009). Re-envisioning the European union: Identity, democracy, economy. JCMS: Journal of Common Market Studies, 47(1), 17-42.

Schmidt, V. A. (2015). Conceptualizing Europe as a 'region-state'. In A. Spanakos \& F. Panizza (Eds.), Conceptualising comparative politics (pp. 17-45). New York: Routledge.

Schmidt, V. A. (2016). Conceptualizing Europe as a "Region-State". In T. Spanakos \& F. Panizza (Eds.), Conceptualizing comparative politics (pp. 17-45). New York: Routledge.

Schnapper, D. (1994). La communaute des citoyens: Sur L'idee modern de nation. Paris: Gallimard. Schwab, J. J. (1969). The practical: A language for curriculum. The School Review, 78(1), 1-23.

Schwab, J. J. (1978). Education and the structure of the disciplines. In Science, curriculum, and liberal education (pp. 229-272). Chicago: University of Chicago Press.

Senge, P. (1990). The fifth discipline: The art and science of the learning organization. New York: Currency Doubleday.

Sennett, R. (1998). The spaces of democracy. Ann Arbor: University of Michigan, College of Architecture+ Urban Planning.

Sheppard, B. (1996). Exploring the transformational nature of instructional leadership. Alberta Journal of Educational Research, 42(4), 325-344.

Shields, C. M. (2004). Dialogic leadership for social justice: Overcoming pathologies of silence. Educational Administration Quarterly, 40(1), 109-132.

Shields, C. M. (2010). Transformative leadership: Working for equity in diverse ontexts. Educational Administration Quarterly, 46(4), 558-589.

Shields, C. M. (2012). Transformative leadership in education: Equitable change in an uncertain and complex world. New York: Routledge.

Shields, C. M. (2014). Leadership for social justice education: A critical transformative approach. In International handbook of educational leadership and social (in) justice (pp. 323-339). Dordrecht: Springer.

Shulman, L. S. (1986). Those who understand: Knowledge growth in teaching. Educational Researcher, 15(2), 4-31.

Silins, H., \& Mulford, B. (2002). Schools as learning organisations: The case for system, teacher and student learning. Journal of Educational Administration, 40(5), 425-446.

Siljander, P. (2000). Kasvatus ja sivistys. Gaudeamus: Helsinki.

Siljander, P. (2008). Educability and Bildung in J.F. Herbart's Theory of Education. In P. Siljander, A. Kivelä, \& A. Sutinen (Eds.), Theories of Bildung and Growth. Connections and controversies between continental educational thinking and American Pragmatism. Rotterdam: Sense Publishers.

Siljander, P., Kivelä, A., \& Sutinen, A. (Eds.). (2012). Theories of bildung and growth. Rotterdam: Sense.

Simon, H. (1976). Administrative behavior: A study of decision making processes in administrative organization (3rd ed.). New York: MacMillan.

Simon, H. A. (1991). Bounded rationality and organizational learning. Organization Science, 2(1), $125-134$.

Sivesind, K. (2008). Reformulating reform: Curriculum theory revisited. Oslo: Faculty of Education, University of Oslo.

Sleeter, C. E., \& Grant, C. A. (1985). Race, class, and gender in an urban school a case study. Urban Education, 20(1), 37-60.

Sleeter, C., \& Grant, C. (1987). An analysis of multicultural education in the United States. Harvard Educational Review, 57(4), 421-445.

Smith, G. (2001). Curriculum and teaching face globalization. In W. F. Pinar (Ed.), International handbook of curriculum research (pp. 35-52). Mahwah: Lawrence Erlbaum.

Smylie, M. A., \& Denny, J. W. (1990). Teacher leadership: Tensions and ambiguities in organizational perspective. Educational Administration Quarterly, 26(3), 235-259.

Snellman, J. V. (1861/1893). Föreläsningar i pedagogik Lectures in Education (1861). In X. Band (Ed.), Samlade skrifter (pp. 193-309). Helsinki: Otava.

Somr, M., \& Hrušková, L. (2014). Herbart's philosophy of pedagogy and educational teaching. Studia Edukacyjne, 33, 413-429. Poznań: Adam Mickiewicz University Press. 
Sousa, J. M. (2015). Curriculum and Didactics: A matter of power. The case of the University of Madeira. European Journal of Curriculum Studies, 2(2), 282-296. http://pages.ie.uminho.pt/ ejcs/index.php/ejcs/article/view/92/46.

Spillane, J. P. (2002). Local theories of teacher change: The pedagogy of district policies and programs. Teachers College Record, 104(3), 377-420.

Spillane, J. P., \& Healey, K. (2010). Conceptualizing school leadership and management from a distributed perspective: An exploration of some study operations and measures. The Elementary School Journal, 111(2), 253-228.

Spillane, J. P., Halverson, R., \& Diamond, J. B. (2001). Investigating school leadership practice: A distributed perspective. Educational Researcher, 23-28.

Steiner-Khamsi, G. (Ed.). (2004). The global politics of educational borrowing and lending. New York: Teachers College Press.

Steiner-Khamsi, G. (2013). What is wrong with the "what-went-right" approach in educational policy? European Educational Research Journal, 12(1), 20-33.

Steiner-Khamsi, G., \& Waldow, F. (Eds.). (2011). Policy borrowing and lending in education. World yearbook of education. London: Routledge.

Stogdill, R. M. (1948). Personal factors associated with leadership: A survey of the literature. The Journal of Psychology, 25(1), 35-71.

Stoll, L., Fink, D., \& Earl, L. (2002). It's about learning. London: Routlege Falmer.

Sutton, M., \& Levinson, B. A. (2001). Policy as practice: Toward a comparative sociocultural analysis of educational policy (Vol. 1). Westport: Greenwood Publishing Group.

Sztompka, P. (1990). Agency and progress: the idea of progress and changing theories of change. In Rethinking progress. Movements, forces, and ideas at the end of the 20th century (pp. 247263). Boston: Unwin Hyman.

Taba, H., \& Taba, H. (1962). Curriculum development: Theory and practice. (No. 37.013 TAB). New York: Harcourt Brace.

Taylor, F. (1911). The principles of scientific management (pp. 5-29). New York: Harper \& Brothers Publishers.

Taylor, F. W. (1947). Scientific management. New York: Harper \& Brothers.

Taylor, F. W. (1949). Scientific management. New York: Harper.

Taylor, C. (1994). Multiculturalism. Princeton: Princeton University Press.

Tenorth, H.-E. (1988). Geschichte der Erziehung. Juventa: Weinheim.

Terhart, E. (2009). Allgemeine Didaktik: Traditionen, Neuanfänge, Herausforderungen. In M. Meyer, M. Prenzel, \& S. Hellekamps (Eds.), Perspektiven der Didaktik (pp. 13-34). Dordrecht: Springer.

Theoharis, G. (2007). Social justice educational leaders and resistance: Toward a theory of social justice leadership. Educational Administration Quarterly, 43(2), 221-258.

Theoharis, G. (2009). The school leaders our children deserve: Seven keys to equity, social justice, and school reform. New York: Teachers College Press.

Tillman, L. C. (2004). Chapter 4: African American principals and the legacy of Brown. Review of Research in Education, 28(1), 101-146.

Tilly, C. (1984). Retrieving European lives.

Tschannen-Moran, M. (2014). Trust matters: Leadership for successful schools. San Francisco: Wiley.

Tyler, R. (2013). Basic principles of curriculum and instruction. Chicago: University of Chicago Press.

Uljens, M. (1992). Phenomenological features of phenomenology. Gothenburg: University of Gothenburg.

Uljens, M. (1995). A model of school didactics and its role in academic teacher education. In S. Hopmann \& K. Riquarts (Eds.), Didaktik and/or curriculum (pp. 301-332., Report 147). Kiel: Institut für die Pädagogik der Naturwissenschaften an der Universität Kiel.

Uljens, M. (1997a). School didactics and learning. Hove: Psychology Press.

Uljens, M. (Ed.). (1997b). European identity in change - The meeting between German, Russian and Nordic Educational traditions. (Report 10). Vaasa: Åbo Akademi University. 
Uljens, M. (1998). School didactics and learning. Hove: Psychology Press.

Uljens, M. (2000). Allgemeine Pädagogik in Finland during the 20th century. In M. Uljens (Ed.), Pedagogikens problem. Kulturella utvecklingslinjer och teoretiska spörsmål (pp. 1-36. Rapport 13/2000). Vasa: Pedagogiska institutionen, Åbo Akademi University.

Uljens, M. (2001). On general education as a discipline. Studies in Philosophy and Education, 20(4), 291-301.

Uljens, M. (2002). The idea of a universal theory of education - An impossible but necessary project? Journal of Philosophy of Education, 36(3), 353-375.

Uljens, M. (2007). Education and societal change in the global age. In R. Jakku-Sihvonen \& H. Niemi (Eds.), Education as a societal contributor (pp. 23-51). New York: Peter Lang.

Uljens, M. (2015). Curriculum work as educational leadership: Paradoxes and theoretical foundations. Nordic Journal of Studies in Educational Policy, 1(1), 22-30. Retrieved from http:// nordstep.net/index.php/nstep/article/view/27010.

Uljens, M. (2016). Non-affirmative curriculum theory in a cosmopolitan Era? Revista Tempos e Espaços em Educação, 9(18), 121-132. Retrieved from http://www.seer.ufs.br/index.php/ revtee/article/view/4970.

Uljens, M. \& Mielityinen, M. (2004). Schleiermachers pedagogiska föreläsningar - en modern pedagogik för det moderna samhället. (Schleiermacher's Lectures on Education) I: L. Lövlie \& K. Steinsholt (Red.), Pedagogikkens mange ansikter. Pedagogisk idéhistorie fra antikken til det postmoderne (pp. 215-231). Oslo: Universitetsforlaget.

Uljens, M., \& Ylimaki, R. (2015). Towards a discursive and non-affirmative framework for curriculum studies, Didaktik and educational leadership. Nordic Journal of Studies in Educational Policy, 1(3). http://nordstep.net/index.php/nstep/article/view/30177

Uljens, M., \& Ylimaki, R. (2017). Implications and future directions for a New research agenda grounded on non-affirmative education theory. Leadership and Policy in Schools, 16(2), 389-396.

Uljens, M., Möller, J., Ärlestig, H., \& Fredriksen, L. F. (2013). The professionalization of Nordic school leadership. In L. Moos (Ed.), Transnational influences on values and practices in Nordic educational leadership: Is there a Nordic model? (pp. 133-157). Dordrecht: Springer.

Uljens, M., Sundqvist, R., \& Smeds-Nylund, A.-S. (2016). Educational leadership for sustained multi-level school development in Finland - A non-affirmative approach. Nordic Studies in Education, 36(2), 103-124.

van Manen, M. (1991). The tact of teaching. The meaning of pedagogical thoughtfulness. New York: Suny Press.

Wæraas, A., \& Agger Nielsen, J. (2016). Translation theory“ translated': Three perspectives on translation in organizational research. Working Papers No. 16/2015. Norwegian University of Life Sciences School of Economics and Business. https://www.nmbu.no/sites/default/files/ pdfattachments/hh_wp_16_2015.pdf

Waks, L. J., \& English, A. R. (Eds.). John Dewey's democracy and education: A centennial handbook. New York: Cambridge UP.

Wallerstein, I. (1974). The rise and future demise of the world capitalist system: Concepts for comparative analysis. Comparative Studies in Society and History, 16(04), 387-415.

Wallerstein, I. (2006). European universalism: The rhetoric of power. New York: The New Press.

Weber, M. (1947). Legitimate authority and bureaucracy. InThe theory of social and economic organisation (pp. 328-340). New York: Free Press.

Weber, M. (1978). Economy and society: An outline of interpretive sociology (2 volume set). Berkeley: University of California Press.

Weick, K. E. (1976). Educational organizations as loosely coupled systems. Administrative science quarterly, 21, 1-19.

Weick, K. E. (1995). Sensemaking in organizations (Vol. 3). Thousand Oaks: Sage.

Weniger, E. (1965). Didaktik als Bildungslehre. Band 2, Didaktische Voraussetzungen der Methode in der Schule. Weinheim: Beltz. 
Wermke, W. (2013). Development and Autonomy. Conceptualising teachers' continuing professional development in different national contexts (p. 16). Stockholm: Department of education.

Westbury, I. (2000). Teaching as a reflective practice: What might Didaktik teach curriculum. In I. Westbury, S. Hopmann, \& K. Riquarts (Eds.), Teaching as a reflective practice: The German Didaktik tradition (pp. 15-39). New York: Routledge.

Whitty, G. (1974). Sociology and the problem of radical educational change. In Educability, schools and ideology (pp. 112-137). London: Croom Helm.

Wiggins, G. P., \& McTighe, J. (2005). Understanding by design. Alexandria: Association for Supervision and Curriculum Development (ASCD).

Wimmer, F. M. (2013). Intercultural philosophy-problems and perspectives. Cirpit Review, 4, $115-24$.

Williams, R. R. (1997). Hegel's ethics of recognition. Berkeley/Los Angeles: University of California Press.

Young, M. F. (1998). The curriculum of the future: from the "new sociology of education" to a critical theory of learning. Hove: Psychology Press.

Ylimaki, R. M. (2011). Critical curriculum leadership. A framework for progressive education. New York: Routledge.

Ylimaki, R. M. (2012). Curriculum leadership in a conservative era. Educational Administration Quarterly, 48(2), 304-346.

Ylimaki, R., \& Brunner, C. C. (2011). Power and collaboration-consensus/conflict in curriculum leadership: Status-quo or change? American Educational Research Journal, 48, 1258-1285.

Ylimaki, R., \& Henderson, J. (2016). Curriculum in educational leadership preparation. In G. Crow \& M. Young (Eds.), Handbook of research on the education of school leaders (2nd ed., pp. 148-172). New York: Routledge.

Ylimaki, R., \& Jacobson, S. (Eds.). (2013). US and cross-national policies, practices and preparation: Implications for successful instructional leadership, organizational learning, and culturally responsive practices. Dordrecht: Springer-Kluwer.

Ylimaki, R., \& Uljens, M. (2017). Theorizing educational leadership studies, curriculum, and Didaktik - non-affirmative education theory in bridging disparate fields. Leadership and Policy in Schools, 17(2), 175-227.

Ylimaki, R., Fetman, L., Matyjasik, E., Brunderman, L., \& Uljens, M. (2016). Beyond normativity in sociocultural reproduction and sociocultural transformation: Curriculum work-leadership within an evolving context. Educational Administration Quarterly, 1-37. doi:10.1177/00131 $61 X 16669200$.

York-Barr, J., \& Duke, K. (2004). What do we know about teacher leadership? Findings from two decades of scholarship. Review of Educational Research, 74(3), 255-316.

Young, M., Lambert, D., Roberts, C., \& Roberts, M. (2014). Knowledge and the future school: Curriculum and social justice. London: Bloomsbury Publishing.

Open Access This chapter is licensed under the terms of the Creative Commons Attribution 4.0 International License (http://creativecommons.org/licenses/by/4.0/), which permits use, sharing, adaptation, distribution and reproduction in any medium or format, as long as you give appropriate credit to the original author(s) and the source, provide a link to the Creative Commons license and indicate if changes were made.

The images or other third party material in this chapter are included in the chapter's Creative Commons license, unless indicated otherwise in a credit line to the material. If material is not included in the chapter's Creative Commons license and your intended use is not permitted by statutory regulation or exceeds the permitted use, you will need to obtain permission directly from the copyright holder.

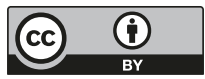

